\title{
INTRODUCTION TO THE PEKING UNIVERSITY HAN BAMBOO STRIPS: ON THE AUTHENTICATION AND STUDY OF PURCHASED MANUSCRIPTS
}

\author{
Christopher J. Foster*
}

\begin{abstract}
Over the past two decades, remarkable collections of Warring States, Qin, and Han manuscripts have been purchased on the behalf of major academic institutions in China. This article introduces one of the latest acquisitions, the Han bamboo strips donated to Peking University in January 2009. Although the Peking University Han strips offer exciting new materials that promise to significantly advance the study of early China, research on them has been encumbered by the fact that they were not archaeologically excavated. This has invited concerns not only over the manuscripts' authenticity, but also about the role our scholarship plays in fostering a market for looted artifacts. The article reviews current debates over the authentication of purchased bamboo strips, and discusses how the Peking University Han manuscripts were authenticated in particular. A refutation is given to recent arguments that the Peking University Laozi is a forgery. A methodology is then proposed to positively authenticate purchased manuscripts, taking the Peking University Cang Jie pian as a case study and establishing its antiquity. The article concludes by addressing the professional ethics of scholars working with looted manuscripts, giving voice to the "rescue archaeology" position largely adopted in Chinese scholarship.
\end{abstract}

In January 2009, Peking University acquired a large cache of bamboo-strip manuscripts dated to the Western Han, whose contents promise to significantly advance our understanding of early China. ${ }^{1}$ The

\footnotetext{
*Christopher J. Foster, 傅希明, Harvard University Ph.D. Candidate, cjfoster@fas. harvard.edu.

1. One year later, in 2010, another large cache of manuscripts was again acquired by Peking University, these dated earlier to the Qin period. Included in this collection is a text akin to the Wei li zhi dao 為吏之道 genre (from Shuihudi 睡虎地 and in the Yuelu Academy 岳麓書院 cache), an etiquette manual for women, mathematical treatises, a geographical work charting out distances and travel routes in the Jiang Han 江漢 region, a drinking song and game, a resurrection tale, and other materials. For a brief introduction, see Beijing Daxue chutu wenxian yanjiusuo [Peking University Excavated Manuscript Research Center], "Beijing Daxue cang Qin jiandu gaishu” 北京大學 藏秦簡牘概述, Wenwu 文物 2012.6, 65-73. Six other articles on the Peking University
} 
collection contains over 3,300 pieces of bamboo in total, of which 1,600 strips are still intact. ${ }^{2}$ These strips are generally well preserved, and the writing on them is clear, making the Peking University Han manuscripts extremely convenient sources to study. Highlights from this cache include one of the most complete early editions of the Laozi 老子 discovered to date; the lost Daoist work Zhou xun 周馴—listed as Zhou xun 周 訓 in the Han shu 漢書 Yiwen zhi 藝文志; an historical treatise on the passing of the First Emperor of Qin and its immediate aftermath titled Zhao Zheng shu 趙正書; a fu 賦 rhapsody called Fan yin 反淫 that echoes the received Qifa 七弡; and an amusing vernacular rhapsody (or su fu 俗 賦) on the domestic strife between a scorned wife and lovely concubine, titled Wang Ji 妄稽; in addition to medical recipes, divination materials, and fragments of masters' works.

Within this collection is also an extremely important edition of the Cang Jie pian 蒼頡篇, a text that is the subject of my own research. ${ }^{3}$ The Cang Jie pian is an early character book or zishu 字書, purportedly authored in part by Li Si 李斯, the Qin statesmen well known for his advocacy of writing reform. ${ }^{4}$ Although the Cang Jie pian was initially lost sometime during the Song dynasty, portions of the text have been rediscovered among the manuscript finds of the past century. 5 Unfortunately, most of these finds are fragmentary, while the two longer editions from Fuyang 阜陽 and Shuiquanzi 水泉子 are poorly preserved and not yet

Qin strips were also published in the same Wenwu issue. This article however will focus only on Peking University's previous collection of Western Han manuscripts. Citations for the Peking University Han manuscripts may be found in nn. 7-10 below.

2. The editors estimate that the collection consists of what were originally around 2,300 intact strips. See Beijing Daxue chutu wenxian yanjiusuo, "Beijing Daxue cang Xi Han zhushu gaishuo" 北京大學藏西漢竹書概說, Wenwu 2011.6, 49.

3. See Zhu Fenghan 朱鳳瀚, “Beida Han jian Cang Jie pian gaishu” 北大漢簡蒼頡篇 概述, Wenwu 2011.6, 57-63. For the most recent overview of research on the Cang Jie pian: Liang Jing 梁靜, Chutu Cang Jie pian yanjiu 出土荅頡篇研究 (Beijing: Kexue, 2015). See also my chapter, "Cang Jie pian," in the forthcoming revision to Early Chinese Texts.

4. Han shu 漢書 Yiwen zhi 藝文志 (Beijing: Zhonghua, 1975 [1962]), 30.1719-22; corroborated in the Shuowen jiezi postface. See Shuowen jiezi zhu 說文解字注 (Shanghai: Shanghai guji, 1986 [1981]), 15.758. For Li Si's memorial on standardizing writings, see also Shi ji 史記 (Beijing: Zhonghua, 1972 [1959]), 87.2546-7.

5. In addition to Liang Jing 2015 cited in n. 3 above, another convenient compilation of these materials may be found in: He Shuangquan 何雙全, "Cang Jie pian canjian jishi" 蒼頡篇殘簡輯釋, Wenxian yanjiu 文獻研究 3 (2011), 56-74, (http:/ / www.ch50oo.cn/ wxyj/wxyjxq.aspx?id=40), accessed September 29, 2016. My forthcoming dissertation supplements this work with additional pieces newly identified. Caches with Cang Jie pian fragments include: Aurel Stein's Dunhuang strips (including the British Library shavings); Juyan (I); Juyan (II); Fuyang Shuanggudui; Yumen Huahai; Majuanwan; Houfang and Yanchiwan; Xuanquan; Niya; Ejin Banner; and Shuiquanzi. 
adequately published. ${ }^{6}$ The Peking University Cang Jie pian is the most complete version to date, bearing over 1,300 characters and even including complete or nearly complete chapters, offering us an invaluable glimpse into the nature of this text during the Western Han.

After an initial flurry of press releases, in 2011 the Chinese journal Wenwu 文物 printed a series of articles introducing the contents of the Peking University Han manuscripts, as well as a report analyzing certain physical characteristics of the artifacts.7 The next year, the Laozi manuscript was published in full, under the title Beijing Daxue cang Xihan zhushu (er) 北京大學藏西漢竹書或. ${ }^{8}$ Although this was the first book to be printed, it still—somewhat confusingly—retains the designation of Volume Two (或), as the original publication schedule intended for it to follow the Cang Jie pian volume. Four additional books from the Beijing Daxue cang Xihan zhushu series have recently seen print, including Volume One (壹) with the Cang Jie pian, Volume Three (参) with Zhou xun, Zhao Zheng shu, Ru jia shuo cong 儒家說叢, and Yinyang jia shuo 陰陽家說, Volume Four (肆) with Wang Ji and Fan yin, and Volume Five (伍) containing the divination texts Jie 節, Yu shu 雨書, Zhen yu 揕舆, Jing jue 荊決, and Liu bo 六博. 9 Each of these books includes photographs of the bamboo

6. For the badly damaged Fuyang manuscript, see Fuyang Han jian zhenglizu, “Fuyang Han jian Cang Jie pian" 阜陽漢簡蒼頡篇, Wenwu 1983.2, 24-34. This initial report includes transcriptions, with partial photographs and hand drawings. Full photographs, though often unclear, are included in Zhongguo jiandu jicheng bianji weiyuanhui ed., Zhongguo jiandu jicheng 中國簡牘集成 (Lanzhou: Dunhuang wenyi, 2005) vol. 14, 295-313. A brief English introduction may also be found at: Roger Greatrex, "An Early Western Han Synonymicon: The Fuyang copy of the Cang Jie pian," in Outstretched Leaves on His Bamboo Staff: Studies in Honour of Göran Malmqvist on his 7oth Birthday, ed. Joakim Enwall (Stockholm: Association of Oriental Studies, 1994), 97-113. Partial photographs and transcriptions for the Shuiquanzi manuscript, now also heavily damaged, have been published mainly in Zhang Cunliang 張存良, “Shuiquanzi Han jian qiyanben Cang Jie pian lice” 水泉子漢簡七言本蒼頡篇蟲測, Chutu wenxian yanjiu 出土文獻研究 9 (2010): 60-75, plates 8-11. The full data should soon be available in Zhang's dissertation: “Shuiquanzi Cang Jie pian zhengli yu yanjiu” 水泉子 蒼頡篇整理與研究 (Ph.D. dissertation, Lanzhou University, 2015).

7. For one such early press release: "Beijing Daxue shoucang zhengui Xi Han zhushu" 北京大學收藏珍貴西漢竹書, Guangming ribao 光明日報, November 6, 2009 (http://www.gmw.cn/o1gmrb/2009-11/06/content_1004281.htm), accessed September 29, 2016. The overview in Wenwu 2011.6, as cited in n. 2 above, is Beijing Daxue chutu wenxian yanjiusuo, "Beijing Daxue cang Xi Han zhushu gaishuo," 49-56. There are eleven other articles on the Peking University Han strips in this issue.

8. Beijing Daxue chutu wenxian yanjiusuo, Beijing Daxue cang Xi Han zhushu [er] 北 京大學藏西漢竹書 [或] (Shanghai: Shanghai guji, 2012).

9. These four books are also printed under the title Beijing Daxue cang Xi Han zhushu 北京大學藏西漢竹書 from Shanghai guji. The copyright for these volumes is 2014 (Volume Five 伍) and 2015 (Volume One 壹, Volume Three 参, and Volume Four 肆). 
strips (rectos) in their original size and magnified, along with infrared photographs for areas that are unclear, hand drawings of the strips' versos, tables of measurements for physical aspects of the artifacts, charts comparing textual parallels with other works when appropriate, and often thematic research essays. Two more books are forthcoming, namely Volume Six (陸) covering the daybook materials Ri shu 日書, Ri ji 日忌, and Ri yue 日約, and Volume Seven (染) with the medical recipes.

Meanwhile, in order to keep scholars apprised of their ongoing work, the Peking University Excavated Manuscript Research Center has been releasing online newsletters, which are available in PDF format through the Peking University Ancient History Research Center's website. ${ }^{10}$ These briefs provide insights into the reception and early treatment of both the Han and Qin caches, minutes for conferences held on these collections, notices on the publication of the edited volumes, bibliographies for research conducted by members of the center, and other pertinent information. Nine briefs have been written to date. They are an invaluable resource for any scholar looking to familiarize themselves with the Peking University strips.

Despite the immense importance of these new manuscripts, research on the Peking University Han bamboo strips is hampered by the fact that the collection was not archaeologically unearthed, but rather purchased from an antiquities dealer. ${ }^{11}$ While the last century has witnessed the discovery of unprecedented numbers of early Chinese manuscripts written on wood, bamboo, and silk, unfortunately not all of these artifacts were collected through controlled scientific excavation. The Peking University strips are the latest example of a recent trend in which major academic institutions within China have acquired caches of manuscripts from the antiquities market. ${ }^{12}$ In lacking any detailed provenance or sci-

10. The briefs are titled "Beijing Daxue chutu wenxian yanjiusuo gongzuo jianbao" 北京大學出土文獻研究所工作簡報. An index for the briefs where they are available for download may be found at the following URL (http:/ / www.zggds.pku.edu.cn/o05/ index7.htm), accessed September 29, 2016.

11. "Purchased" manuscripts in this article refers to those artifacts which were obtained from the antiquities market. Details about the financial transactions however are often unclear. In a number of cases, an alumnus or other entity first bought the artifacts, and then donated them to the university. This was the case with both of Peking University's caches. Describing the artifacts as "looted" makes an assumption both about their origins and authenticity.

12. Aurel Stein might have purchased strips during his expeditions in northwest China, and the Chu silk manuscript from Zidanku 子彈庫, Changsha 長沙, is another infamous early case. It is only over the past couple of decades however that major academic institutions in China began to acquire caches of such manuscripts. The Shanghai Museum's purchase of Chu bamboo strips in 1994 initiated this trend, and subsequently manuscripts have since been obtained from the antiquities market by the 
entifically documented archaeological context, the Peking University manuscripts are robbed of crucial data that could have significantly furthered scholarship. ${ }^{13}$ The uncertainty of their origins moreover opens the door to speculation that these texts are in fact only modern forgeries, and thus of little academic value. ${ }^{14}$ There are also scholars who oppose the study of artifacts purchased on the antiquities market-authentic or otherwise- on the grounds that this is academically irresponsible (by knowingly "validating" dubious materials), and moreover fosters a trade for pilfered artifacts, thereby indirectly supporting the destruction of archaeological remains.

It is therefore necessary to establish the authenticity of the Peking University Han strips, and address concerns over the impact scholarship on purchased caches of bamboo strips may have on preserving China's cultural heritage. In this article, I will offer an argument, from the perspective of my own research on the Peking University Cang Jie pian, both for why I am convinced that this manuscript is genuine, and why we should not feel constrained in researching the Peking University corpus. After a review of current debates over the authentication of purchased collections of bamboo strips, I discuss the methods employed to authenticate the Peking University Han manuscripts in particular. As part of this discussion, I will refute statements made by Xing Wen 邢文 in a recent article claiming that the Peking University Laozi is a forgery. ${ }^{15}$

Chinese University of Hong Kong, Yuelu Academy, Tsinghua University, Peking University, Zhejiang University, and Wuhan University. Just this past spring, Anhui University announced the acquisition of yet another amazing collection: "An Da jian: Xian Qin wenxian you yi zhongda faxian” 安大簡：先秦文獻又一重大發現, Guangming ribao, May 16, 2016 (http://news.gmw.cn/2016-05/16/content_2011160o.htm), accessed September 29, 2016.

13. Paul Goldin makes a distinction between "provenance" (history of ownership) and "provenience" (original location) when discussing purchased manuscripts. Out of convenience, my study employs "provenance" in a broader sense that accommodates both these terms. See Paul R. Goldin, "Heng Xian and the Problem of Studying Looted Artifacts," Dao 12 (2013), 156, n. 6.

14. Even if proven to be modern forgeries, these manuscripts might still be of interest, if only to help calibrate methods of authentication. I do however find modern fakes of supposedly ancient bamboo-strip manuscripts a fascinating subject for study in their own right, as they are a valuable lens on the cultural values (real or perceived) invested in Chinese history today.

15. Xing Wen 邢文, “Beida jian Laozi bianwei” 北大簡老子辨偽, Guangming ribao, August 8, 2016 (http://epaper.gmw.cn/gmrb/html/2016-o8/o8/nw. D11000ogmrb_20160808_1-16.htm?div=-1), accessed September 30, 2016; "Bianzheng zhi mei yu sandian toushi一Beida jian Laozi zai bianwei” 讋證之美與散點透視一北大 簡老子再辨偽, Guangming ribao, September 12, 2016 (http://epaper.gmw.cn/gmrb/ html/2016-09/12/nw.D1100oogmrb_20160912_2-16.htm?div=-1), accessed September 30, 2016. 
Next I will present a method for positively authenticating purchased manuscripts of unknown provenance, taking the Cang Jie pian as an example and demonstrating its antiquity. I conclude by addressing the professional ethics of working with these collections, responding to concerns most publicly raised by Paul Goldin and giving voice to the "rescue archaeology" orientation largely adopted in Chinese scholarship. ${ }^{16}$

\section{Recent Debates on the Authenticity of Purchased Collections of Bamboo Strips}

Purchased collections of bamboo-strip manuscripts offer exciting new evidence for the study of early China. They also however present a great risk to our field, as we begin to develop new narratives informed by these texts which may ultimately be misguided if the manuscripts are proven to be forgeries. It is thus surprising - and unfortunate- that currently there is no transparent process by which we may authenticate purchased collections of bamboo strips. A handful of experts are often called upon to render initial judgment behind closed doors, following which other researchers are usually left to rely on their connoisseurship. Scientific methods of authentication, such as radiocarbon dating, are at times employed, but without any regularity. ${ }^{17}$ Indeed, the question of forgery has been a topic conspicuously avoided in formal Chinese publications dedicated to these paleographic sources, perhaps to escape criticism of respected peers who would then be held responsible for potentially very costly mistakes in judgment. ${ }^{18}$ Silence is therefore the

16. Paul R. Goldin, "Heng Xian and the Problem of Studying Looted Artifacts," 153-60.

17. For example, the Shanghai Museum conducted Accelerator Mass Spectrometry (AMS) radiocarbon testing, possibly on two occasions, for their collection of Warring States strips. Although in the first volume of strips they cite a report, "Shanghai bowuguan zhujian yangpin de celiang zhengming 上海博物館竹簡樣品的測量證明," and state that the laboratory results would be published, to the best of my knowledge neither is publicly available. See Ma Chengyuan 馬承源, “Qianyan: Zhanguo Chu zhushu de faxian baohu he zhengli" 前言: 戰國楚竹書的發現保護和整理, in Shanghai bowuguan cang Zhanguo Chu zhushu [yi] 上海博物館藏戰國楚竹書 [一], ed. Ma Chengyuan, 1-4 (Shanghai: Shanghai guji, 2001), 2. The only data I have been able to locate is found in an interview with $\mathrm{Ma}$, where he gives a date of $2257+/-65 \mathrm{BP}$, but provides no other data for us to evaluate whether the tests are representative or the findings significant. See “Ma Chengyuan xiansheng tan Shangbo jian” 馬承源先生談上博簡, in Shangboguan cang Zhanguo Chu zhushu yanjiu 上博館藏戰國楚竹書研究, ed. Zhu Yuanqing 朱淵清 and Liao Mingchun 廖名春, 1-8 (Shanghai: Shanghai shudian chubanshe, 2002), esp. 3.

18. The risks involved in discussing authenticity are felt by collector and appraiser alike. Hu Pingsheng 胡平生 recalls how one scholar, suspicious of the fake Xi'an Sun $W u$ Bingfa 孫武兵法 manuscript, was even reported to the police, for what I can only 
loudest condemnation in China at the moment, as an absence of research on such collections most strongly signals scholarly unease on their authenticity. ${ }^{19}$

One of the few Chinese scholars to broach the topic of authenticating these newly purchased bamboo-strip manuscript collections early on is $\mathrm{Hu}$ Pingsheng 胡平生, who has currently authored three articles on this subject. ${ }^{20} \mathrm{Hu}$ warns that forged strips have already flooded the antiquities market, not only in Hong Kong but also in other regions of China as well. While no systematic survey exists to aid scholars in tracking when and where potential forgeries came on the market, or who might have bought them, $\mathrm{Hu}$ does list a number of instances that he can recall or with which he was personally involved (having been asked to provide authentication). ${ }^{21}$ For example, in 1995 a large cache of strips was sold in Japan, which radiocarbon dating later proved to be made of wood from the 1970s. The same year fake strips were also offered to the National Palace Museum 台灣故宮博物館 and Institute of History and Philology, Academia Sinica 中央研究院歷史語言研究所 in Taiwan. A university in Hong Kong at that time did buy some strips, in which a few genuine

imagine was defamation. See Hu Pingsheng 胡平生, “Lun jianbo bianwei yu liushi jiandu qiangjiu" 論簡帛辨偽與流失簡牘唅救, Chutu wenxian yanjiu 9 (2010), 78. Jiang Guanghui 姜廣輝 likewise alleges that an article co-authored with Fu Zan 付贊 questioning the authenticity of the Tsinghua strips was previously accepted by a "prestigious Beijing journal," but later unduly pulled. This complaint is reported by Yuri Pines in "Zhou History and Historiography: Introducing the Bamboo manuscript Xinian," T'oung Pao 100.4-5 (2014), 296-97, n. 15, though unfortunately the blog post he cites is no longer available. Jiang and Fu's article was subsequently published in Hunan Daxue xuebao. See n. 39 below.

19. For a similar observation, see Sarah Allan, Buried Ideas (Albany: State University of New York Press, 2015), 69, n. 75. Allan succintly defends the Shanghai Museum and Tsinghua collections on pp. 68-70.

20. Hu Pingsheng 胡平生, “Xianggang Zhongwen Daxue wenwuguan cang Wang zhang jian de zhenwei wenti" 香港中文大學文物館藏王杖簡的真偽問題, Zhongguo wenwu bao 中國文物報, March 15, 1998; “Gudai jiandu de zuowei yu shibie” 古代簡牘 的作偽與識別, Shoucangjia 收藏家 2 (1999), 46-49; “Lun jianbo bianwei yu liushi jiandu qiangjiu," Chutu wenxian yanjiu, 76-108 (cited in n. 18 above). Hu's 2010 article updates and expands upon his 1999 piece. For another article that draws largely from Hu's, but also focuses primarily on one example of a forged manuscript, see Wei Hongwei 魏宏 偉, “Jiandu de jianshi yu bianwei” 簡牘的鑒識與辨偽, Wenwu Jianding yu Jianshang 文 物鑒定與鑒賞 7 (2011), 48-51.

21. Hu, "Gudai jiandu de zuowei yu shibie," 46; Hu, "Lun jianbo bianwei yu liushi jiandu qiangiiu," 76-84. Slightly different accounts are given in both, though the latter is more thorough. Collectors are understandably reluctant to admit having mistakenly purchased strips that have later been deemed forgeries. There are also potential legal repercussions that may need to be considered. Such factors lead to an unwillingness to discuss past transactions involving counterfeit manuscripts, making it difficult to obtain information about these caches. 
specimens were mixed within many fake ones, revealing just how complicated authenticating an entire cache may be. ${ }^{22} \mathrm{Hu}$ also reminds us of the Sun Wu bingfa 孫武兵法 manuscript discovered in Xi'an in 1996, a forgery that at first received much media attention. More recently, $\mathrm{Hu}$ discusses multiple occasions when individual collectors had either contacted him directly, or posted in online forums, to evaluate their private holdings, which inevitably turned out to be fakes. A silk manuscript was even purchased from Beijing's “Ghost Market”—Panjiayuan 潘家園—in 2007, as forgers continue to diversify their media. ${ }^{23}$ These are just a few of the examples raised by $\mathrm{Hu}$ that speak to the immense problem at hand.

Of course, the forgery of bamboo-strip manuscripts is not purely a modern phenomenon. In the Han shu chapter Rulin zhuan 儒林傳, Ban $\mathrm{Gu}$ 班固 recalls how a 102 chapter edition of the Shang shu 尚書 was dismissed as counterfeit, its content deemed too unsophisticated to be the actual classic. ${ }^{24}$ It is instructive that this alleged imitation was presented to the throne during Emperor Cheng's reign (32-7 в.C.E.), in response to a call by the court for ancient-script manuscripts to be brought in from among the masses. This was a time marked by classical polemics, when the words of the ancient sages were both sacred and contested. In this intellectual climate, forging a work like the Shang shu was one means of garnering political influence. Indeed, as Yoav Ariel shows in his study of the Kong congzi 孔叢子, the authenticity of the classics was a topic of great concern by the end of the Han. For the compilers of the Kong congzi, however, the criteria for "authenticity" vis-à-vis textual identity were more liberally defined. ${ }^{25}$ Thus, in an anecdote from

22. This problem is later reiterated by Jiang Guanghui, who wonders how experts called on to authenticate these caches can, over the course of a half-day or day-long conference, sort through thousands of strips that they claim may take a decade to publish properly. Inevitably, they must only be able to investigate a limited number of samples. See Jiang Guanghui 姜廣輝, “Qinghua jian jianding keneng yao jingli yige changqi guocheng-Zai tan dui Baoxun pian de yiwen" 清華簡鑒定可能要經歷一個長 期過程——再談對保訓篇的疑問, Guangming ribao, June 8, 2009 (http:/ / www.gmw. cn/o1gmrb/2009-06/o8/content_931257.htm), accessed September 30, 2016.

23. $\mathrm{Hu}$, "Lun jianbo bianwei yu liushi jiandu qiangiu," 81 has a brief account of this forgery, though Hu mistakenly lists it as "1997." Context suggests that he meant "2007" instead.

24. Hu mentions this also, as well as giving an example of forgery during the Ming Dynasty: “Lun jianbo bianwei yu liushi jiandu qiangiiu," 85-86. Han shu, 88.3607.

25. Ariel believes that the Kong congzi was actually compiled by the Three Kingdoms scholar Wang Su 王肅. See Yoav Ariel, K'ung-ts'ung-tzu: The K'ung Family Master's Anthology: A Study and Translation of Chapters 1-10, 12-14 (Princeton: Princeton University Press, 1989); K'ung-ts'ung-tzu: A Study and Translation of Chapters 15-23 with a Reconstruction of the Hsiao Erh-ya Dictionary (Leiden: E.J. Brill, 1996). 
the chapter Zhijie 執節 of this work, when the Warring States figure Yu Qing 虞卿 is censured for authoring a text with the title of Chun qiu 春秋, borrowing Confucius' name for his classic, Yu retorts: "A classic draws from the constancy of affairs. If a work speaks to these constant principles, then it is a classic. If it is not by Confucius, does this then mean it is not a classic?"26

Today textual forgery has once again become a topic of great concern. More than a century ago, Aurel Stein had already uncovered a rather sophisticated forgery racket headed by Islam Akhun, which had previously deceived the eminent scholar A. F. Rudolf Hoernle and other Western explorers. ${ }^{27}$ In the case of bamboo-strip manuscript forgeries, however, it appears that the industry was spurred on by the remarkable finds of the 1970s, such as those from Yinqueshan 銀雀山, Mawangdui 馬王堆, Shuihudi 睡虎地, and the latest Juyan 居延 cache. As Hu argues, most of the fake manuscripts he has inspected are modeled after discoveries from the 1970 onward. ${ }^{28} \mathrm{He}$ writes that "starting from the beginning of the last century, but especially since the 1970s, the excavation of wood and bamboo-strip manuscripts and silk documents has been a bright spot for the field of [Chinese] archaeology, while the forgery of these manuscripts has also gradually increased, and thus naturally the authentication of bamboo and silk manuscripts has become a new field of research [in its own right]. ${ }^{29}$

When he penned "Gudai jiandu de zuowei yu shibie" in 1999, $\mathrm{Hu}$ seemed confident that the quality of the forgeries currently on the market was low enough that they may be easily detected by experts in the field. Hu recalls for instance how, during a visit to the Gansu Provincial Institute of Archaeology in 1996, he first saw a news report claiming that

26. “經者取其事常也可常則為經矣且不為孔子其無經乎?” See Kong congzi zhuzi suoyin 孔叢子逐字索引 [A Concordance of the Kong congzi], D. C. Lau, ed. (Hong Kong: Shangwu, 1998), ICS Ancient Chinese Texts Concordance Series, Philosophical works No. 32, main text, 17.58. As Ariel summarizes this passage: "The sages do not have a monopoly over their books' titles, nor should they be considered the only ones capable of producing everlasting masterpieces." See K'ung-ts'ung-tzu: A Study and Translation of Chapters 15-23, chapters 18 for this quotation, and 56 for his own translation. Ariel also discusses this passage and the motivations for forgery in antiquity in "The K'ung-Family-Masters' Anthology and Third-Century Confucianism," in Confucianism: The Dynamics of Tradition, ed. Irene Eber, 39-6o (New York: Macmillan, 1986), 52-56. Unless otherwise noted, all translations from Chinese into English are my own.

27. Aurel Stein, Sand-Buried Ruins of Khotan: Personal Narrative of a Journey of Archaeological and Geographical Exploration in Chinese Turkestan (London: Hurst and Blackett, 1904), "Chapter XXXI," 447-59. See also Hu, "Lun jianbo bianwei yu liushi jiandu qiangjiu," 86-87.

28. $\mathrm{Hu}$, "Gudai jiandu de zuowei yu shibie," 47.

29. $\mathrm{Hu}$, "Lun jianbo bianwei yu liushi jiandu qiangjiu," 84 . 
a Sun Wu bingfa bamboo-strip manuscript was discovered in Xi'an. $\mathrm{Hu}$ and his colleagues, "long-time experts in wooden and bamboo-strip manuscripts, all exclaimed that the strips must be fakes as soon as they saw the report." 30 In this instance, the bizarre binding method and use of black paint for writing immediately signaled problems regarding the authenticity of this manuscript to the eyes of scholars like Hu who have personally handled numerous collections of genuine strips. ${ }^{31}$ Considering the complexity of such texts, Hu argues that only highly skilled paleographers would be able to convincingly forge a bamboo-strip manuscript, and any dedicated scholar with this skill set would have no motivation to do so..$^{22}$

With his updated article in 2010, "Lun jianbo bianwei yu liushi jiandu qiangiu," Hu still firmly holds that fakes today have yet to reach a level of sophistication where they could confuse a connoisseur. ${ }^{33}$ He does admit, nonetheless, that forgers have grown craftier in their trade and seem to have made advancements since 2008 , both in aging techniques (that is, falsely weathering the bamboo or wood) and in imitating archaic calligraphy. ${ }^{34}$ Indeed, Hu writes that he was motivated to expand upon his previous article when, on being called to authenticate a batch of bamboo strips he quickly deemed fake, he learnt that, just the previous day, another expert had issued a report rendering the same collection authentic. It seems that confusion abounds. As Hu wondered over how museums today are still purchasing these forgeries-even putting them on brazen display - he "felt with great sorrow that 'the authentication of bamboo and silk manuscripts' has truly become an issue to which we must pay more and more urgent attention." 35

Elaborating upon how to detect a fake manuscript, Hu outlines four basic areas where the forgeries often come up short: textual errors; physical constitution of the manuscript; calligraphy; and provenance..$^{36}$ For

30. $\mathrm{Hu}$, "Gudai jiandu de zuowei yu shibie," 47. This anecdote is repeated in Hu's 2010 article, though he has changed the wording of this sentence slightly. See Hu, "Lun jianbo bianwei yu liushi jiandu qiangjiu," 89-90.

31. Once further data on the manuscript was published and subjected to closer examination, Hu claims that many other features give away the forgery as well.

32. "If a forger were able to grasp the rules governing the evolution of characters as seen on Han strips, then he is truly a scholar, and I do not think he would then need to forge texts to sell." Hu, "Gudai jiandu de zuowei yu shibie," 48.

33. The line cited in $\mathrm{n} .32$ above is repeated, with slight alterations in his later article. See "Lun jianbo bianwei yu liushi jiandu qiangjiu," 97-98.

34. Hu, "Lun jianbo bianwei yu liushi jiandu qiangiu," 101.

35. Hu, "Lun jianbo bianwei yu liushi jiandu qiangjiu," 76 .

36. Hu, "Lun jianbo bianwei yu liushi jiandu qiangjiu," 98-101. In his updated article, $\mathrm{Hu}$ models these four principles on Fu Zhai's 笽齋 discussion of authenticating bronze inscriptions. Fu gives a trifold division of “以義理別," “以文字別,” and “以制作別.”

footnote continued on next page 
example, regarding the physical constitution of strips, forgers will often utilize wood or bamboo that is too fresh in appearance, or if they have tried aging the strips, the coloring will be too even, as genuine pieces will often have varying shades of color, despite coming from the same location. It is likewise difficult to mimic the precise calligraphy of a given period, and forgers copying from a model may miswrite graphs, producing forms that do not exist (this is particularly true with the less familiar Chu script). Content errors also abound, from misunderstanding dating conventions, to the inclusion of anachronistic anecdotes, and more nuanced gaps in vocabulary usage. Finally, Hu cautions that most forged strips are coming from either Hubei or Lanzhou. ${ }^{37}$ These are regions where authentic manuscripts have been discovered and are on display in museums, museums that often also happen to sell facsimile models that a forger may easily use for copying. $3^{8}$

While initial concerns over the first high-profile purchase of bamboo-strip manuscripts by the Shanghai Museum in 1994 may have been expressed in private, criticism was not published in formal scholarly venues. It seems that the concerns of most scholars were alleviated by the assumption Hu advocates: that these manuscripts were far too complex for anyone other than an expert paleographer to counterfeit, and such an expert would have little motivation to do so in the first place. After the Tsinghua University acquisition in 2008, however, various scholars have begun to raise doubts more publicly. Jiang Guanghui 姜廣 輝 for example has released a series of articles questioning whether the

The first two categories are subsumed under Hu's principle of “文字、文法與文理," while the last category is given by Hu as “質材與形制." Note that Hu's four principles are already given in his 1999 article, in the order of: physical constitution; calligraphy; textual errors; provenance. See $\mathrm{Hu}$, "Gudai jiandu de zuowei yu shibie," 48.

37. In his 1999 article, Hu also mentions Xi'an as a city known for manuscript forgeries; in the 2010 article, however, a number of different locales are listed, including Shanxi, Henan, Jiangsu, and Hunan. "It seems that in the last decade there has been a trend of continuous expansion [of locations where manuscripts are forged] ..." $\mathrm{Hu}$, "Lun jianbo bianwei yu liushi jiandu qiangjiu," 100.

38. Hu tells the story of how one museum in Hubei even made replicas out of wood taken from coffin planks in an actual burial. My assumption is that these replicas were originally for display purposes. Someone later came to sell the replicas on the market, presenting a huge problem, as the wood would be able to pass radiocarbon dating tests. Hu claims that coffin planks of this sort are not numerous, and that the practice of making replicas out of actual ancient wood was soon stopped. We must however note the possibility of forging texts on ancient blank strips. See "Lun jianbo bianwei yu liushi jiandu qiangjiu," 100. A similar hypothesis is raised by Wei Hongwei to explain why the fake manuscript he appraised uses phoebe zhennan 楠木. It was likely taken from an existing coffin, then made into strips for forging a text. See Wei, "Jiandu de jianshi yu bianwei," 48 . 
Tsinghua strips are authentic. ${ }^{39} \mathrm{He}$ warns that although it would be difficult to fake manuscripts like these, we should remain vigilant: it is always possible that there are technically skilled, educated, and wellfunded forgers out there who have the means to deceive us..$^{40}$ Jiang calls for a return to more traditional forms of textual criticism to catch subtle content-based mistakes an otherwise sophisticated forger may still make. ${ }^{41} \mathrm{He}$ thus attempts to find instances where, for example, vocabulary is misused, the grammar is incorrect, there are logical inconsistencies in the text, and anachronistic ideas are advanced or taken from later commentaries. Although I do not find the specific evidence Jiang raises against the Tsinghua strips to be convincing, his approach is largely representative of the type of critiques which have begun to gradually appear in published literature. $4^{2}$

More recently, a very public debate was initiated by Xing Wen when he declared the Zhejiang University Zuo zhuan manuscript to be fake in a series of Guangming ribao 光明日報 articles, 43 to which Cao Jinyan

39. Jiang Guanghui, “Baoxun shi yi” 保訓十疑, Guangming ribao, May 4, 2009 (http://theory.gmw.cn/2009-05/18/content_916754.htm), accessed September 30, 2016; "Qinghua jian jianding keneng yao jingli yige changqi guocheng" (see n. 22); “Baoxun yiwei xinzheng wuze” 保訓疑偽新證五則, Zhongguo zhexueshi 中國哲學史 3 (2010), 30-34; with Fu Zan 付贊, and Qiu Mengyan 邱夢燕, “Qinghua jian Qiye wei weizuo kao" 清華簡耆夜為偽作考, Gugong bowuyuan yuankan 故宮博物院院刊 4.168 (2013), 86-94; with Fu Zan, “Qinghua jian Yingao xian yi” 清華簡尹誥獻疑, Hunan daxue xuebao (shehui kexue ban) 湖南大學學報（社會科學版） 28.3 (2014), 109-14. On this last article, see also n. 18 above.

40. This refers to his “三高" criteria, namely that a forger would need to possess the technical wherewithal to trick scientific tests like radiocarbon dating, the specialist historical or paleographic training to throw off expert connoisseurship, and the wealth to be able to invest considerable capital into creating the forgery. See Jiang, "Qinghua jian jianding keneng yao jingli yige changqi guocheng," 1 .

41. Jiang, "Qinghua jian jianding keneng yao jingli yige changqi guocheng," 2.

42. To raise one minor example, he questions how in Baoxun 保訓 from the Tsinghua strips the sage Shun 舜 is said to have "personally tilled the fields 親耕” when he was a “commoner 小人." Jiang argues that using “qin 親” here would be inaccurate, since it is a technical term for when a ruler goes out to the fields (for ritual purposes), and moreover superfluous, as at this point in the anecdote farming would have been Shun's expected duty (as but a commoner). I am skeptical of this reading, however, particularly considering Shun's hallowed status in the Warring States, when the manuscript itself was produced. To this end, Paul Fischer's discussion on the shortcomings of traditional “authentication studies 辨偽學” in light of new understandings of textual production in early China may also equally apply to Jiang's methodology. See Paul Fischer, "Authentication Studies (辨偽學) Methodology and the Polymorphous Text Paradigm," Early China 32 (2008-9), 1-43.

43. Xing Wen 邢文, “Zheda cang jian bianwei shang一Chu jian Zuo zhuan” 浙大藏 簡辨偽上——楚簡左傳, Guangming ribao, May 28, 2012 (http:/ / epaper.gmw.cn/ $\mathrm{gmrb} / \mathrm{html} / 2012-05 / 28 / \mathrm{nw}$.D11000ogmrb_20120528_1-15.htm), accessed September 
曹錦炎, the main editor of this collection, likewise published his own refutations. ${ }^{44}$ Xing Wen's suspicions are grouped around three areas, which accord with Hu's earlier categorization: the unusual physical constitution of the strips, errors in textual content, and mistakes in the calligraphy. I will not list all his criticisms here, but allow me to offer one example. ${ }^{45}$ Xing notices that the writing on the Zhejiang University edition of the Zuozhuan 左傳 is across a series of broken strips, with the text accommodating the breaks to run continuously, when we would expect gaps in content instead. ${ }^{6}$ That is to say, sections of text will often end coincidently right where the breaks occur, and even the writing of individual characters or the spacing between them is unaffected by splits in the bamboo. Xing claims that this curious feature, along with the fact that the strips are uneven in length and width, and lack any notches or

30, 2016; “Zheda cang jian bianwei xia一Zhanguo shufa” 浙大藏簡辨偽下一一戰 國書法, Guangming ribao, June 4, 2012 (http://epaper.gmw.cn/gmrb/html/201206/04/nw.D11000ogmrb_20120604_1-15.htm?div=-1), accessed September 30, 2016; "Zheda cang jian zai bianwei-wenben fuyuan de guanlianxing yu Zheda weijian zai pipan" 浙大藏簡再辨偽——文本復原的關聯性與浙大偽簡再批判, Guangming ribao, June 25, 2012 (http://epaper.gmw.cn/gmrb/html/2012-06/25/nw. D11000ogmrb_20120625_2-15.htm?div=-1), accessed September 30, 2016. Although not related to the Zhejiang University strips debate, see also Xing Wen's discussion on Qin calligraphy, where he outlines his method for detecting forgeries: "Qin jiandu shufa de bifa-Qin jiandu shuxie jishu zhenshixing fuyuan" 秦簡牘書法的筆法——秦簡牘 書寫技術真實性復原，Jianbo 簡帛 8 (2013), 439-50. Xing has also questioned the authenticity of manuscripts in other collections. See for instance: “New Light on the Li Ji 禮記: the $\mathrm{Li} \mathrm{Ji}$ and the Related Warring States Period Guodian Bamboo Manuscripts," Early China 37 (2014), 522, and esp. n. 7. I will address his critique of the Peking University Laozi in more detail below.

44. Cao Jinyan 曹錦炎, “Zheda Chu jian wuyong zhiyi—cong wenben jiaodu lun Zheda Chu jian de zhenshixing" 浙大楚簡冊庸置疑——從文本角度論浙大楚簡的真實 性, Guangming ribao, June 18, 2012 (http://epaper.gmw.cn/gmrb/html/2012-06/18/ nw.D11000ogmrb_20120618_1-15.htm?div=-1), accessed September 30, 2016; "Zai lun Zheda jian de zhenwei一da Xing Wen xiansheng" 再論浙大簡的真偽——答邢文先生， Nanfang zhoumo 南方周末, July 22, 2012 (http://www.infzm.com/content/78639), accessed September 30, 2016. Other scholars have joined in on the debate, for instance: Liu Shaogang 劉紹剛, “Cong wenzi xingti he shufa kan Zheda jian” 從文字形體和書法 看浙大簡, Guangming ribao, July 2, 2012 (http://epaper.gmw.cn/gmrb/html/201207/02/nw.D11000ogmrb_20120702_1-15.htm?div=-1), accessed September 30, 2016; Wu Jiabi 武家璧, “Lun Zheda Chu jian Sirizhi de tianwen lifa neihan ji qi yiyi shang” 論浙大楚簡四日至的天文歷法內涵及其意義上，Fudan Daxue chutu wenxian yu guwenzi yanjiu zhongxin, September 11, 2012 (http://www.gwz.fudan.edu.cn/SrcShow.asp?Src_ID=1928), accessed September 30, 2016.

45. I highlight this specific point as he uses a similar logic to cast doubt upon one piece of the Peking University Laozi, as will be discussed shortly.

46. Xing, "Zheda cang jian bianwei shang." 
binding marks, varies significantly from other excavated examples of bamboo-strip manuscripts.

Cao Jinyan, for his part, appeals to the radiocarbon dating and ink tests which were conducted on the Zhejiang strips as undeniable proof of their authenticity, and asserts that there are in fact examples of excavated bamboo strips of uneven dimensions, and without notches or binding marks. 47 However, on this former point, Xing had already questioned the representativeness of the samples..$^{8}$ Was a forger able to trick these scientific tests, perhaps by obtaining blank ancient strips and writing new text on them? Or are we seeing a different form of manuscript production here, where an ancient scribe employed already broken strips as a textual carrier (perhaps as practice writing, which might also explain many of the calligraphy and content errors Xing Wen also proposes)?

The debate between Xing Wen and Cao Jinyan is instructive because it aptly reflects the sorts of anxieties keenly felt in the study of early China today as we address how best to handle these new sources with unknown provenances. No longer are scholars satisfied with the excuse that these purchased collections of manuscripts are too sophisticated to be a forgery. Scientific tests like radiocarbon dating are increasingly being adopted, but they are not infallible; we must consider, for instance, the representativeness of the samples, margins of error, and the possibility of contamination. Connoisseurship then must continue to play a role in authenticating bamboo-strip manuscripts, yet here too scholars are now demanding more transparency. Hopefully, inspiration will be drawn from other fields of study that have faced similar issues with authentication as well. 49 For the moment however, early China scholars

47. Cao, "Zheda Chu jian wuyong zhiyi." The scientific reports for the Zhejiang University Zuo zhuan 左傳 are available in: “Tan-14 ceshi baogao" 碳一14 測試報告, and “Zhujian jiance fenxi baogao" 竹簡檢測分析報告, in Zhejiang Daxue cang Zhanguo Chu jian 浙江大學藏戰國楚簡, ed. Cao Jinyan 曹錦炎 (Hangzhou: Zhejiang Daxue, 2011), 191-97.

48. Xing, "Zheda cang jian bianwei shang." The institutions preserving these manuscripts are hesitant to subject the artifacts to destructive testing procedures, and generally only a few strip pieces are tested, usually those that do not bear any writing.

49. Biblical studies is one such field that has faced comparable issues. A recent example is the controversy surrounding the so-called "Gospel of Jesus's Wife" papyrus fragment. It is introduced in Karen L. King, "'Jesus said to them, "My wife ..."': A New Coptic Papyrus Fragment," Harvard Theological Review 107.2 (2014), 131-59. Harvard Divinity School hosts a website documenting research on this piece (http:// gospelofjesusswife.hds.harvard.edu/), which also makes available reports on the scientific testing conducted to authenticate it. Following an investigative report by The Atlantic into the provenance of the piece (Ariel Sabar, "The Unbelievable Tale of Jesus's Wife," The Atlantic Monthly, Jul/Aug 2016 [318.1], 64-78), King is now also

footnote continued on next page 
are unfortunately left to their own devices when attempting to determine the authenticity of bamboo-strip manuscripts.

\section{Authentication of the Peking University Han Bamboo Strips}

The Cang Jie pian manuscript central to my research was included among the cache of Western Han bamboo strips donated to Peking University early in 2009. The strips are said to have arrived at the Arthur M. Sackler Museum of Arts and Archaeology at Peking University on January 11 of that year, though the donation was inevitably the result of a longer process of investigation and negotiation..$^{\circ}$ Few details have been published about the circumstances surrounding the actual purchase of this cache. Tsinghua University's acquisition of a similar collection from the Hong Kong antiquities market however might provide a comparable scenario, for which we fortunately have more documentation. ${ }^{51}$

Tsinghua University formally received their collection of bamboo strips on campus on July 15, 2008. Just over a month prior, in June 2008, Tsinghua University officials had already begun to discuss acquiring the collection. Li Xueqin 李學勤 and other scholars were likewise asked to ascertain the academic value of the artifacts beforehand. Moreover, there is reason to believe that the Warring States manuscripts eventually donated to Tsinghua University were already for sale as early as the winter of 2006, at least two and half years before their final purchase, having been seen by Zhang Guangyu 張光裕 on the market at that time. ${ }^{2}$

suspicious of the papyrus's authenticity. In addition to turning to fields further afar, we may also look to debates raised over the authenticity of other media in early China, specifically that of bronze vessel inscriptions. A useful overview of this debate in Western scholarship, placing the work of Henri Maspero, Bernhard Karlgren, Noel Barnard, and Herrlee Creel into proper historical context, may be found in Edward Shaughnessy, Sources of Western Zhou History (Berkeley and Los Angeles: University of California Press, 1991), 30-34; see also ch. 2 "The Casting of an Inscribed Bronze Vessel, with Remarks on the Question of Authenticity."

50. For the specific date the Western Han strips arrived at Peking University, see Beijing Daxue chutu wenxian yanjiusuo, "Gongzuo jianbao" 工作简报, Beijing Daxue Zhongguo gudaishi yanjiu zhongxin, 1 (2009), I (http://www.zggds.pku.edu. cn/005/007/o01.pdf), accessed September 30, 2016.

51. Liu Guozhong 劉國忠 offers one of the only behind-the-scenes glimpses into the decision-making process that has gone into the purchase of this sort of collection off the black market. See his Zoujin Qinghua jian 走近清華簡 (Beijing: Gaodeng jiaoyu, 2011), esp. ch. 4-6, 35-64. William French and I have recently completed a translation of this work into English: Introduction to the Tsinghua University Bamboo-Strip Manuscripts (Leiden: Brill, 2015).

52. Later, in April 2007, Hu Pingsheng 胡平生 also heard rumors about an important collection of Warring States texts floating on the market in Hong Kong. See Liu, Zoujin Qinghua jian, 35-36; Hu, "Lun jianbo bianwei yu liushi jiandu qiangjiu," 102; 
If we may assume that a similar time frame was required for Peking University to adjudicate the strips and arrange for their procurement, then it is likely that there was knowledge of this cache by the end of 2008 at the latest, while the actual artifacts were unearthed from their original archaeological site and above ground for an indefinite amount of time beforehand. Hu Pingsheng also offers indirect confirmation of this timeline. He states that "at the end of 2008, Li Jiahao 李家浩 and I participated in the authentication of a cache of looted Han strips, led by Professor Zhu Fenghan 朱鳳瀚 of Peking University's History Department. After we confirmed that the strips were genuine, Peking University acquired them for their preservation." 53

Following the initial cleaning, preservation, and photography of the Peking University bamboo strips, a conference was convened on November 5, 2009, where many of the foremost experts on this class of artifact were invited to discuss the nature of the manuscripts. Minutes from this conference, along with abbreviated comments by the experts who attended, are available in the second brief issued by Peking University's Excavated Manuscripts Research Center, part of the series reporting on their continuing study of the manuscripts. 54 Judging from the comments provided, the consensus of these experts was that the Peking University bamboo strips are in fact Han period artifacts.

There are, however, a few scholars who mention they originally questioned the authenticity of the Peking University cache. Hu Pingsheng, for instance, confesses that he at first doubted the strips were genuine, because when he initially viewed pictures of them he did not see any traces of binding marks or notches. His concerns were alleviated though when he was shown clearer photographs, which revealed the existence of not only binding marks and string remnants, but also how the strips were splintering, in a way that is typical for artifacts of this type and commonly encountered by those who clean and prepare such strips. 55 Song Shaohua 宋少華 also agrees with this point, emphasizing how these particular features cannot be faked. Although Song first believed the Peking University strips were a forgery, he was now convinced of the authenticity of the collection.

Zhang Guangyu 張光裕, “You jian Jing Chu yizhen” 又見荊楚遺珍, Qinghua daxue xuebao 清華大學學報5 (2009), inside front cover.

53. Hu, "Lun jianbo bianwei yu liushi jiandu qiangjiu," 105.

54. Beijing Daxue chutu wenxian yanjiusuo, "Gongzuo jianbao," Beijing Daxue Zhongguo gudaishi yanjiu zhongxin, 2 (2009), 4-12 (http://www.zggds.pku.edu. cn/o05/o07/o02.pdf), accessed September 30, 2016.

55. Beijing Daxue chutu wenxian yanjiusuo, "Gongzuo jianbao," 2009.2, 8. 
According to the minutes from the November conference, it appears that the invited experts were not only provided with photographs of the strips, but they also had an opportunity to view the artifacts in person..$^{6}$ Peng Hao 彭浩 however requests that the Peking University editors eventually publish a report on the methods they used to authenticate the strips, reminding them how questions still linger about the Shanghai Museum collection because they neglected to publish sufficient data on their AMS radiocarbon testing. 57 He goes on to wonder about how the red pigment coloring the Peking University daybook (Rishu 日書) was made to stick to the strips so remarkably well, especially considering the primitive technology available in those times-perhaps raising a subtle critique at the strips' authenticity. ${ }^{8}$ In any case, Peng Hao's request, also echoed by Zhao Guifang 趙桂芳, suggests that scientific data of this sort was not made available to the experts at the conference.

Two years later, a report was issued by Peking University's School of Archaeology and Museology 北京大學考古文博學院 offering the results of their scientific analysis of the Han strips. ${ }^{99}$ They observed the cellular structure of three samples of bamboo, and identified them as Phyllostachys or gangzhu 剛竹, which accords with expectations. Two of the samples however were taken from strips without writing, with the third cut from the end of an unlabeled suanchou 算筹 divining rod, which might lead one to question how representative these pieces truly are. Fragments of the binding string were also analyzed, and shown to be structurally consistent with ma 麻 hemp, and the authors offer a preliminary identification of Boehmeria or zhuma 苛麻. This is a form of hemp that again was available in the Han period. Crusted onto the surface of the hemp were yellow contaminants, while grains of soil and bacteria were lodged within the fibers. Finally, the red pigment that Peng Hao wonders about was also subjected to laser-induced Raman spectroscopy, and found to be zhusha 朱砂 cinnabar.

Notably absent from the scientific analysis conducted by Peking University's School of Archaeology and Museology however is any discussion of radiocarbon dating for these strips. In the fifth brief issued by Peking University's Excavated Manuscripts Research Center, announcing the overviews published in Wenwu 2011.6, they call these scientific results "partial 部分," perhaps hinting at additional tests. ${ }^{60}$ Moreover, in

56. Beijing Daxue chutu wenxian yanjiusuo, "Gongzuo jianbao," 2009.2, 5.

57. See n. 17 above.

58. Beijing Daxue chutu wenxian yanjiusuo, "Gongzuo jianbao," 2009.2, 9.

59. Hu Dongbo 胡東波, Zhang Qiong 張瓊, and Wang Kai 王愷, “Beida Xi Han zhujian de keji fenxi" 北大西漢竹簡的科技分析, Wenwu 2011.6, 90-93.

6o. Beijing Daxue chutu wenxian yanjiusuo, "Gongzuo jianbao," 2012.5, 2. 
the same brief, an update is given for the Peking University team's work on editing the other recently acquired cache of Qin strips, where it is reported that radiocarbon dating was planned for the Qin strips. ${ }^{61}$ And indeed, the following year the results for these tests were given in Wenwu 2012.6. ${ }^{62}$ Nothing however has been mentioned in these or later briefs about radiocarbon dating for the Han strips. The lack of scientific dating for this cache of Han bamboo strips is a serious concern when evaluating their authenticity.

In the general overview to the Peking University Han manuscripts in the same issue of Wenwu, the editors date the majority of manuscripts to the mid-Western Han, most likely to the end of Emperor Wu's 武帝 reign (140-87 B.C.E.), and no later than that of Emperor Xuan 宣帝 (73-49 B.C.E.). ${ }^{63}$ This conclusion seems to have been reached primarily based on a comparison of the manuscripts' calligraphic style and character forms against other excavated caches. ${ }^{64}$ The clerical script of most Peking University manuscripts is distinctly later than that found on the Zhangjiashan 張家山, Mawangdui, and Yinqueshan manuscripts, which is close to Qin clerical or early Han clerical script, while being not quite as mature as the writing found on the Dingzhou Bajiaolang 定州八角廊 strips.

With the Peking University Cang Jie pian, however, we cannot so easily rely on an analysis of calligraphic style and character forms to date the text. Zhu Fenghan describes the calligraphy in the Cang Jie pian as at times closer to Qin clerical script (as seen with the Shuihudi cache), while many characters even preserve seal script forms, contrasting sharply with the other strips from this collection. ${ }^{65} \mathrm{Zhu}$ attributes these features to the close relationship between the Cang Jie pian and the earlier Shi Zhou pian 史䈏篇, as stated by the Han shu Yiwen zhi (and corroborated by the Shuowen Jiezi 說文解字 postface). ${ }^{66}$ In short, the Cang Jie

61. Beijing Daxue chutu wenxian yanjiusuo, "Gongzuo jianbao," 2012.5, 6.

62. Beijing Daxue chutu wenxian yanjiusuo, "Beijing Daxue cang Qin jiandu shinei fajue qingli jianbao" 北京大學藏秦簡牘室內發掘清理簡報, Wenwu 2012.6, 41-42.

63. Beijing Daxue chutu wenxian yanjiusuo, "Beijing Daxue cang Xi Han zhushu gaishuo," 53 .

64. The editors also point out that no dates in Emperor Wu's reign were found on the strips, with only one strip writing “first year of [Emperor] Xiao Jing 孝景元年," using the posthumous title here. The calendar employed in the daybook and divination manuscripts (Rish $u$ 日書 and Yushu 雨書) also reflects changes that only occur after the calendar reform (in 104 B.C.E.), which gives us an upper limit for their date. Taboo avoidances are considered, though the editors note that this practice is not necessarily consistent in the early Han. See Beijing Daxue chutu wenxian yanjiusuo, "Beijing Daxue cang Xi Han zhushu gaishuo," 53 , as well as 55-56, nn. 4 and 5.

65. Zhu, "Beida Han jian Cang Jie pian gaishu," p. 57.

66. Han shu 30.1721; Shuowen jiezi zhu 15.758. 
pian might incorporate deliberately archaic calligraphic styles and character forms as a result of its function as a character book. This purposeful archaizing of writing would complicate any attempt to date the text based on calligraphy alone.

To summarize the conversation above, we are confronted with the following facts pertinent to authenticating the Peking University manuscripts: (1) There is no detailed provenance for this cache. Besides the date that the strips were donated to the university, additional information is not available about its purchase or time on the market beforehand, though we may surmise that by the end of 2008 certain scholars were aware of the cache. (2) Although a few scholars were at first suspicious, the consensus from experts invited to examine the cache is that the strips are authentic. How the bamboo strips splintered, the remnants of binding, and similar physical features are mentioned by connoisseurs as telling characteristics for genuine strips. (3) The type of bamboo used is consistent with other excavated Han strips, and we know the hemp and cinnabar on the strips was also available in early China. (4) The calligraphy on the majority of the Peking University manuscripts is comparable to other Han examples. With the Cang Jie pian, however, this type of comparison is perhaps frustrated by its at times purposefully archaic nature. (5) Results from scientific dating methods, such as radiocarbon dating, are not available for this collection of strips. Considering these points, it would appear that we are left to rely mainly on the connoisseurship of the editors and other experts who have personally handled the Peking University Han manuscripts.

\subsection{A Response to Xing Wen's Critique of the Peking University Laozi}

In a recent Guangming ribao article, Xing Wen warns that this places other scholars in a very precarious position. Xing believes that the Peking University Laozi 老子 manuscript is in fact a forgery, and suggests that the editors of the collection have been intentionally misleading in their presentation of the data, so as to quiet criticism about the text's genuineness. ${ }^{67}$ His critique is based primarily on observations that the writing seems to accommodate or morph around breaks in the strips, and that there are irregularities in the manuscript's verso marks and material presentation.

Even if we agree with Xing's assessment of the Laozi manuscript, we must keep in mind that this does not necessarily prove that the entirety of the Peking University collection-including the Cang Jie pian-is fake.

67. Xing Wen 邢文, "Beida jian Laozi bianwei," see n. 15 above for a link to the article online. 
The authenticity of each discrete manuscript, and indeed every single strip in the collection, ought to be considered individually, to whatever extent possible. This is particularly true as there is no guarantee that all the strips in this cache have the same provenience, although it does seem likely. In the interest of addressing concerns about this collection writ large however, I will respond to the points made in Xing's assessment.

In declaring the Peking University Laozi to be fake, Xing Wen raises the following main arguments. Points one and two relate to his "technical calligraphy analysis," while points three through six all pertain to the verso marks, either directly or indirectly:

1. Xing believes that the character "無" on strip \#2 of the Peking University Laozi is written in a curious fashion. ${ }^{68}$ The character is written to slant in an unusual way that appears to avoid the break at this point in the bamboo strip, with the right side of the character seemingly following alongside the crack, particularly in its bottom-right quarter. The character thus appears to squeeze itself into the space remaining on the broken bamboo piece. This, Xing suggests, is evidence that "無" was written after the bamboo strip was split in two, a practice that he asserts was not present in early China.

2. Xing also questions the integrity of the character “得" on strip \#52 which straddles the break in the bamboo. The top-right half of the character remains on the upper piece and the bottom-left half of the character is found on the lower piece. ${ }^{69}$ Xing argues that the break hides the fact that “得" was miswritten. A proper reconstruction, according to Xing's own analysis, reveals that the construction of “得" here is not typical, and in fact does not even constitute a complete character..$^{\circ 0}$ On this point, he accuses the editors of the cache of purposefully manipulating the data they published to mislead readers, so that they might not notice the misshapen “得” graph. A forger must have written part of the character on one piece of broken bamboo, and then tried to finish the character on another, with poor results.

68. The image is reproduced below in Figure $4 \mathrm{~b}$. Photographs of this character at its original size and magnified may be found at: Beijing Daxue chutu wenxian yanjiusuo, Beijing Daxue cang Xi Han zhushu [er], 3 and 32.

69. For photographs of this character in its original size, magnified, and in infrared, see Beijing Daxue chutu wenxian yanjiusuo, Beijing Daxue cang Xi Han zhushu [er], 9, 49 and 108 .

70. Details on why Xing reconstructs “得” in this fashion are provided below. 
3 Considering the overall conformity of the verso marks, Xing then argues that the lines that appear to cross over multiple strips are not in perfect alignment. Rather, in certain instances, the line on an individual strip is carved at a slant whose angle differs from the lines found on neighboring strips. Two examples Xing highlights are the verso marks on strip \#86 in comparison with those running from strip \#87 onwards, and those on strips $\#_{182}$ and $\#_{183}$, for which he also supplies hypothetical extensions. Noticing that their gradients are not the same, Xing believes that a forger attempted to replicate a straight line, but failed to accurately connect it across multiple strips.

4. Xing also observes that if we were to try to align the verso marks as closely as possible, we would need to adjust the height of the strips, rearranging how they are currently presented in Beijing Daxue cang Xi Han zhushu (Volume 2). In doing so, the layout of the manuscript would be altered, with the tops and bottoms of the strips not falling level with one another, but rather positioned at various heights. Such a layout is not what we would expect to find for an ancient bamboo-strip scroll. Either the layout of the manuscript (in terms of the varying strip height) betrays it as a fake, or once again the verso marks do not accurately align with one another, betraying them to be fake.

5. Strips $\# 84$ and $\# 187$ are also devoid of any line-like mark on their versos. The absence of marks on these two strips is noteworthy because they seem to be inserted among other strips where there is a clear running line. Xing emphasizes that, to explain this oddity, the editors for the Peking University Laozi suggest that the manuscript was "written first and then bound." They argue that a mistake must have been made in the initial writing on the original strips (with the appropriate verso marks), and that these strips with mistakes were later replaced with other strips (that did not have verso marks), which were then bound together into the manuscript we now have..$^{71}$ Xing however points out that the writing on the Laozi manuscript seems to avoid where the binding strings were laid, which to him suggests that it was instead "bound first and then written upon." If this were the case, then Xing finds no explanation for the insertion of these strips with blank verso marks, and thus assumes that the manuscript was faked. 
6. In critique (2) above, Xing disputed how the character “得” was written in strip \#52. He further notes that in the hand drawing of its verso, only the top piece includes a line-like mark, while the bottom piece (or the right side of the drawing) does not show any such mark. He takes this as evidence that the two pieces are actually not from the same original bamboo strip. According to Xing, this would demonstrate that the text was written and supposedly pieced together on these separate broken fragments, thus confirming a forgery.

Despite the clarity of the published photographs, when investigating materially complicated features of the bamboo, such as writing around breaks in the strips or the faint verso marks, ideally one should refer to the actual artifact. This is particularly true since all photographs of these bamboo-strip manuscripts are doctored to some degree in preparation for publication, even if this means simply removing the background color. $7^{2}$ Caution is doubly warranted when relying solely on the hand drawings, as this entails yet another degree of separation away from the artifact itself. In this case, production of the hand drawings for the verso marks was based on measurements conducted in the fall of 2010, shortly after the importance of this feature was first realized in full.73

A personal inspection of the Laozi manuscript artifact on two occasions revealed to me that most of Xing Wen's critiques were based on unclear or incomplete data. 74

72. For more on this point, see Jia Lianxiang 賈連翔, Zhanguo zhushu xingzhi ji xiangguan wenti yanjiu一yi Qinghua Daxue cang Zhanguo zhujian wei zhongxin 戰國竹書形制 及相關問題研究——清華大學藏戰國竹簡為中心, in the Qinghua jian Xinian yu gushi xintan yanjiu congshu 清華簡繫年與古史新探研究叢書 series, ed. Li Shoukui 李守奎 (Shanghai: Zhongxi, 2015), 256-81.

73. See Han Wei's paper: "Zai lun Beida Han jian Laozi de jianbei huahen-jian shi dui Han jian Laozi zhenwei de 'zhiyi'” 再論北大漢簡老子的簡背劃痕一一兼釋對漢簡老 子真偽的 “質疑," from his talk delivered at the Beijing Forum 北京論壇, Peking University, November 6, 2016, pp. 1-2; Han Wei, "Xi Han zhushu Laozi jianbei huahen de chubu fenxi," 227; Beijing Daxue chutu wenxian yanjiusuo, "Gongzuo jianbao," Beijing Daxue Zhongguo gudaishi yanjiu zhongxin, 4 (2011), 4 (http:/ /www.zggds.pku.edu. cn/005/007/o04.pdf), accessed September 30, 2016.

74. After requesting permission from the Peking University Excavated Manuscript Research Center, I was allowed to inspect the Laozi artifact twice, first on September 5, then again on October 26, 2016. Under the direction of center personnel, photographs were taken of the versos to a number of the strips currently under question, and I have received permission to publish them here (Figures 1, 2, and 3). Han Wei has also prepared an introduction of our findings on these two dates, along with a more detailed introduction to their discovery and treatment of the verso marks. This was delivered as a talk in the Beijing Forum in November 2016, and a handout was also provided. See the above cited "Zai lun Beida Han jian Laozi de jianbei huahen," which also includes 
During my first inspection in September, I noticed that there is in fact a line-like verso mark on the bottom piece of strip \#52 that was not recorded in the editors' initial measurements or hand drawings, contra Xing's critique (6). See Figure 1. The gradient of the line seems to match that of the mark found on the top piece of strip \#52, the left side, that is, of the verso in the hand drawing. Moreover, it anchors the two pieces in such a way that Xing Wen's new reconstruction is impossible, undermining the version of "得" for which he gives his "technical calligraphy" analysis, in critique (2). 75 How the editors arranged the recto photographs is more in line with how the strip would have been originally presented vertically, except of course that the pieces should overlap slightly horizontally as well, and not be angled off to the side of one another for convenience of display.

In October when we were observing the strips again and taking photographs of the versos, Han Wei discovered that the bottom piece of strip \#32 also bears a verso mark that was missed in the initial measurements and hand drawings. The verso mark is found below the break in the strip. Xing Wen refers to strip \#32 when arguing in his critique (4) that

(a)

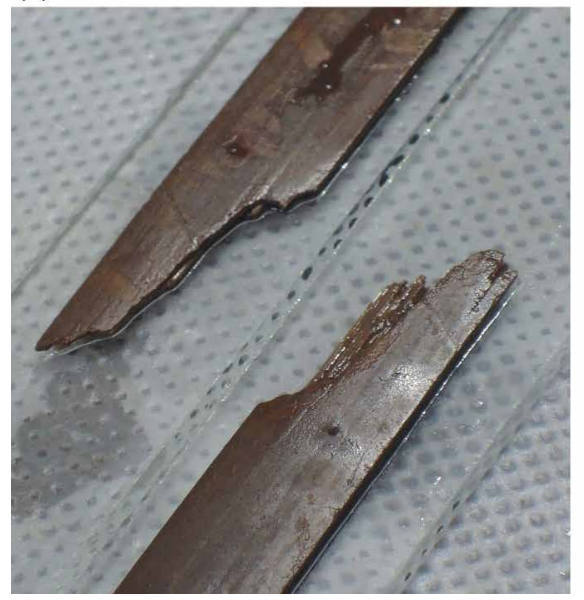

(b)

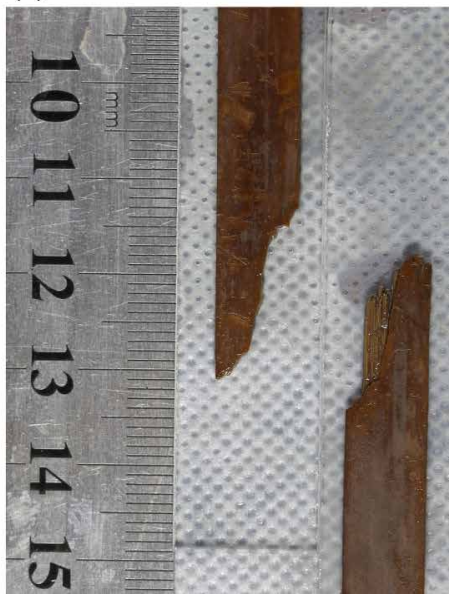

Figure 1. (color online) Verso mark on strip \#52 (photographs taken on October 26, 2016, at Peking University).

photographs. I am grateful to Zhu Fenghan 朱鳳瀚, Han Wei 韓巍, and Chen Kanli 陳 㑆理 for all of their assistance.

75. In this instance, with two pieces from the same strip, relying on the verso line to re-piece the individual strip is the most secure approach. See below, however, for why we should turn to traces of binding strings and notches over the verso lines alone when connecting different strips within the same manuscript. 
(a)

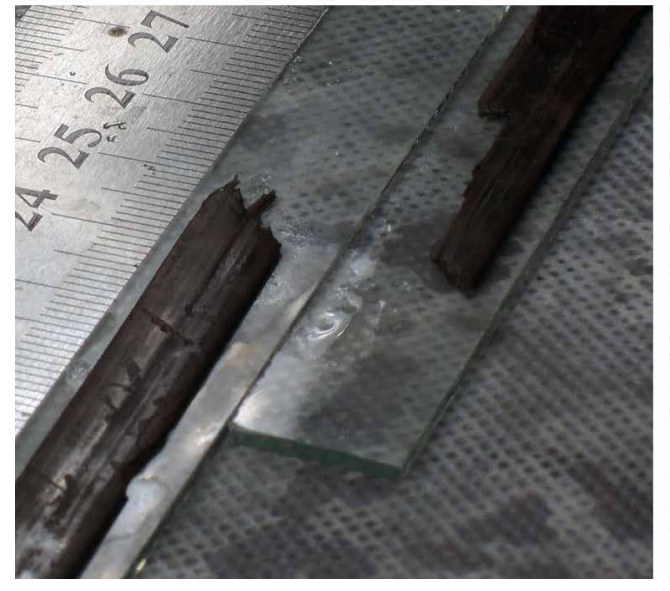

(b)

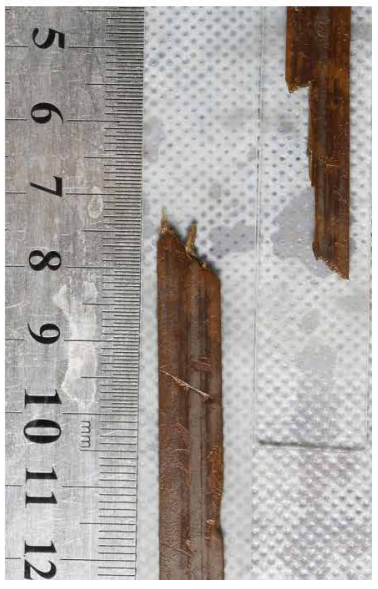

Figure 2. (color online) Verso mark on strip \#32 (photographs taken on October 26, 2016, at Peking University).

the heights of the strips were not level in the bound Laozi manuscript. He assumed that the break represents where the verso mark should have been on strip \#32 (as the bamboo will often split along these verso marks, where it is made structurally weaker), and subsequently aligns this group of strips with \#32 placed significantly lower than its neighbors. I will discuss below why this methodology for arranging the layout of the manuscript is problematic, however in this case the newly discovered verso mark accords well with those marks found on the neighboring strips, meaning that this set of strips would be arranged in the bound manuscript with level heights.

The mark on the bottom piece of strip \#52 is close to the break in the bamboo, and is extremely faint and hard to notice. It would have been easy to overlook during the initial measurements of this feature. The mark on the bottom piece of strip \#32 is positioned further away from the break, and is clearer to the eye, with an almost reddish-orange hue present from what seems to be tearing in the bamboo. It was however hidden under the metal identification tag, which is attached to the string that binds together the glass plates securing the strip. Han removed the glass plates for this strip when we were viewing the Laozi in October, and only then noticed the verso mark..$^{6}$ In both cases, the

76. According to Han Wei, the strips were left in the glass plates when the verso marks were first recorded, in fall 2010. See "Zai lun Beida Han jian Laozi de jianbei huahen," 1 . 
mistaken omission of these verso marks was unfortunately replicated in the publication of the Laozi verso hand drawings.77 I may now confirm that critiques (2), (4), and (6) are based on incomplete data, which could have been rectified upon inspecting the artifact itself. Note however that I was not able to detect verso marks on strips \#84 or \#187, which Xing raises in critique (5). Cognizant of the difficulty of identifying this feature, I would recommend they be checked again more thoroughly.

Another observation has to do with the angle of the line-like verso marks, which Xing Wen believes to be irregular in critique (3). The measurements taken for the verso marks are inevitably imprecise, as they were rounded to the nearest tenth of a centimeter. $7^{8}$ This is a crucial point, as any dramatic discrepancies to the gradient of verso lines across neighboring strips — as shown in the hand drawing - might amount to a mathematical illusion, rather than being a sign of forgery. Consider for instance the marks on strip $\#_{1} 82$ and $\#_{1} 83$, which Xing raises in his article as an example for verso lines with widely divergent gradients. According to the "Xi Han zhushu Laozi zhujian yilanbiao 西漢竹書老子 竹簡一覽表," the width of each strip is the same, at $0.8 \mathrm{~cm}$, while the overall height for the verso marks (that is, measured from their topmost entry on the left of the strip to their bottommost exit on the right) is $0.4 \mathrm{~cm}$ and $0.6 \mathrm{~cm}$ respectively, leading to a $10.3^{\circ}$ variance in the line gradient. Sensitive to the fact that the data is rounded off, however, it is possible that the actual width of each strip is, when not rounded off, $0.80 \mathrm{~cm}$ and $0.84 \mathrm{~cm}$, while the overall height for these verso marks could be $0.44 \mathrm{~cm}$ and $0.56 \mathrm{~cm}$ in turn. This now gives a more tolerable $4.9^{\circ}$ difference, which is a nearly negligible $2.45^{\circ}$ off from a theoretical mean gradient for the ideal verso line. 79

77. Further mistakes were also possibly made, either in recording the initial measurements, or then replicating them in the hand drawings. Thies Staack points out, for instance, that in the full-size rendering of the Laozi verso, the position of the mark on strip \#35 differs from what is seen in the smaller format version. See Thies Staack, "Identifying Codicological Sub-units in Bamboo Manuscripts: Verso Lines Revisited," in Manuscript Cultures 8 (2015), 162, n. 35 (https: / / www.manuscript-cultures.uni-hamburg.de/MC/manuscript_cultures_no_8.pdf), accessed September 30, 2016.

78. This is explained in the "Xi Han zhushu Laozi zhujian yilanbiao" 西漢竹書老子 竹簡一覽表 appended to Beijing Daxue cang Xi Han zhushu [er]. See p. 165, article 8. I thank Chen Kanli also for the helpful discussion we had on this point, and the Peking University editors' general workflow.

79. On the other hand, the rounding effect could also swing the opposite way as well, leading to an even greater apparent discrepancy in the line gradient across individual strips. I would urge any interested scholar working on the Laozi to similarly inspect the manuscript itself to form their own judgment. 
(a)

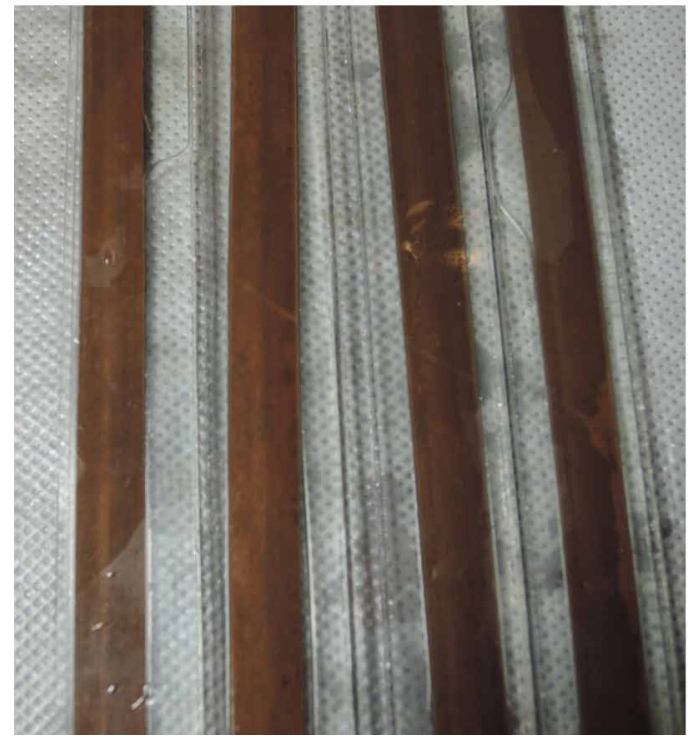

(b)

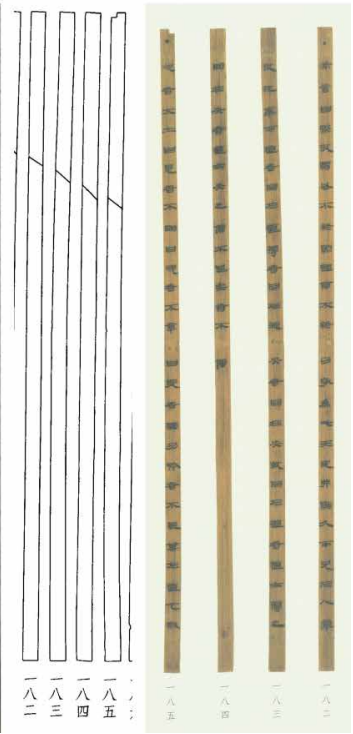

Figure 3. (color online) Verso marks on strips \#182-85 (photograph taken on October 26, 2016, at Peking University; the hand drawing and recto photograph are after Beijing Daxue cang Xi Han zhushu [er], 116 and 26, respectively).

In my examination of the verso marks for strips $\#_{1} 82-85$, I noticed that for the most part the angle of the line running across these four strips was largely in accord, with the gradient to the line on strip \#184 in particular more amenable to the series than reflected in the hand drawing. The only exception though was still the verso mark on strip $\#_{18}$, which does seem to have a slightly steeper gradient than the others. See Figure 3, which shows the versos of strips \#182-85, from left to right respectively, compared to the hand drawing. When observing the artifact's verso, however, it is apparent that the strip is warped, curving with a slight bend to the right. The bend in the strip is not obvious from the hand drawing, but may be seen in the original-sized photographs, where it appears curving towards the top left from the recto. This warping makes the verso line seem steeper in comparison to those on the other three strips here, when in actuality there is not a dramatic difference, should the strip be straightened. ${ }^{80}$

8o. Han Wei was the first to notice this bend while we were handling the artifact, and speculated that it was causing the apparent variance. Lining up the strips for observation is hindered by the fact that they are kept bound between two wide glass plates, meaning that you cannot place the strips immediately side-by-side, or easily adjust how they are positioned within the plates. For the original-sized photograph, see Beijing Daxue cang Xi Han zhushu [er], 26. 
Of course, it is not always possible for every scholar who writes about these manuscripts to examine them in person, as access is often restricted for preservation purposes or, for those of us based outside of China, not logistically convenient. To help scholars verify the observations reported above, I have included photographs taken during my second viewing of the Laozi manuscript, on October 26; hopefully further documentation will be made available in the near future by the Peking University editors as well. ${ }^{81}$ Appreciating however that most scholars will not be able to personally confirm my findings by handling the artifact itself, I will offer below additional responses to Xing Wen's critiques, using data publicly available, such as the photographs and "Yilanbiao" published in Beijing Daxue cang Xi Han zhushu (Volume 2). My emphasis here nevertheless is that in working with manuscript artifacts (as with any other object of study for that matter), we need to appreciate how the data we rely on is collected and presented, as well as the limitations that are then placed upon their use in our research. One of my major reservations regarding Xing's methodology is that it lacks such an appreciation for the limitations of either the artifact itself or the published data provided.

Let me therefore now address, in turn, each of Xing's critiques listed above exclusively on the basis of publicly available data. To this end, it should also be noted that about a month after Xing Wen published his critique of the Peking University Laozi, Li Kai 李開 offered an initial defense of the manuscript, printed again in Guangming ribao. In the same issue, Xing Wen answers Li Kai and provides further comments clarifying his position. ${ }^{82}$ When relevant, details from this exchange are included in the discussion below; there are however aspects of Li's approach that I find problematic, which is why it is not treated in full here. ${ }^{83}$ As this article was under review, a further brief

81. As cited before, Han Wei has already delivered a paper introducing the verso marks we noticed, and more high-quality photographs were taken of these features by himself and Chen Kanli. See "Zai lun Beida Han jian Laozi de jianbei huahen."

82. Li Kai 李開, “Guanyu Beida jian Laozi de bianwei” 關於北大簡老子的辨偽， Guangming ribao, September 12, 2016 (http://epaper.gmw.cn/gmrb/html/201609/12/nw.D11000ogmrb_20160912_1-16.htm?div=-1), accessed September 30, 2016; Xing Wen, "Bianzheng zhi mei yu sandian toushi一Beida jian Laozi zai bianwei” 讋證 之美與散點透視一北大簡老子再辨偽, Guangming ribao, September 12, 2016 (http:/ / epaper.gmw.cn/gmrb/html/2016-09/12/nw.D1100oogmrb_20160912_2-16. htm?div=-1), accessed September 30, 2016.

83. For example, Li turns to traditional theories of Chinese calligraphy to justify the discrepancies Xing presents with the characters “無” on strip \# 2 and “得” on strip \#52. I find it anachronistic however to apply later aesthetic norms such as "the beauty of dialectical juxtaposition 辯證之美" or “dispersed perspective 散點透視” to writing on Western Han (or earlier) manuscripts. Regarding the irregularities in the verso marks, Li also repeatedly relies on the notion that complexity betrays authenticity, as he believes a modern forger would avoid inventing anomalies that might call their 
response by Yao Xiaoou 姚小鷗 was published in Chinese, while Thies Staack also prepared his own defense of the Peking University Laozi in English. ${ }^{84}$ Xing Wen has since replied to Yao's response, and I have also incorporated this in my discussion below when appropriate. ${ }^{85}$

For the reader's convenience, I will post in italics Xing's argument in abbreviated form before my responses.

1. The character "無" on strip \#2 seems to be written in a manner that intentionally avoids a break, suggesting it was written after the strip was split in two.

In his first article, Xing Wen offers images from only three other instances of the character "無" found on strip \# 1 of the Peking University Laozi. These three examples happen to exacerbate the difference Xing is hoping to highlight in how the characters were written. Even if we grant that the "無" found above the break in strip \# 2 is complete, a broader survey of how "無" is written across the entire manuscript will reveal that this specimen is not exceptional. It is possible that the perceived avoidance of the break in the bamboo is not actually a purposeful distortion of the writing by a forger's hand, but rather a mere coincidence in the positioning of the character vis-à-vis the remaining edge. Consider the following chart (Figure 4), which shows the examples Xing provides, followed by three other examples I have selected from elsewhere in the Laozi manuscript. For comparison purposes, I have also included an image of

work into question. We cannot make this assumption however, as a savvy forger may anticipate this concern and purposefully include blemishes for a more "genuine" appearance, while a clumsy forger is apt to simply make mistakes. Li's response is also limited by a number of misunderstandings, both on the presentation of data in Beijing Daxue cang Xi Han zhushu [er] and the arguments Xing Wen raises, but I will not enumerate them here.

84. Yao Xiaoou 姚小鷗, “You pinjie yu shufa kan zhenwei一yu Xing Wen xiansheng shangque" 由拼接與書法看真偽——與邢文先生商榷, Guangming ribao, December 12, 2016 (http:/ / epaper.gmw.cn/gmrb/html/2016-12/12/nw.D1100oogmrb_20161212_1-16. $\mathrm{htm})$, accessed December 13, 2016. Yao and I are in agreement on the fact that the reconstruction of “得" on strip \#52 is hindered by difficulties in re-piecing together the broken halves of this strip. He also discusses the representativeness of the various "無" on strips \#1 and questions whether "無" on strip \#2 is exceptional. Thies Staack's article is titled: "Could the Peking University Laozi 老子 really be a forgery? Some skeptical remarks." Staack offers many of the same responses to Xing Wen's critiques that I give below. Since our articles were drafted independently, we have agreed to maintain this independence by not elaborating upon each other's work. Once published, I would encourage readers to consult Staack's article for a complementary perspective.

85. Xing Wen, “Jishu shufaxue yu jiandu bianwei-da Yao Xiaoou xiansheng" 技術 書法學與簡牘辯偽——答姚小鷗先生, Guangming ribao, December 19, 2016 (http:/ / news.gmw.cn/2016-12/19/content_23286332.htm), accessed January 2, 2017. 


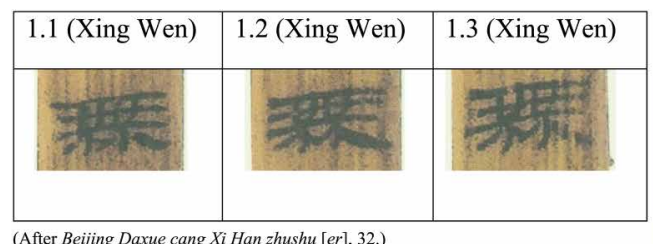

The character "無” on PKU \#2:

\begin{tabular}{|c|c|c|}
\hline 14.2 & 19.2 & 56.2 \\
\hline 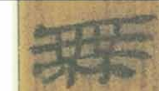 & 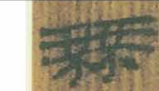 & $\frac{1}{25}=$ \\
\hline
\end{tabular}

(After Beijing Daxue cang Xi Han zhushu [er], 36, 38, and 50.)

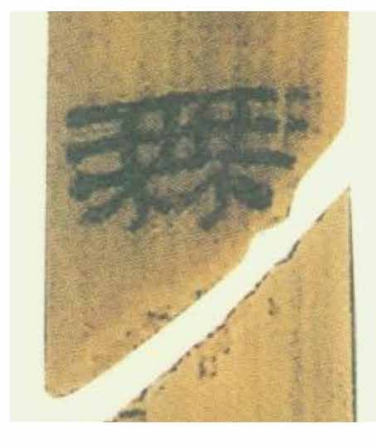

(After Beijing Daxue cang Xi Han zhushu [er], 32.)

Figure 4. (color online) Instances of the character “無” in the Peking University Laozi.

the "無" on strip \#2 that Xing Wen believes was written to accommodate the break.

If the reader were to look only at the examples Xing provided, it would appear that his argument holds: whereas the three "normal" "無" from strip \#1 are aligned parallel to the right edge of the bamboo, or even slant outwards toward the edge of the bamboo in their bottom-right quarter, the "irregular" "無" from strip \#2 has a dramatic slant inwards away from the bamboo's edge in its bottom-right quarter. Imagine instead however that Xing showed only the three examples I now provide: $14.2,19.2$, and 56.2. ${ }^{86}$ They would paint an entirely different picture, as these also are written to have their right side slant inwards, away from the edge of the bamboo, seemingly pinching the character form into a more triangular shape. Amongst these examples, our "irregular" “無” from strip \#2 does not seem quite so extraordinary.

If we are going to evaluate whether the "無" on strip \#2 is in fact an aberration, then we need to determine if a single scribal hand is responsible for the whole manuscript, and if so, survey how that hand typically handles this character. Although creating a proper profile of graphic variation for the Peking University Laozi is beyond the scope of this article, I have found no evidence for different scribal hands in the

86. In labeling these characters, the first number indicates strip number, while the number after the decimal point refers to the specific instance of "無" on that strip. Thus here I am citing the second instance of "無" on strips \#14, 19, and 56. For their magnified photographs, see Beijing Daxue cang Xi Han zhushu [er], pp. 36, 38, and 50, respectively. 
manuscript. ${ }^{87}$ There are eighty-six instances of "無" in the Peking University Laozi manuscript by my count. Among these eighty-six instances, there are numerous examples of "無" from the Peking University Laozi that compare especially favorably with the character under dispute, found throughout the entire manuscript, including also: 19.1; $19.3 ; 25.1 ; 56.1 ; 59.1 ; 71.3 ; 76.1 ; 77.1 ; 129.1 ; 148.1$; and 149.1. Other instances of "無" exist whose bottommost component alone is comparable, or whose forms are more ambiguous, but I have not included them here. While the examples raised above do not comprise an overwhelming majority, they do prove that, for this scribal hand, the "無" written on strip \# 2 is by no means a solitary anomaly. In my view, Xing Wen therefore has not introduced sufficient evidence that the writing occurred after the break in this bamboo strip.

While Li Kai argues that the calligraphic variation Xing identifies between his examples of "無" on strip \# 1 and that of "無" on strip \#2 was artistically permissible in the Han, Yao Xiaoou-like myself-instead focuses on the issue of representativeness in Xing's argument. ${ }^{88}$ Yao mentions that the handwriting for this scribe tends to slant toward the upper right in overall character construction-which Han Wei also documents in his early introduction of the Peking University Laozi. ${ }^{89} \mathrm{He}$ also argues that the "無" found on strip \# 1 are unusual in their final stroke; namely, they all finish with an elongated sweeping na 捺 stroke, while most other instances of "無" in the Peking University Laozi (including that on strip \#2) finish with either a dot dian 點 stroke or a shortened form of the $n a$ 捺 stroke. Yao thus finds Xing's examples inappropriate for a comparison.

In Xing Wen's latest article, a response to Yao, he does address the issue of representativeness. $9^{\circ}$ Xing contends that the "無" on strip \#2 angles dramatically away from the break in the bamboo in its bottom-right quarter, to a degree unexplained by the overall orientation of the handwriting on the Laozi manuscript slanting toward the upper

87. On this point, see Matthias Richter's conversation on determining scribal hands in early Chinese manuscripts and its importance in: "Towards a Profile of Graphic Variation: On the Distribution of Graphic Variants within the Mawangdui Laozi Manuscripts," in Methodological Issues in the Study of Early Chinese Manuscripts: Papers from the Second Hamburg Tomb Text Workshop, ed. Matthias Richter, Asiatische Studien/Etudes Asiatiques 59.1 (2005), 169-207. As the title suggests, Richter aptly enough takes the Laozi manuscripts found at Mawangdui for his case study.

88. Li Kai, "Guanyu Beida jian Laozi de bianwei," sec. titled "Guanyu zhujian shufa de bianwei 關於竹簡書法的辯偽"; Yao Xiaoou, "You pinjie yu shufa kan zhenwei," sec. 2.

89. Yao cites Han Wei in his article. See Han Wei, “Beida Han jian Laozi jianjie” 北大 漢簡老子簡介, Wenwu 2011.6, 67 .

9o. Xing Wen, "Jishu shufaxue yu jiandu bianwei," sec. 2.1. 
right. Moreover, he claims that Yao overlooks how the brushwork to this character seems to be aborted for those strokes that approach the break (and not just the final stroke). That is to say, the "intention of the strokes 筆意" is unusual for “無" on strip \#2, whereas the examples of “無" on strip \# 1 are more in line with the rest of the manuscript, including in their final strokes. I invite the reader to survey the instances of "無" I have listed above with these additional points also in mind; I myself maintain that the "無" on strip \#2 will be found unexceptional.

The above analyses assume that the character for "無" on strip \#2 is not missing any ink due to the break. Even if one is unable to observe strip \#2 in person, a closer look at the magnified photograph provided in Beijing Daxue cang Xi Han zhushu [er] shows a shift in coloring to the bamboo near the edges of the tear, which alerts us to the potential that "無" here is incomplete. ${ }^{91} \mathrm{It}$ is possible that there is surface damage to the strip..$^{2}$ The top-down, two-dimensional photographs of this break would hide such three-dimensional aspects. If the Peking University manuscripts are authentic, then they were not only subjected to the harsh conditions of a tomb environment, but were also handled by looters, transported to an antiquities dealer, and stored for an indefinite amount of time in an unknown fashion, all of which could have caused significant damage to the strips. 93

\section{Following Xing's new reconstruction, the character “得” on strip \#52 is shown to be an impossible form.}

I am skeptical of Xing's argument concerning “得" for two reasons. First, his re-piecing of the two halves to strip \#52 is untenable. For reference, see Figures $5 \mathrm{a}-\mathrm{e}$ below, which shows how Xing believes the pieces should be combined ( $5 \mathrm{a})$, juxtaposed with the presentation of the pieces in the Beijing Daxue cang Xi Han zhushu [er] publication (5b-e). In short, Xing utilizes the Peking University editors' hand drawing of the verso marks (5d) and the positioning in the infrared photographs (5e), where

91. Beijing Daxue chutu wenxian yanjiusuo, Beijing Daxue cang Xi Han zhushu [er], 32 .

92. In September, when I first viewed the Laozi strips, it appeared to me that strip \#2 was damaged on its surface along the bottom-right edge, potentially impacting the brushstrokes. It was difficult however to find an unobstructed view, even while using a magnifying glass. The piece is kept wet and was left in its protective glass casing, resulting in significant glare. I was unable to view this strip again in October. Owing to these difficulties, I would suggest that the strip be subjected to closer inspection before confirming whether or not the brushwork to the character is complete.

93. As with the Tsinghua strips, the Peking University collection was also packaged as bundles of strips wrapped together in plastic wrap, according to Zhu Fenghan (personal communication). 
(a)

图十四:

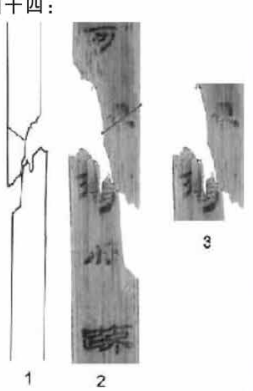

(b)

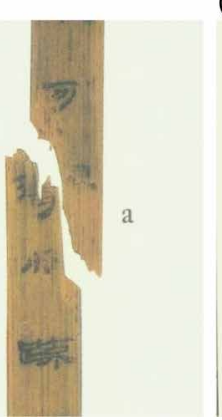

(c)

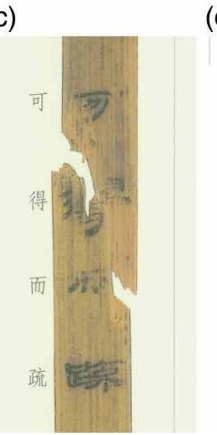

(d)

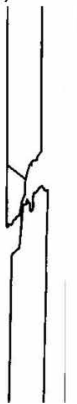

(e)

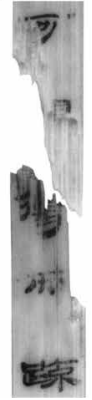

Figures 5a-e. (color online) Various presentations of “得" on PKU \#52 (5a: Xing Wen's reconstruction, after "Beida jian Laozi bianwei," image 14; 5b: Original-sized photograph after Beijing Daxue cang Xi Han zhushu [er], 9; 5c: Magnified photograph after Beijing Daxue cang Xi Han zhushu [er], 49; 5 d: Hand drawing after Beijing Daxue cang Xi Han zhushu [er], 112; 5e: Infrared photograph after Beijing Daxue cang Xi Han zhushu [er], 108).

the two pieces of \#52 are presented as separated with more vertical space than appears on the photographs of the recto in their original size $(5 b)$ and magnified (5c). Xing seems to prefer the hand-drawing arrangement because it aligns the top edge of the bottom piece with the line-like verso mark found on the top piece. He then speculates that the editors, realizing this arrangement mangles the "得" written on the recto, decided to present the strip closer together in some of the recto photographs, even though this was inappropriate.

Following the hand drawing for the positioning of the strip pieces is problematic however, not just due to the overlooked verso mark on the bottom piece of strip \#52 mentioned before, but also because it would throw the notches and gaps in writing for the binding strings out of alignment. ${ }^{94}$ When considering how the manuscript was actually bound together-that is, the relationship between the positioning of neighboring strips-evidence pertaining to the binding strings themselves should take precedence over any other criteria, when that evidence is available. In the Peking University Laozi manuscript here, some wear from the string remains, there are notches carved into the strips for holding the string in place, and the writing itself seems to avoid the area where the string was intended. Xing readily acknowledges these points,

94. It also leads to the strip being noticeably longer than the other strips in the manuscript, as is clear even from the hand drawing provided in the Peking University volume. See my discussion below. 
when they are useful for his own argumentation. 95 In short, there is no justification for following the hand drawing's placement of the pieces when the evidence pertaining to the binding strings demands that we follow how the strips are vertically aligned in the original size and magnified recto photographs instead, evidence that Xing is fully aware of.

Once again, Yao Xiaoou has likewise questioned whether or not the two pieces to strip \#52 should be positioned differently, and proposes that they are in fact overlapping as well..$^{6}$ Responding to Yao's comments, Xing argues in his latest article that we cannot however re-piece a strip based primarily on the desire to reconstitute character forms across breaks (as Yao implies), but must take into account aspects of the bamboo's materiality as well. ${ }^{97}$ This includes an appreciation not only of how bamboo tears, but also its age and how saturated it may be with water. On these points I am in full agreement with Xing.

Xing however continues to defend his reconstructed images in Figure $5 \mathrm{a}$, this time by providing measurements calculated during his technical calligraphy analysis for the width of the strip at various heights when re-pieced together in this fashion. He shows that when the top and bottom piece of strip \#52 are positioned as he argues, the width of the strip is largely uniform throughout, including at the break. Xing then measures the combined widths of different locations at the break in strip \#52 when it is re-pieced according to the magnified photograph's arrangement (Figure 5c), where he accuses the Peking University Laozi editors of being deceptive. Here the combined width of the two pieces at the top of the break (where "得" is written) is significantly larger than toward the bottom of the break (where "而" is written), and both areas have combined widths larger than the intact areas on either extremity of strip \#52's two pieces. Indeed, in the magnified image here, it is clear that neither the far left nor far right edges of both pieces fall into alignment with one another. Because it distorts the width of the reunited strip, Xing thus argues that we cannot follow the positioning of strip \#52 in the magnified photograph (where the top and bottom pieces are overlapping vertically to a large degree), but must instead follow the hand drawing (where the top and bottom pieces are only overlapping vertically to a small degree).

Xing's measurements prioritize strip width, but do not take into account total strip length. According to the "Yilanbiao" table appended in Beijing Daxue cang Xi Han zhushu [er], the total length of strip \#52, with

95. See his section 3, where he argues that the manuscript must have been "first bound and then written."

96. Yao Xiaoou, "You pinjie yu shufa kan zhenwei," sec. 1.

97. Xing Wen, "Jishu shufaxue yu jiandu bianwei," sec. 1.1. 
each piece measured to its individual extremities, would equal $33.9 \mathrm{~cm}$. This is nearly $2 \mathrm{~cm}$ more than most of the intact strips in the manuscript, which all measure between 31.9 and $32.2 \mathrm{~cm}$ long. This implies significant vertical overlap for the two pieces of strip \#52. I have no means to accurately measure where Xing Wen positions the bottom piece in his reconstruction, however if we assume that it is flush with the verso mark (which is at $11.7 \mathrm{~cm}$ ), then the total strip length for his reconstruction is 32.4 (11.7 + the total length of the bottom piece at $20.7 \mathrm{~cm}$ ), which falls outside the range of acceptable lengths established by the still intact strips. Moving the bottom piece up further by 0.2 to $0.5 \mathrm{~cm}$ places it comfortably into this range.

What these measurements demonstrate is that there should be both significant vertical and horizontal overlap to the pieces at the site of the break in strip \#52.98 In this regard, we cannot rely on either Xing's reconstruction (based on the hand drawing, where the length is too large), or the Peking University editors' alternative arrangement (as seen in the original and magnified photographs, where the width is too large) to be an accurate reflection of the re-pieced strip. When Xing then argues that the various com-

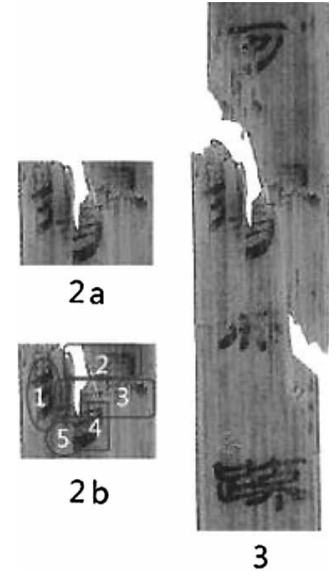

Figure 6. Xing Wen's analysis for the character "得" (after "Beida jian Laozi bianwei," images 13.2a, 13.2b and 13.3). ponents for “得" in the magnified image are still distorted (see Figure 6), he is basing his analysis on a misaligned strip. 99 While he does acknowledge the possibility of both vertical and horizontal overlap when responding to Yao's suggestion, Xing seems to dismiss the likelihood of this break occurring naturally on strip \#52. He moreover wonders at how the bamboo could tear in this fashion without any signs of damage then also remaining in the same area on neighboring strips. To this latter point, note that among archaeologically excavated bamboo strips there are numerous

98. The photograph I have supplied of the verso to strip \#52 offers supplemental evidence for this as well. This data was not available to either Yao or Xing however, so it should not detract from the merits of their arguments.

99. Figure 6 is found in Xing Wen 邢文, "Beida jian Laozi bianwei" and his conclusion is reiterated in "Jishu shufaxue yu jiandu bianwei." 
examples in which an individual strip is damaged or split, while neighboring strips remain intact. ${ }^{100}$

In deliberating over how best to re-piece strip \#52, I would remind the reader that it may be impossible to connect the pieces together perfectly, no matter how closely we may try to align them by eye or measure the strips via digital scans. Moreover, in our analysis of the character form for “得," we must once again wonder whether ink has been lost, particularly around the "目" component. It is not surprising that pieces of bamboo broken off from the same strip do not always fit together perfectly, or that ink may be rubbed off the bamboo's surface, considering the circumstances these artifacts have endured. This leads me to the second reason I am skeptical of Xing's approach here: he is attempting to conduct a detailed analysis of character forms that occur in a heavily damaged area, an area which may be warped in ways we cannot fully anticipate, in a study where even the slightest repositioning of bamboo or ink could have significant implications. In this regard, Xing's analysis, both for the character “得" on strip \#52 and for the character "無" on strip \#2, is inevitably open to debate. His methodology presumes a stable textual carrier for an accurate display of writing, one which is not available in either of these areas.

3. The gradient of the line-like verso marks on individual strips at times appears different from those found on neighboring strips. The verso lines therefore cannot be connected uniformly across the manuscript.

As mentioned earlier, the hand drawings on which Xing Wen bases his argument do not necessarily accurately reflect the actual placement of a verso mark on an individual strip. This is because the hand drawings relied upon measurements for the verso marks that were unavoidably imprecise, as they were rounded off to the nearest tenth of a centimeter. This rounding effect could at times produce an illusion of variance that is larger than how the gradients for the line-like verso marks actually display on the artifact. Moreover, errors may have been made, both in recording the measurements and in producing the hand drawings. Since we cannot appeal to more accurate data however, other explanations should be sought to explain the misalignment.

Aside from a brief reference to the hypothesis raised by Han Wei 韓巍 in the Peking University Laozi volume, Xing Wen does not engage with scholarship on the verso mark phenomenon which has accumulated

100. See for instance strip \#50 of the Qin lü shiba zhong 秦律十八種 from Shuihudi, in Shuihudi Qin mu zhujian, p. 19, which offers a break at a very similar angle. It is obviously more difficult to assess the question of overlapping tears without handling these artifacts personally. 
over the past few years. ${ }^{101}$ This body of work suggests that there are other explanations for why the gradient of individual verso marks may not always be consistent and form one longer cohesive line that runs across neighboring strips. In Sun Peiyang's groundbreaking article in 2010, multiple different possibilities were already offered for how the creation of verso marks (carving or brushing) may fit into the overall chaîne opératoire for a bamboo-strip manuscript. ${ }^{102}$ One option Sun raises is that the marks were carved or drawn onto pre-fashioned strips, either before or after writing occurred. If this is the case, then the strips would have been laid out next to one another while a knife or brush was then run across them to give the line-like effect we see on the versos. Sun, in the 2010 article, had already noted that any variation in how the strips were laid out for carving or brushing would then translate over onto the gradient of the line on individual strips, or where the line starts and ends on each specimen, making it seem out of alignment once the strips were later bound together. ${ }^{103}$ Carving the verso lines in this manner would produce precisely the phenomena we are witnessing in the

101. Han Wei, "Xi Han zhushu Laozi jianbei huahen de chubu fenxi," 227-35. A convenient and thorough overview in English of recent work on the verso marks may be found in: Staack, "Identifying Codicological Sub-units in Bamboo Manuscripts," 157-86. The article is from his dissertation, to which I would also refer the reader. Sun Peiyang 孫沛陽, “Jiance bei hua xian chutan" 簡冊背劃綫初探, Chutu wenxian yu guwenzi yanjiu 出土文獻與古文字研究 4 (2011)，449-62, is in many ways still relevant, and was the first article to expand about the verso mark phenomenon. Other discussions of the verso marks include: Li Tianhong 李天虹, who discusses verso marks in newly excavated strips from Hubei, in Li Tianhong 李天虹, “Hubei chutu Chu jian (wuzhong) geshi chuxi” 湖北出土楚簡 (五種) 格式初析, Jiang Han kaogu 江漢考古 4.121 (2011), 102-6; He Jin 何晋, “Qianyi jiance zhidu zhong de 'xunlian'—Yi chutu Zhanguo Qin Han jian wei li” 淺議簡冊制度中的 “序連”——以出土戰國秦漢簡爲例, Jianbo 簡帛 8 (2013), esp. 458-68; Xiao Yunxiao 肖芸曉, “Qinghua jian jiance zhidu kaocha" 清華簡簡冊制度考察 (MA thesis, Wuhan University, 2015). Most recently, Jia Lianxiang's new book, Zhanguo zhushu xingzhi ji xiangguan wenti yanjiu, offers great insight into the production (and editing) of bamboo-strip manuscripts, focusing on the Tsinghua strips. He includes a chapter on verso marks. See esp. pp. 82-102.

102. Sun, "Jiance bei hua xian chutan," 456-57.

103. Not only might the strips have been arranged (for carving the line) at different heights, but they also might not be perfectly vertical in orientation (vis-à-vis one another), leading to gradient differences. Moreover, if strips were fashioned at different times, from different bamboo culms, then it is likely that they would individually come to have slightly different shapes and sizes, if only because the splitting of the strips itself would not have been exactly the same in each case. For this reason, even if a craftsman or scribe tried to line the strips up next to one another, and fit them together as closely as possible, the slight variations in their shapes alone would cause gaps between them, or not always allow for a perfectly vertical orientation. Jia Lianxiang emphasized this latter point to me (personal communication). 
Peking University Laozi, and on many other manuscripts across the Tsinghua and Yuelu collections as well. ${ }^{104}$

Another possibility that has recently gained more support is the "spiral line theory," where the marks we are now seeing are carved on a tube from the bamboo culm before the strips themselves have been individually split, creating a single spiraling line that might overlap on one or two strips. ${ }^{105}$ This is what the Peking University editors believe happened with the Laozi manuscript in their collection. Leading them to this conclusion is the fact that certain strips have "parallel lines" of verso marks, but oddly enough at these points the gradients of the lines seem to diverge dramatically from neighboring strips. They realized that overlapping slanting verso lines were not carved continuously across the entire manuscript, but rather that at these junctures they actually connected backwards to a previous strip, thereby delineating one coherent but isolated set. ${ }^{106}$ Take for example the set of Laozi strips \#71-86 in Figure 7 below (which is compared with the set of strips \#87-100). The topmost verso line on strip \#86 does not connect readily with that of \#87, as Xing Wen points out. It does however appear to connect smoothly back to the topmost verso line on strip \#71. Similarly, if we were to place strip \#86 before \#71, the bottommost verso lines (of the "parallel" set) on

104. In his own defense of the of Laozi manuscript, Li Kai also considers how laying all the strips out on a flat surface for carving and writing might have impacted the appearance of the verso marks. See: "Guanyu Beida jian Laozi de bianwei," Guangming ribao, September 12, 2016. Xing Wen however argues that there is no evidence for writing tables in the Western Han (he notes but then disregards the Lingbao 靈寶 Zhangwan 張灣 discovery of a table-like artifact in an Eastern Han tomb), and that in his own experience as a calligrapher, doing such work on the ground is impracticable. See "Bianzheng zhi mei yu sandian toushi-Beida jian Laozi zai bianwei" in the same issue. Links to both articles may be found in $\mathrm{n} .82$ above. For the Peking University Laozi however, the evidence seems to point to a different production technique for the verso marks, namely the "spiral line" theory, introduced below.

105. See especially Han, "Xi Han zhushu Laozi jianbei huahen de chubu fenxi"; Jia, Zhanguo zhushu xingzhi ji xiangguan wenti yanjiu, 82-102; Staack, "Identifying Codicological Sub-units in Bamboo Manuscripts." Nevertheless, I wonder how the craftsman was able to estimate so accurately, while carving on the culm, where to complete the line-like mark so that it falls at exactly the width of one or two strips. I would expect there to be more instances of verso lines not running across the entirety of a strip's width. It is possible that the craftsman re-carved the line after the strips were fashioned, to extend it to reach the entire length of the strip. I have not however found conclusive evidence of this yet in the published photographs, such as instances where there are two partial and overlapping cut marks. This would also explain why there are sometimes two strips with overlapping parallel verso lines, as opposed to just a single strip's width. See my conversation below for what may be one example of a verso line running partially across the width of a strip.

106. Han, "Xi Han zhushu Laozi jianbei huahen de chubu fenxi," 228. 
(a)

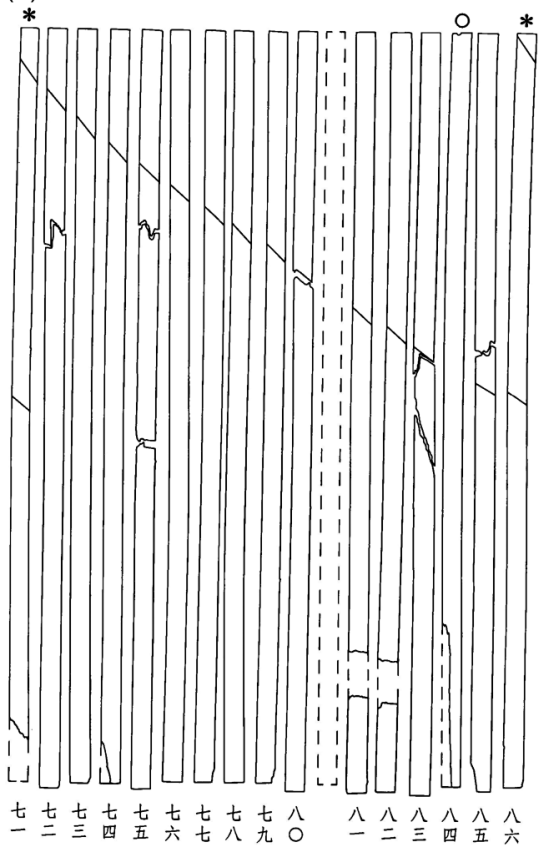

(b)

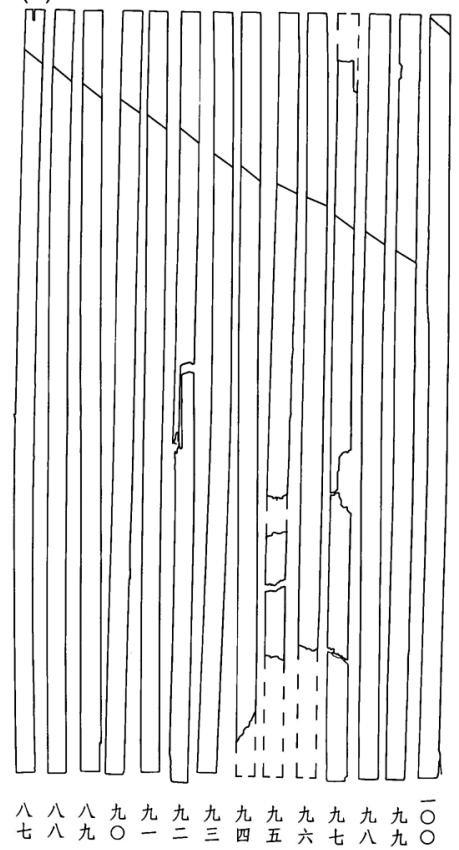

Figure 7. Peking University Laozi verso, strips \#71-86 vs. 87-100 (after Beijing Daxue cang Xi Han zhushu [er], 113).

these strips would be in alignment. ${ }^{107}$ The best way to understand this phenomenon is to think of each such set of strips connected together in the shape of a cylinder (as opposed to laid flat), with a spiral line running around it. This suggests to the Peking University editors that the carving actually took place on the bamboo culm itself. Coincidentally, when we measure the widths of strips in these "sets" of verso marks, we find that the total correlates well with the circumference of a typical Phyllostachys culm, offering further confirmation of the Peking University editors' theory. ${ }^{108}$ In questioning the gradient of strip \#86 vis-à-vis strip \#87, Xing mistakenly conflates two separate sets of strips.

107. Another clear example of this on the Laozi manuscript is the relationship of the verso marks on strips $\#_{142}$ and $\#_{157}$, versus what is found then on $\#_{141}$ and $\#_{15} 8$ respectively, considering also the vertical alignment of the strips as recorded in the "Yilanbiao."

108. See for instance Han, "Xi Han zhushu Laozi jianbei huahen de chubu fenxi," 233; Jia, Zhanguo zhushu xingzhi ji xiangguan wenti yanjiu, 99-100; Staack, "Identifying Codicological Sub-units in Bamboo Manuscripts," 164-65. Han Wei allows that there 
It is perhaps more difficult to justify why the gradient of the verso lines may be inconsistent across strips from within the same bamboo culm set in this model. An unsteady hand carving or drawing around a circular tube would result in variations in how the line runs, particularly if a ruler or other tool was not used. ${ }^{109}$ With a knife, having the blade lodged into the bamboo culm might help guide the hand however, stabilizing the cut as it was twisted around the tube. There is some evidence of "curving" in the line-like verso marks across multiple strips, though this is harder to discern on any given individual strip, and would not lead to the obvious gradient shifts we see in the hand drawing of the Laozi manuscript. ${ }^{110}$ The lines might also have been formed via multiple cuts, that is, when the blade is lifted to turn around the culm, and then pressed into the bamboo to cut again. This process would give more subtle gradient shifts, but there should be consistency across the length of a single blade stroke, without varying each strip.

More importantly, we once again cannot assume that the textual carrier we now possess is a pristine representation of its original condition. If the tube itself was first marked, then strips would need to be split from it, dried out, and otherwise manipulated. The splitting might entail splintering and loss of material, thereby creating some of the vertical misalignment we witness between the beginning and end of neighboring strips' verso marks. ${ }^{111}$ As for the varying line gradients, the act of “killing the green 殺青” or whatever else was done to process the strips might have potentially caused them to morph. This is not to mention any additional damage that could have befallen the strips during their time in the tomb (where they became waterlogged and structurally unsound), or if they were roughly handled by looters afterward. Warping to the strips undergoing such processes could very well impact how

would have been some loss between the strips when they were split, and incorporates this into his measurements. See $n$. 111 below.

109. Li Kai also makes this point in his "Guanyu Beida jian Laozi de bianwei."

110. Staack, "Identifying Codicological Sub-units in Bamboo Manuscripts," 180, fig. 13 offers a highlighted image of the verso marks on part of the Zhiri 質日 calendar (year 34) in the Yuelu Academy collection, clearly demonstrating how such lines may curve up and down as they run across multiple strips.

111. Han, "Xi Han zhushu Laozi jianbei huahen de chubu fenxi," 233. He assumes approximately $0.1 \mathrm{~cm}$ of loss per strip. Vertical misalignment could also happen if, after the tube was split into individual strips, a mistake occurred upon leveling them further, in terms of each strip's overall height. In other words, if for some reason one strip in the batch was positioned higher than the others when their tops were leveled (thereby losing more bamboo in this area than the other strips), and then the batch was evened and leveled again on the bottom (thereby losing less bamboo in that area than the other strips), the verso line would appear to have shifted vertically in relation to the marks on neighboring strips. 
(a)

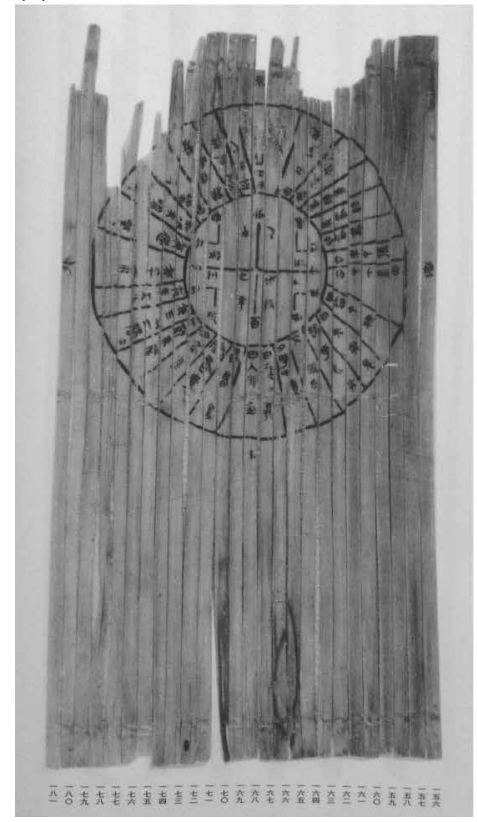

(b)

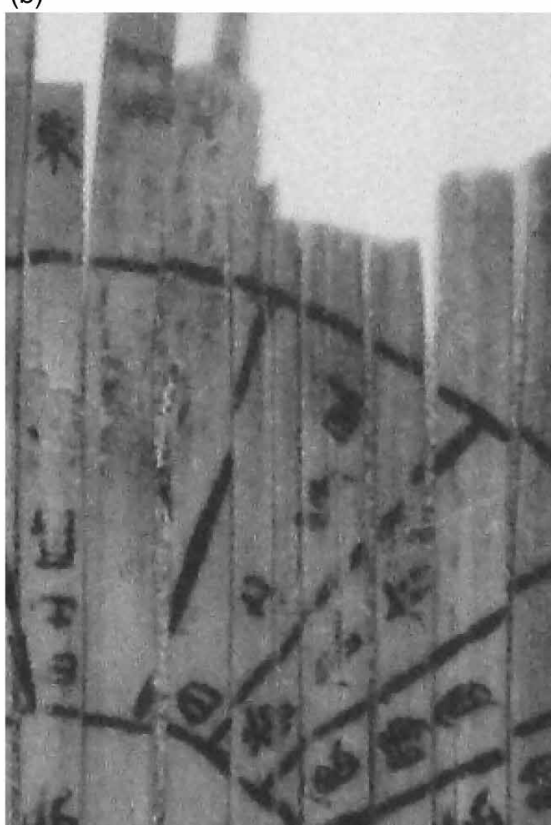

Figure 8. Zhoujiatai Rishu Xiantu yi, with the top section of strips \#165-67 highlighted (after Guanju Qin Han mu jiandu, 44).

the verso lines appear to run, as evidenced by the mark on strip \#183 compared to neighboring marks, as discussed before.

By way of supplemental proof, we may also consider examples of archaeologically excavated manuscripts that include pictures drawn in ink on the rectos of strips, and see how the ink lines might have morphed alongside the textual carrier over time, assuming as Xing does that connected lines were the scribe's objective. See for instance the Zhoujiatai 周家臺 Qin period Rishu 日書 Xiantu yi 綫圖一 drawing (Figure 8). ${ }^{112} \mathrm{I}$ have highlighted in the second image the top section of strips \#165-67 as one example. In a number of places in this drawing, strips are positioned so that some of the ink lines run continuously, while at the same time other lines on those same strips are impossible to connect directly across neighboring strips. That is to say, no matter how you try to position the strips, there is no way to force all the ink lines to accord perfectly across the entirety of the manuscript; the spacing and at times the gradients of

112. Hubei sheng Jingzhou shi Zhouliang Yuqiao yizhi bowuguan, Guanju Qin Han $m u$ jiand $u$ 關沮秦漢墓簡牘 (Beijing: Zhonghua, 2011), 44. 
the lines both shift. It is possible that the strips have morphed, leading to the misalignment now evident. ${ }^{113}$

In both production processes hypothesized above, application of the line-like verso marks may occur before writing and binding take place. ${ }^{114}$ A number of possibilities thus arise to explain inconsistencies between the continuity of a verso line and how the strips are arranged into a longer manuscript, particularly in reference to the text on the recto. Once a set of strips was marked, sometimes only portions of that set may actually be written upon, with the rest of the set possibly used elsewhere in the manuscript or not at all (resulting in various gradients or shorter sets respectively); individual strips might be broken or lost in the production process and thus not used (resulting in "skips"); or the initial order for the set when it was marked might be rearranged or even reversed as the manuscript is finalized for writing (resulting in "reverse-angled steps"), and so forth. ${ }^{115}$ That is to say, it is entirely possible that conspicuous variance between the line gradient of any two individual strips' verso marks might also be the result of strips being rearranged or inserted after the production of the marks, and before writing or binding took

113. The Zhoujiatai Rishu however may only be raised as a rough analogy, limited in its relevance for two reasons. First, if the spiral line theory is correct, then an ink drawing like this would occur at a different step in the production of a bamboo-strip manuscript, likely after the strips were individually fashioned, but before being first bound. The middle binding string seems to overlap ink from the drawing, though elsewhere in the daybook material the writing does avoid this area. Second, we must also consider the impact of preservation treatments on the strips, particularly if the Zhoujiatai Qin strips were dewatered, as the Peking University Han manuscripts were photographed while still waterlogged.

114. There is evidence of the carved verso marks falling in spaces where the binding also took place, necessitating that it was a previous step. For instance, verso lines often begin at the very top of the bamboo strips, running through where the upper row of binding string lays. Han, "Xi Han zhushu Laozi jianbei huahen de chubu fenxi," 228. I would caution however against dogmatically adhering solely to such a rigid "threestep" production processes (that is, marking, writing, binding in various permeations). See my conversation below on how the life of a manuscript could in fact be much more dynamic.

115. For an example of what I mean by "reversed-angle steps," see the verso marks on the Tsinghua Chu ju 楚居 manuscript, \#3-6. There also appears to be an instance of a multi-strip "skip" here, between the marks on strips \#2 and 3. See Qinghua Daxue chutu wenxian yanjiu yu baohu zhongxin, Qinghua daxue cang Zhanguo zhujian (yi) 清 華大學藏戰國竹簡 (壹) (Shanghai: Zhongxi, 2010), 29. The phenomenon is introduced in Sun, "Jiance bei hua xian chutan," 458; and further discussed in He, "Qianyi jiance zhidu zhong de 'xunlian'_— Yi chutu Zhanguo Qin Han jian wei li," 463-64; Staack, "Identifying Codicological Sub-units in Bamboo Manuscripts," 159-60, where he calls them "reversed verso lines." 
place. This observation is also particularly relevant to Xing's critiques (4) and (5) below.

4. If the verso lines are connected as closely as possible, then the bound manuscript would display strips at varying heights, which differs from what we know of early Chinese bamboo-strip scrolls.

In Li Kai's response to Xing Wen's critique, he questions the assumption that the strips of a bounded bamboo-strip scroll need necessarily be of the same length. He points out that the Guodian 郭店 Laozi 甲 (I) manuscript-among others-includes a few strips noticeably longer or shorter than their neighbors, highlighting for example strip \#2 in relation to strip \#1, \#3, and \#4. ${ }^{116}$ Xing concedes that not all scrolls bound together strips of the exact same size. He argues however that it is unfair to compare the Peking University Laozi with the earlier Guodian witness, as the former represents a polished and complete classical treatise from the Han, whereas the latter is merely "jottings 記” from the Warring States, and therefore they differ both in genre and dating. ${ }^{117}$ Whether or not we should accept this classification of the Guodian Laozi manuscripts, or more broadly speaking assume that a substantial difference in strip selection and binding practices occurred between these periods and genres, deserves further research. Xing nevertheless asserts that the Peking University Laozi strips' heights vary to a significantly larger degree than what we see at Guodian, making it an entirely different phenomenon. He estimates that Guodian Laozi (I) strip \#2 is $0.2 \mathrm{~cm}$ longer than strips $\#_{1}, \#_{3}$, and $\#_{4}$, with the standard length for the manuscript's strips given at $32.3 \mathrm{~cm} .{ }^{118}$ Judging from the data provided in the "Yilanbiao" in Beijing Daxue cang Xi Han zhushu [er], the height difference in Xing's reconstruction for the Peking University Laozi strips \#32 and \#33 is around $1.9 \mathrm{~cm}$, while that for $\#_{53}$ and $\#_{54}$ is $1.8 \mathrm{~cm}$, with the typical strip length again around $32 \mathrm{~cm} .{ }^{119}$

116. Li, "Guanyu Beida jian Laozi de bianwei."

117. He supports the claim that scrolls of classical treatises would have employed strips of equal lengths with a citation from the Shouwen jiezi, which defines the character "deng 等" ("equal, even, of the same class") as "to level bamboo strips 齊簡." See Xing, "Bianzheng zhi mei yu sandian toushi-Beida jian Laozi zai bianwei"; Shuowen jiezi zhu 5.191.

118. Xing Wen appears to derive his measurements from the photograph in Jingmenshi bowuguan, Guodian Chu mu zhujian 郭店楚墓竹簡 (Beijing: Wenwu, 1998), 3. My own measurements taken from this photograph have the difference closer to $0.4 \mathrm{~cm}$.

119. For my calculations here, concerning strips \#32 and \#33, I subtracted the total length of \#32a $(8.1 \mathrm{~cm})$, from the position of the upper-left entry of the verso mark on \#33 (10 cm). For strips \#53 and \#54, I subtracted the bottom-right exit of the verso mark on $\#_{53}(0.9 \mathrm{~cm})$ from the upper-left entry of the verso mark on \#54 $(2.7 \mathrm{~cm})$. 
In evaluating Xing's claim, it is important to distinguish between strip length and strip height, the latter being the relative positioning of strips vis-à-vis one another in the final bound manuscript. As I mentioned previously, a survey of the Peking University Laozi "Yilanbiao" reveals that the lengths of all intact strips fall in the range of $31.9-32.2 \mathrm{~cm}$, a range similar to that which Li Kai has pointed out for the Guodian Laozi. ${ }^{120}$ The height difference that Xing calls into question has nothing to do with the actual lengths of the strips, but rather concerns how he imagines the bound manuscript was arranged. Namely, Xing repositions the strips so that the line-like verso marks connect as closely as possible. As I have noted earlier, however, this is not an accurate reflection for how the manuscript would have been bound in antiquity. The correct arrangement of the strips should follow an alignment of the notches and traces from the binding string, as depicted in the recto photographs, for which there is then no significant discrepancy in the strip heights. ${ }^{121}$

Since the difference in height Xing Wen notices occurs rather with the positioning of the verso lines, we again must ask why variance would exist in this feature. If we disregard the overlooked verso mark later discovered on strip \#32, one possibility is that this is the insertion of a single strip within a larger coherent set. ${ }^{122}$ For the shift in height between \#53 and 54, again we have the placement of one independent set of strips next to another. Indeed, this is the precise logic Han Wei employs to justify his presentation of the hand drawings for the Peking University Laozi verso marks, a logic which Xing ignores when he claims that the editors manipulated the data. ${ }^{123}$ Thus, strip \#53 must be separated from the neighboring strips beginning with $\# 54$, as this is the boundary

120. It is more difficult to accurately estimate the length of broken strips, as each piece was measured separately to its furthest extremity. Adding up the total length of two overlapping pieces therefore results in an exaggerated length. Comparing the measurements and recto photographs of strip $\#_{32}$ and $\#_{54}$ provides a perfect example of this.

121. See for instance the alignment of these features on strips $\#_{32}$ and $\#_{33}$ in the original sized photographs on Beijing Daxue cang Xi Han zhushu [er], 7. When the notches, traces from the binding strings, and gaps in the writing are all appropriately lined up, there is no significant height difference.

122. That the verso lines are also sometimes slightly off in terms of their starting or ending heights across multiple lines (as Xing emphasizes in his rearrangement) was also addressed above. See my response to critique (3). Note that Xing's arrangement also assumes that the break on strip \#32 is where the verso line would have been found; no verso line is actually recorded in the "Yilanbiao" or on the hand drawing.

123. Han, "Xi Han zhushu Laozi jianbei huahen de chubu fenxi," 228. Unfortunately, Li Kai also seems to both accept Xing Wen's repositioning of the strips uncritically, and misunderstand the reasoning behind why the Peking University editors grouped the hand drawings as they have. See his "Guanyu zhujian changdu zhi wei" 關於竹簡長度之偽 section. 
(a)

图六:

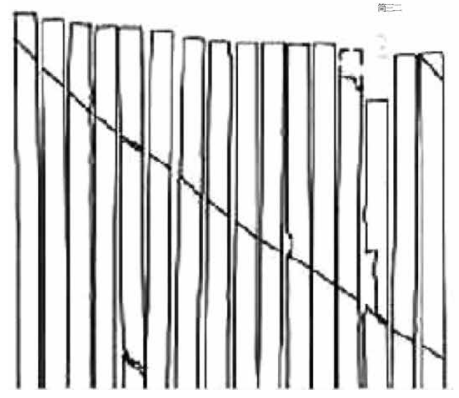

(b)

图七:

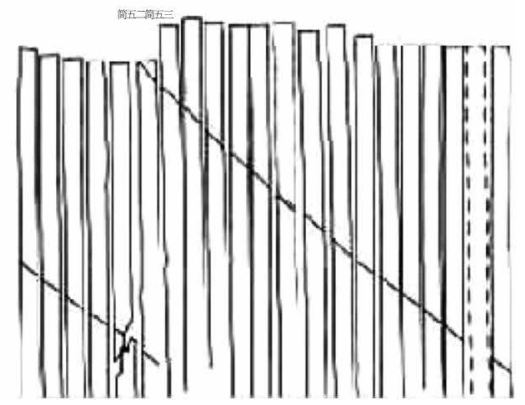

Figure 9. Xing Wen's rearrangement of the Laozi strips \#19-34 and \#48-67 (after "Beida jian Laozi bianwei," images 6 and 7).

between two completely different sets of strips (as marked on separate tubes of bamboo culm beforehand); the verso lines on strip \#53 connect back instead with those on strip \#35, hence that set is shown together. Xing's reconstruction of the strip heights disregards the "spiral line theory" under which the Peking University editors were explicitly operating, and he assumes continuity between what are ultimately two completely different verso lines. In this way, and contra Xing's criticisms, Han Wei's hand drawing helps readers appreciate an important codicological unit in the Laozi manuscript, as Thies Staack has convincingly argued we should treat such sets. ${ }^{124}$

\section{Strips \#84 and $\#_{1} 87$ do not bear any verso marks, and yet fit into a set where} the line is otherwise complete.

Xing Wen believes that, contrary to the Peking University Laozi editors' conjecture, the manuscript was bound first and written on afterward, as evidenced by how the writing avoids the spaces where the binding string was laid. If that were the case, he finds it difficult to agree with the Laozi editors' explanation that, during the act of writing on these two strips, an error was made and the strips discarded and replaced, all before binding. ${ }^{125}$ For the sake of argument, let us assume that Xing's

124. Staack, "Identifying Codicological Sub-units in Bamboo Manuscripts," 157-86. Han Wei conducts a similar preliminary comparison between the verso mark sets and the text on the recto of the Peking University Laozi, commenting that the relationship between these features is rather complex. See "Xi Han zhushu Laozi jianbei huahen de chubu fenxi," 233-34.

125. Han, "Xi Han zhushu Laozi jianbei huahen de chubu fenxi," 234. As Li Kai also points out, Han Wei does not eliminate the possibility that the strips were first bound 
observation about the manuscript being "bound first and then written upon" is correct. We must note however that even if writing seems to avoid the spaces where binding strings were positioned, this is not in itself enough proof that binding occurred before the writing. With notches carved into the strips, it would be possible for a scribe to anticipate where the binding would occur, and leave spaces in the writing around the notches' location, a point which Han Wei explicitly raises to defend his "writing first and then binding" position. ${ }^{126}$

Other explanations are possible however for why the verso lines seem to "skip" in places, leaving an otherwise blank strip to fill in the gap. Han Wei has already suggested for instance that the verso marks were not applied uniformly. ${ }^{127}$ The knife could have failed to cut as deeply or visibly here as it did in the neighboring areas, perhaps due to an imperfection in the culm, or just the unsteadiness of the craftsman's hand. In my opinion, a more convincing argument, however, is that the chaîne opératoire for a bamboo-strip manuscript was more complex than Xing Wen seems to believe. Must we imagine marking, writing, and binding as happening only in a static three-step process? The production of these manuscripts could have been much more dynamic, with each of the steps of marking, writing, and binding occurring in multiple stages and at multiple times over the life of the manuscript, from its initial production, to its consumption, and then eventual disposal.

It is possible, for instance, even assuming Xing Wen's "binding first and then writing," that after these portions of the Peking University Laozi were initially bound (which might not have been at the same time as the rest of the manuscript ${ }^{128}$ ), a mistake was still made when copying

and then written upon, he only states that they found it more likely the other way around.

126. Han moreover points out that this accords with early painted depictions of writing on bamboo strips, for instance, or with clay sculptures showing a scribe holding a single strip in one hand, while carrying the brush in the other. "Xi Han zhushu Laozi jianbei huahen de chubu fenxi," 234.

127. "Xi Han zhushu Laozi jianbei huahen de chubu fenxi," 233.

128. Evidence may be supplied by the Yongyuan qiwu bo 永元器物薄 register discovered in Juyan 居延 (strip \#128.1), a rare example of a scroll with its binding strings still preserved intact. In this manuscript, multiple smaller sections are bound as individual units, and these sections are joined together into the longer continuous scroll. The binding therefore did not necessarily occur all at the same time. A five-page pull-out insert with beautiful color photographs of the scroll may be found in Lishi wenwu chenlieguan congshu zhizuo xiaozu, Xiaoxue zhi dao: cong Han jian kan Han dai shizi jiaoyu 小學之道: 從漢簡看漢代識字教育 (Taipei: Zhongyang yanjiuyuan lishi yuyan yanjiusuo, 2013). Xiao Yunxiao, "Qinghua jian jiance zhidu kaocha," 84-89, identifies a similar phenomenon with Xinian 繫年 in the Tsinghua collection. This sort of analysis might be fruitful for the Laozi, though it is beyond the scope of this article. 
out the text (as the Peking University Laozi editors hypothesize) or more likely the strips were broken while the scroll was being handled, dictating that the strips then be removed, replaced, then rebound and rewritten (in either order). ${ }^{129}$ This would allow for an initial binding as Xing supposes, while also explaining how an extra strip with a blank verso could have been inserted into an otherwise uniform set of neighboring strips.

Interestingly, the Shuihudi Rishu 日書 daybook甲 (I) manuscript may offer confirmation that this phenomenon is in fact attested on archaeologically excavated bamboo strips, and thus is not necessarily a sign of forgery (Figure 10). ${ }^{130}$ On the versos of strips \#102-6, a series of marks runs across the bottom third of this set. Strip \#104 however does not have a mark where one would expect it to be, should the pattern established from \#106 -> 105 -> 103 -> 102 be completed. As a codiocological unit, this set of verso marks seems to correlate with the beginning of the text "Shi Ji 室忌" on the recto, up through the first section of the "Tu Ji 土忌," in the first row at the top of the strips, further supporting the hypothesis that the strips were selected together as one batch in the preparation of the manuscript. ${ }^{131}$

\section{The top piece of strip \#52 has a verso mark, while the bottom piece does not.}

Ignoring my own observation of the strip and the overlooked presence of a verso mark on the bottom piece of strip \#52, I would once again question whether this uncommon feature is necessarily proof of forgery. There are numerous other explanations for why a verso mark may be missing on only half of a strip, especially near an area with a break. It could be that surface layers of the bamboo were lost, along with evidence of a verso mark. It might be, as Han Wei suggested before, that in carving this line the craftsman erred and missed a portion of this one individual strip. Perhaps one blade cut only ended halfway on the strip,

129. Breakage upon handling is perhaps more likely, in my opinion, because with simple writing mistakes the scribe could either make corrections in the margins or on the verso, or shave off the error and re-write the text completely. A break would necessitate that the whole strip be replaced. Han Wei anticipates this point in "Xi Han zhushu Laozi jianbei huahen de chubu fenxi," 234.

130. I qualify my position here because I have not been able to inspect the Shuihudi bamboo strips in person. It is possible that the photograph is hiding a verso mark. There does seem to be an angled discoloration significantly below where the gap takes place on strip \#104, but the clarity of the other line-like marks leads me to believe that this is not akin to them. See Shuihudi Qin mu zhujian zhengli xiaozu, Shuihudi Qin mu zhujian 睡虎地秦墓竹簡 (Beijing, Wenwu, 1990), esp. 103-16. These are the only photographs available to us for an entire manuscript's verso from an archaeologically excavated cache, making them invaluable for comparison purposes.

131. Shuihudi Qin mu zhujian, 111 for photographs of these five strips. 
(a)

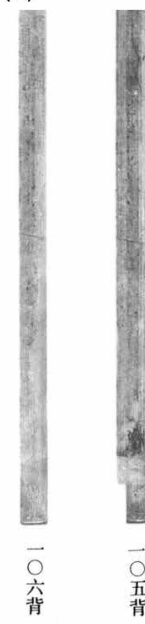

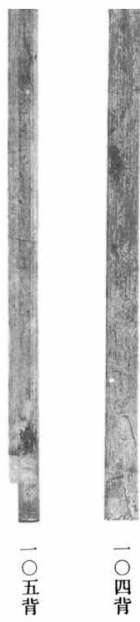

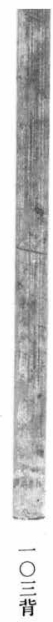

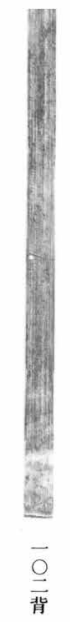

(b)

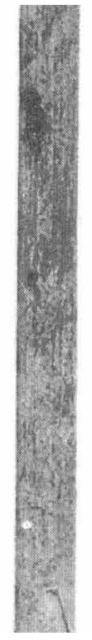

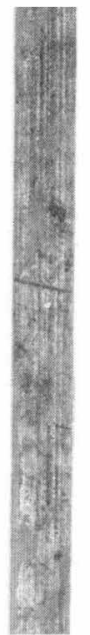

Figure 10. Versos of strips \#102-6, with a close-up of strip \#104 (after Shuihudi Qin mu zhujian, 111).

and then carving continued where the next strip was then fashioned. If additional polishing or finishing was done on the strip after the verso marks were carved, this would also erase evidence of their existence, though this is an unlikely explanation in this one instance. ${ }^{132}$

To this end, the Shuihudi Rishu (I) again presents archaeologically obtained evidence that the verso lines may only partially appear on a strip. In the Shuihudi Rishu (I), a verso line appears to run from strip \#130, across \#129, and onto \#128.133 Without seeing the actual artifact, it is impossible to tell for certain, although the photographs (presented below, Figure 11) show that this line only cuts into the leftmost portion of \#128, without running completely across the strip. This is not a perfect analogy with the Peking University Laozi strip \#52, of course, as the verso line does not continue onto Shuihudi Rishu (I) strip \#127; there is instead writing obscuring where the line would have run. This example does however demonstrate that the verso marks were not always consistent across the entirety of a given strip.

132. Jia Lianxiang finds evidence for this on the verso of the Tsinghua Yinzhi 尹至 manuscript, where the knot on strip \# 3 has been shaved off, along with most of the verso line on that strip. See Jia, Zhanguo zhushu xingzhi ji xiangguan wenti yanjiu, 73, and 89 image 6.3.

133. Shuihudi Qin mu zhujian, 113. 
(a)

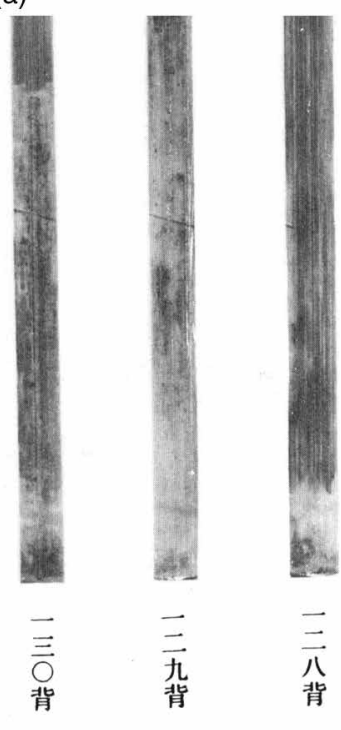

(b)

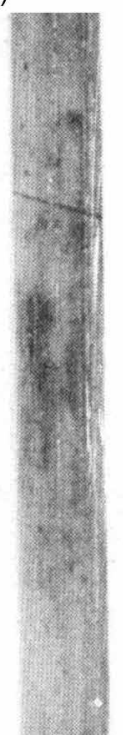

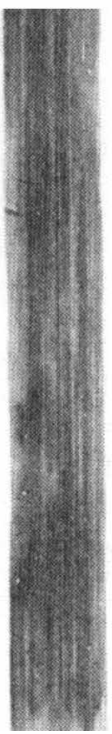

Figure 11. Versos of strips \#128-30, with a close-up of strip \#128 (after Shuihudi Qin mu zhujian, 113).

Admittedly, my point here is highly speculative in nature, as has been much of the conversation above. Despite the progress that has already been made researching the verso marks, we currently still know too little about these processes to definitively claim how or why they were created on ancient bamboo-strip manuscripts. Unusual characteristics such as line "skips," or intriguing coincidences like how some sets of marks seem to correlate with a typical culm circumference for this species of bamboo, demand further explanation. The best we can do is look to the evidence at hand, and conceive of a range of possibilities for what conditions most likely produced the phenomena we have observed. Ultimately however, this also presents a fundamental flaw in Xing Wen's own argument: whatever procedure he imagines a modern-day forger to have attempted (and failed) in creating proper verso lines (however he chooses to define "proper"), it is equally possible in theory for an ancient scribe to have acted in the same manner. What is troubling about Xing Wen's approach is that, until all other possibilities may be excluded, appealing to forgery is not constructive for the growth of the field, as it fails to offer any new understanding of early Chinese textual practices. 
For the sake of completeness, I have addressed each of Xing Wen's critiques individually. Let me conclude however by emphasizing what I see as two common shortcomings that emerge in Xing's discussion which undermine his basic strategy for disproving the authenticity to the Peking University Laozi manuscript. First, his methodology lacks an appreciation for the complexities of the material condition of the Laozi's textual carrier. This is demonstrated particularly by his refusal to acknowledge that damage around breaks might impact a "technical calligraphy" analysis to writing on or nearby fissures, but it has also limited his understanding of the verso marks' alignment. Second, Xing has failed to consider alternative processes for textual production in early China, especially in trying to explain why unusual characteristics consistently appear with the verso marks. All of the phenomena that Xing points to as signs of a forger's clumsy hand may be explained instead by imagining different ways for how the bamboo-strip manuscript was physically fashioned. Our scholarship must proceed with patience and contemplation; we cannot afford to prematurely dismiss as fake some of the most valuable new data available to us for the study of early China.

\subsection{A Method for Positively Authenticating Purchased Bamboo-strip Manuscripts}

For the reasons presented above, I do not find Xing Wen's critique convincing. His methodology in many respects requires a precision in data that is not available at present, while there are alternative explanations for the irregularities he notices that do not necessitate modern forgery. Besides my personal observations of the artifact itself however, my responses are at times also speculative, without presenting positive evidence to prove the Laozi manuscript's authenticity. In this regard, while I agree with the opinions rendered by the experts convened to authenticate the Peking University collection, and do not question their connoisseurship, I do believe it is necessary to strengthen their conclusion by appealing to more objective criteria that will be accessible to all future scholars interested in working with these manuscripts, with my primary concern again being the Cang Jie pian in particular.

One methodology I propose for authenticating a purchased bamboo-strip manuscript begins, ironically enough, at precisely the point from which Xing Wen launches his critique. We must identify within the newly purchased manuscripts completely novel features, ideally irregularities that are unanticipated by the current state of knowledge in the field. Such features may include aspects of the manuscript's physical constitution (from the raw materials used, to how the strips are fashioned and bound), calligraphy (the type or style of brushwork, unusual 
character forms), and content (vocabulary usage, odd grammar, surprising facts that go against accepted history, etc.) -in short, most of the same areas $\mathrm{Hu}$ Pingsheng also questions in his own appraisals. If these novel features can then be confirmed by archaeologically excavated data first available or fully appreciated only after the purchased artifact was secured, then we may be convinced of its authenticity. ${ }^{134}$

Of course, applying this methodology to the Peking University Han manuscripts faces some obvious challenges. The collection was secured just a few years ago, and there is only a limited amount of newly excavated materials now available with which to conduct a comparison. ${ }^{135}$ Over time, as new data is accumulated, we will be in a better position to check novel features found in the Peking University manuscripts against later finds, but at the moment we are left wanting. Moreover, the Han period calligraphic style found on these manuscripts is more familiar to paleographers than that of the Chu script on their Pre-Qin counterparts. Consequently, surprising anomalies in the calligraphy are more rarely encountered. Similarly, manuscripts like the Peking University Laozi are also especially encumbered by the fact that, with regard to content, textual counterparts are available in our received corpus. ${ }^{136}$ Finding truly unattested and unanticipated content in the Peking University Laozi is thus

\footnotetext{
134. Sarah Allan adopts a similar approach in her defense of the Shanghai Museum manuscripts. She mentions for instance that the Shanghai Museum writings revealed to us for the first time the consistent style of the Chu script, and included unknown forms that matched characters in the Guodian manuscripts, which were published only after the Shanghai Museum purchase. See Allan, Buried Ideas, 69. Other arguments that Allan raises for the authenticity of the Shanghai Museum include: the level of water saturation to the strips, requiring careful conservation; the fact that fakes tend to mimic known material, while many of the Shanghai Museum texts have no parallels in the received corpus; how variants in these manuscripts have helped with the decipherment of unknown characters in archaeologically excavated sources; how there is a large number of scribal hands responsible for these manuscripts, making their forgery impracticable; and the complexity of the relationships between these texts and our understanding of early China writ large, from our interpretation of the intricacies of paleographic data across other media, up to considerations of intellectual history. See Buried Ideas, 68-70.

135. One exciting discovery was recently made, when thousands of bamboo strips and other inscriptions were archaeologically excavated from the tomb of Liu He 劉賀， the Marquis of Haihun 海昏侯. For the preliminary report, see Jianxi sheng wenwu kaogu yanjiusuo et al., “Nanchang shi Xi Han Haihun Hou mu” 南昌市西漢海昏侯墓, Каogu 2016.7, 45-62.

136. Han Wei does suggest a few differences between the Peking University Laozi and other editions, including variations in wording and unique chapter divisions. See his: “Xi Han zhushu Laozi de wenben tezheng he xueshu jiazhi" 西漢竹書老子的文本 特徵和學術價值, in Beijing Daxue cang Xi Han zhushu [er], 207-25.
} 
more difficult. ${ }^{137}$ Paradoxically, the lack of a complete transmitted counterpart to the Peking University Cang Jie pian manuscript may actually be a boon for its authentication.

Proceeding from the methodology proposed above, I will now offer two lines of evidence that, in my view, convincingly demonstrate the authenticity of the Peking University Cang Jie pian. In both cases, I introduce novel features first noticed on the Peking University manuscripts (one for the cache generally, the other in the Cang Jie pian specifically), which were then found on other manuscripts taken from controlled archaeological excavations. The timing for when the novel features of the Peking University manuscripts were first noticed, compared to when these foil manuscripts were first excavated and found to bear the same features, precludes the excavated examples from being used by a potential forger as models for the Peking University cache. First, I will return to the verso marks found on many of the Peking University manuscripts. Next, I will catalog textual matches between the Peking University Cang Jie pian and other excavated witnesses.

137. In his defense of the Laozi manuscript, Li Kai attempts to demonstrate the role textual criticism may play in authentication. See "Guanyu Beida jian Laozi de bianwei," esp. sec. “Wenxian jiaokan he xungu shi shibie zhenjia de liqi” 文獻校勘和訓詁是識別 真假的利器. While I support the use of textual criticism for authentication, I believe the examples Li raises ultimately are ineffective, precisely because they fail to meet the two criteria noted above. First, he points out that the line “下德 (為)之而無以為” on strips \#1-2 differs from the parallel text found in the Wang Bi edition (“下德為之而有以為”), and is not found in the Mawangdui versions either. At the same time, Li argues, the antiquity of the variant "無以為" in the Peking University Laozi is demonstrated by its existence in other early editions, such as the Tang period Fu Yi 傅奕 edition. But as Xing Wen rightfully counters, a modern forger could have easily turned to these (perhaps less well known) editions to make the Peking University Laozi. See Xing, "Bianzheng zhi mei yu sandian toushi-Beida jian Laozi zai bianwei." That is to say, this "novel feature" in the Peking University Laozi is not in fact unattested. Li's second proof argues that the Peking University variant of “勉” in “大器勉成” on strip \#14 had the same ancient pronunciation as the “曼” and “免” variants found in our other excavated editions (Guodian and Mawangdui respectively), and was thus an alternative way of writing the same word, meaning wu 無. In the Wang Bi edition, there is instead the variant “晚," a reading he finds less appropriate in the context of this line. A modern forger however could have anticipated a Han manuscript writing the variant “勉” in this line, as it is found as a loan for "免" in other texts, and the phonetic relationship between it and both “免” or “曼” may be ascertained. If another archaeologically excavated Han version of the Laozi is later discovered to have this variant, it may serve as supplemental proof for the Peking University Laozi's authenticity, but it would still be only weak evidence. 


\section{Verso Marks as Proof of Authenticity}

Whereas Xing Wen considers irregularities in the Peking University Laozi's verso marks to be a sign of forgery, the very existence of such marks in this collection is in fact evidence for its authenticity. When editing work on the newly acquired Peking University Qin strips was underway, Sun Peiyang 孫沛陽, an undergraduate student invited to participate, noticed that there were often incised marks on the versos of the strips. Sun's article was the first to systematically study this phenomenon. ${ }^{13^{8}}$ He pointed out that these marks form slanting lines, which when pieced together appeared to correlate roughly with the order of the strips suggested by the text. In addition to the Laozi, the Cang Jie pian and most of the other Peking University Han manuscripts also have these inscribed lines.

It should be noted that Sun was not the first to recognize marks on the versos of bamboo strips. Similar marks were also observed by the scholars editing the Baoshan 包山 collection of Chu strips. In their 1991 publication of that cache, they write that "on the verso of a small number of strips there are slanted lines either inscribed by knife or inked on by brush, which at times may be used to connect adjacent strips, though at other times they are not correlated. These two types of lines are perhaps some sort of record made before the strips were bound together."139 One might argue therefore that the verso marks are not unattested, as my methodology demands. Despite the Baoshan editors' brief notice, however, the full import of these marks was never fully examined, nor have

138. Sun Peiyang, "Jiance bei hua xian chutan," 449-62. One account has the discovery being made in January, 2010. See Beijing Daxue chutu wenxian yanjiusuo, "Beijing Daxue cang Xi Han zhushu gaishuo," 55, n. 1; Han Wei's lastest report however places it slightly later, during photography in April of that year. See "Zailun Beida Han jian Laozi de jianbei huahen," 1 . As Thies Staack points out, other scholars began to take note of the verso marks at around this same time, including: Fudan Daxue chutu wenxian yu guwenzi yanjiusheng dushuhui, "Qinghua jian Chengwu jianxu tiaozheng yize" 清華簡程嗱簡序調整一則, Fudan Daxue chutu wenxian yu guwenzi yanjiu zhongxin, January 5, 2011 (http:/ / www.gwz.fudan.edu.cn/SrcShow.asp?Src_ID=1343), accessed September 30, 2016). Li Tianhong did early work on this phenomenon as well. See Li Tianhong, "Hubei chutu Chu jian (wuzhong) geshi chuxi," esp. 103-4. For Staack's comment on the early publication on verso marks, see "The Wei li zhi guan ji qianshou Manuscript from the Yuelu Academy Collection: a new reconstruction based on verso lines and verso imprints of writing," in Higashiajia no shahon to shosha zairyo 東厂ジ の写本と書写材料 Documents and Writing Materials in East Asia, ed. Tomoyuki Nagata 永田知之 (Kyoto: Kyoto Daigaku Jinbun Kagaku Kenkyujo, 2014) 3, n. 18.

139. Hubeisheng Jing Sha tielu kaogudui, Baoshan Chu jian 包山楚简 (Beijing: Wenwu, 1991), 4. This line is also repeated in the official excavation report, Baoshan Chu $m u$ 包山楚墓. Sun acknowledges the Baoshan editors in his article. See Sun, “Jiance bei hua xian chutan," 455. 
they been mentioned since as a criterion in reconstructing strip order. It was only with Sun's observation twenty years later that the verso marks began to be appreciated in full by scholars in our field, which is why I consider it a novel feature revealed on the Peking University manuscripts.

In his article, Sun investigates published collections of bamboo-strip manuscripts in which photographs of the versos of strips are available, generally because they bear a title or the continuation of text from the recto. He discovered that line-like marks may be found on the Baoshan, Guodian 郭店, Shuihudi 睡虎地, Zhangjiashan 張家山, and Yinqueshan 銀雀山 strips, all obtained through controlled archaeological excavations. Subsequently, other excavated caches of bamboo strips, including those found at Laohekou Angang 老河口安崗 and Jingmen Yancang 荊 門嚴倉, have also been shown to bear this feature. ${ }^{140}$ In addition to the Peking University strips, among purchased collections the Shanghai Museum, Tsinghua University, and Yuelu Academy strips also have verso marks. The publication of these latter two collections at the end of 2010 was particularly important, as they included complete verso photographs for multiple manuscripts, allowing for a thorough analysis of the marks. ${ }^{141}$

Most of the collections listed above were excavated or acquired before the Peking University manuscripts. That being said, only a limited number of photographs documenting the versos of strips were publicly available before the Peking University manuscripts were secured, and most of these usually involved only a single strip from any given manuscript. ${ }^{142}$ The sole exception I have located is in Shuihudi Qin mu zhujian, published in 1990, where photographs of the versos of each strip in the Shuihudi Rishu (I) manuscript are provided, as mentioned briefly

140. Li Tianhong, "Hubei chutu Chu jian (wuzhong) geshi chuxi," 102-6.

141. See Qinghua Daxue chutu wenxian yanjiu yu baohu zhongxin, Qinghua daxue cang Zhanguo zhujian (yi) 清華大學藏戰國竹簡 (壹) (Shanghai: Zhongxi, 2010); Zhu Hanmin 朱漢民 and Chen Songchang 陳松長 eds., Yuelu Shuyuan cang Qin jian 岳麓書 院藏秦簡 (Shanghai: Shanghai cishu, 2010).

142. Take for example the publication of the Guodian cache. In the initial Guodian Chu mu zhujian 郭店楚墓竹簡 (1998) volume, there are photographs of just two versos out of the entire collection, and each from a different manuscript: Ziyi 緇衣 strip \#40, and Yucong si 語叢四 strip \#27 (which bears a line-like mark). See Jingmenshi bowuguan, Guodian Chu mu zhujian, 20 and 107 respectively. A few additional verso photographs were later released in the Guodian volume of Chu di chutu Zhanguo jiance heji 楚 地出土戰國簡冊合集. See Wuhan Daxue jianbo yanjiu zhongxin, Jingmen bowuguan, Chu di chutu Zhanguo jiance heji (Beijing: Wenwu, 2011). The new verso photographs include: Wu xing 五行 strip \#36; Cheng zhi wen zhi 成之聞之 strip \#13; and Zun deyi 尊德 義 strips \#11, 12, 15 and 28 (which has a very unusual series of line-like marks). 
before. ${ }^{143}$ Nevertheless, even here only occasional marks are discernible among the extensive writing on the strips' versos, with most lines running just one or two strips in length, and the longest running across six strips in total. ${ }^{144}$ It is only with the publication of the Tsinghua University and Yuelu Academy collections that we have clear photographs showing an entire manuscript's verso, where there are obvious marks that can be linked into longer lines across numerous strips.

Peking University acquired their Han strips in 2009, before photographs of the Tsinghua University strips' versos were formally published at the end of 2010. It would have been nearly impossible therefore for a forger to fabricate these marks based solely on publicly available information. ${ }^{145}$ While scholars might have examined the artifacts themselves or unofficial photographs of the versos, my suspicion is that this sort of access was very limited. ${ }^{146}$ The absence of discussion among the academic community of these verso marks prior to Sun Peiyang's observation further confirms this point, as does the fact that previous publications of bamboo-strip manuscripts largely ignore these artifacts' versos. I say "nearly impossible" however because of the brief comments in the Baoshan report and the fact that the Shuihudi Rishu (I) manuscript verso shows short series of line-like marks. Might a clever forger have read this sentence in the Baoshan report, seen the Shuihudi Rishu (I) photographs, and then conjured up the verso marks we have now discovered?

Consider, however, that the verso marks on the Peking University strips have unusual characteristics that are also present in the two published collections of Tsinghua University and Yuelu Academy, and which are also not anticipated by the Baoshan report comment or seen in the Shuihudi material. For example, the discovery of regular "sets" of

143. Shuihudi Qin mu zhujian zhengli xiaozu, Shuihudi Qin mu zhujian 睡虎地秦墓 竹簡 (Beijing: Wenwu, 1990), 103-16.

144. The longest series I have noticed is from strip \#161-66, which appears to be drawn in with ink. See Shuihudi Qin mu zhujian, 116. I suspect that the anticipated use of the verso for such widespread writing might have dictated that the scribe select strips without running line-like marks for the manuscript. Alternatively, the strips could have also been polished or otherwise specially prepared to eliminate most of the marks, leaving a clean space for writing. The artifact itself would need to be investigated before confidently asserting this point.

145. There is the possibility that the strips' versos were displayed in a museum exhibit, though I have found no evidence of any museum arranging their manuscript displays in this manner, nor have I seen such displays in the exhibits I have personally toured.

146. For instance, Liu Guozhong notes that the Tsinghua editors relied mainly on photographs to compile manuscripts and finish transcriptions. Assuming that the photographs were of the writing, and thus of the rectos, exposure to the versos would have been limited. See Liu, Zoujin Qinghua jian, 55-56. 
verso lines derived from the same tube of bamboo culm is one such phenomenon that has now been demonstrated in all three of these collections. ${ }^{147}$ Unfortunately, while phenomena like the verso "sets" are both unattested and unanticipated by data published before the Peking University Han manuscripts' acquisition, the Tsinghua University and Yuelu Academy strips are also purchased artifacts. One might therefore disregard these coincidences by suggesting that the same forger (or team) was responsible for making all of these caches.

Complete photographs are not yet available for the verso marks on other archaeologically excavated manuscripts, against which we could possibly confirm the bamboo culm sets as a characteristic of genuine artifacts. With the discovery and publication of more bamboo-strip manuscripts in the future, and the newfound awareness of the importance of verso marks, my hope is that these novel features will eventually prove beyond doubt the authenticity of the three purchased collections mentioned above. What this observation does reveal however is that the authenticity of the Peking University manuscripts is irrevocably wed to that of the Tsinghua and Yuelu caches. On this point, radiocarbon dating and water saturation tests were conducted on the Tsinghua University strips, while the Yuelu Academy strips were subjected to comparative chemical analysis, differential thermal analysis, and similar tests, offering further scientific support that these two caches were made from ancient bamboo. ${ }^{148}$

Proceeding from the conversation above, it is still possible that a modern forger faked the Peking University Han strips' verso marks. Let me enumerate all the other conditions that must nonetheless be satisfied for this to have occurred. First, the potential forger must have read the Baoshan report comment about the existence of such lines, and/or seen the photographs of strips' versos infrequently published, most fully

147. Thies Staack provides a thorough discussion of the "spiral line theory" and such verso "sets," including a more in-depth look at the reconstruction for the Yuelu Academy Zhiri verso lines, to which I would refer the reader: "Identifying Codicological Sub-units in Bamboo Manuscripts: Verso Lines Revisited," 161-74, and esp. 178 for an image of the manuscript's verso. See my conversation above, particularly on the Peking University Laozi set of strips \#35-53: Beijing Daxue chutu wenxian yanjiusuo, Beijing Daxue cang Xi Han zhushu [er], 112. For verso sets in the Tsinghua strips, see especially Xiao, "Qinghua jian jiance zhidu kaocha," 78-80, and Jia, Zhanguo zhushu xingzhi ji xiangguan wenti yanjiu, 82-102.

148. While this does not disprove the text or the verso marks as modern additions to ancient bamboo strips, it does make forgery less tenuous, especially on such a large scale. See Li Xueqin 李學勤, “Qinghua jian zhengli gongzuo de diyi nian” 清華簡整理 工作的第一年, Qinghua Daxue xuebao 清華大學學報 (Philosophy and Social Sciences Edition 哲社版) 2009.5, also appended to Liu, Zoujin Qinghua jian, 181-83; “Jiance baogao" 檢測報告 in Yuelu Shuyuan cang Qin jian, 197-201. 
documented for the Shuihudi Rishu (I) manuscript. Then, despite apparent scholarly neglect of the importance of this phenomenon, the shrewd forger chose to invent similar marks across multiple manuscripts in the Peking University collection. Second, as the verso marks were first publicly acknowledged in full during the editing of the Peking University collection, any correlation of unusual characteristics (such as the bamboo culm sets) between these manuscripts and those in other caches discovered beforehand could only be because either a) the forger had privileged access to data from previously excavated caches most scholars did not; or b) because the forger himself fashioned the strips in the other previously purchased caches as well. Since there are surprising similarities, beyond any question of mere coincidence, between the Peking University collection verso marks and those from the Tsinghua and Yuelu caches, then these too must be regarded as modern forgeries, despite the scientific authentication to which they were separately subjected. ${ }^{149}$

In short, to believe that the verso marks on the Peking University manuscripts are fake is also to subscribe to a conspiracy of massive proportions. A forger or team of forgers must have grasped the significance of a minute point in an old report, and then invented an elaborate system of marks (along with regular unexpected anomalies like spiraling verso-line "sets"), potentially simulating privileged data such as the full versos of the Baoshan or Guodian strips. The forgers then fashioned on a grand scale hundreds of strips that we now see across these multiple purchased collections (Peking University, Tsinghua University, Yuelu Academy, etc.). Furthermore, they created them with such mastery that the fakes trick both the connoisseurship of experts, as well as scientific methods of dating. In this case, the only conclusion to be reached is that the forgers are then in some capacity "insiders" in our field. While this explanation is in the realm of possibility-with terrifying implications if true-Occam's razor suggests that we seriously question its likelihood.

\section{Matching Textual Content as Proof of Authenticity}

Although the verso marks provide circumstantial evidence that most of the Peking University Han manuscripts are authentic, lingering doubts may remain. I will therefore offer more positive evidence for the authenticity of the Peking University Cang Jie pian manuscript in particular. My

149. Moreover, should newly excavated manuscripts also retain verso marks with these same unusual characteristics, then the first condition would be necessary regardless: that the forger had privileged access to data on previously excavated manuscripts (for instance from Baoshan, Guodian, etc.) which also had these same features. 
focus in this discussion will be on novel features in the writing of the Cang Jie pian, as this undeniably confirms the antiquity of the text itself. Such features might include unattested character forms, unique language usage, unusual rhyming relationships, or longer lines of new content. The proof I give below relies on this last feature, and compiles matching textual content between the Peking University Cang Jie pian and other editions, most importantly that of the Shuiquanzi version, whose data was only available or fully acknowledged since the Peking University collection was secured.

From August to October 2008, archaeologists from the Gansu Provincial Institute of Archaeology conducted salvage excavations of a Han period cemetery at Shuiquanzi, Yongchang County 永昌, Gansu, ahead of the large-scale construction of two natural gas pipelines. ${ }^{150}$ Fifteen late Western Han to mid-Eastern Han tombs were excavated, revealing over 1,400 strip fragments in Tomb M5. The strips were broken when the coffin collapsed inward, and further deteriorated after the burial chamber flooded with water. Despite their poor preservation however, the Shuiquanzi wooden strips offer exciting new evidence for the study of the Cang Jie pian. The burial contained what appears to be a completely unique version of the Cang Jie pian, consisting of nearly 140 pieces with close to 1,000 characters written on them, and including three-character "commentaries" appended to each line of the base text.

Unfortunately, the Shuiquanzi Cang Jie pian has not been published in full. In the preliminary report on the Shuiquanzi strips released late in 2009, Wu Hong 呉荒 and Zhang Cunliang 張存良 provide photographs of ten strips, along with transcriptions for these strips and twelve additional fragments. ${ }^{151}$ In 2010, Zhang published photographs of forty-three

150. An early brief on the Shuiquanzi excavation may be found in Wu Hong 吳葒, Wei Meili 魏美麗, and Zhang Cunliang 張存良, “Gansu Yongchang Shuiquanzi Han muqun” 甘肅永昌水泉子漢墓群, Zhongguo wenwu bao 中國文物報, April 24, 2009, 4. See also Wu Hong's article, “Gansu Yongchang Shuiquanzi Han mu” 甘肅永昌水泉子漢墓， in Zhongguo zhongyao kaogu faxian 中國重要考古發現, Guojia wenwuju, ed. (Beijing: Wenwu, 2009), though I have not yet been able to access this later report. For the preliminary report see Gansusheng wenwu kaogu yanjiusuo, "Gansu Yongchang Shuiquanzi Han mu fajue jianbao" 甘肅永昌水泉子漢墓發掘簡報, Wenwu 2009.10, 52-61. The specific construction project is identified as the "Transporting East Western Natural Gas 西氣東輸” initiative in Zhang Cunliang and Wu Hong, "Shuiquanzi Han jian chushi" 水泉子漢簡初識, Wenwu 2009.10, 88.

151. They also offer a transcription of what the opening chapter of the Cang Jie pian looks like according to this edition's new seven-character sentence format, though it is hard to tell where to place divisions for individual strips. Photographs from the Shuiquanzi preliminary report are labeled in my study as SQZ1_P:\#, with the \# following either the first or second plate, then the tags given on the plate. Thus SQZ1_P:1-7 is the strip labeled \#7 on the first plate. The transcriptions in the article are labeled SQZ1_T:\#, 
strips in his “Shuiquanzi Han jian qiyanben Cang Jie pian lice" 水泉子漢 簡七言本蒼頡篇虽測, thirty-six of which are not found in the previous report. ${ }^{152}$ The article proper also gives transcriptions for sixty-six strips, many of them not seen before. ${ }^{153}$ Zhang's dissertation, "Shuiquanzi Cang Jie pian zhengli yu yanjiu" 水泉子蒼頡篇整理與研究, is expected to include data for the entire Shuiquanzi Cang Jie pian in the near future. ${ }^{154}$

The Peking University Han strips arrived on campus on January 11, 2009, just over two months after the Shuiquanzi excavations were completed. This date is also the terminus ante quem for when the Peking University strips could have been forged. As was demonstrated before however, it is likely that representatives from Peking University knew of the strips as early as the end of 2008 , and the cache was possibily available for sale even earlier. Considering that some time would have been needed by the Shuiquanzi excavators to clean and transcribe the strips, it is reasonable to assume that any hypothetical forger could not have based their work on this artifact before its publication. To date, the Shuiquanzi manuscript is still not published in full. The data cited below was first known to the public only late in 2009, with information about certain strips available as late as 2010, long after Peking University had acquired their cache. For these reasons, content from the Shuiquanzi

with the \# being the order by which they appear over the course of the article. See Zhang and Wu, "Shuiquanzi Han jian chushi," 88-91, with photographs on the inside front cover. One strip is transcribed and published (though not identified as Cang Jie pian) in the earlier brief: Wu, Wei, and Zhang, "Gansu Yongchang Shuiquanzi Han muqun," 4. This strip's photograph is also found in Zhang's later publication, which is why I have not highlighted this brief in the main text. The Fudan Reading Group has also released their own transcriptions for these materials. See Fudan Daxue chutu wenxian yu guwenzi yanjiu zhongxin dushuhui, “Du Shuiquanzi jian Cang Jie pian zhaji" 讀水泉子簡蒼頡篇札記, Fudan Daxue chutu wenxian yu guwenzi yanjiu zhongxin, September 11, 2012 (http://www.gwz.fudan.edu.cn/SrcShow.asp?Src_ ID=973), accessed September 30, 2016.

152. Zhang, "Shuiquanzi Han jian qiyanben Cang Jie pian lice," plates 8-11. In this study, these photographs will go by the label SQZ2_P:\#, with the \# following the temporary tag given in this article. Although Zhang provides forty-five photographs (with different labels) in this journal, note that he skips a label (what would be SQZ2_P:26), and moreover confounds SQZ2_P:31 and 40, which are two pictures of the same strip, seemingly taken at slightly different angles.

153. Zhang, "Shuiquanzi Han jian qiyanben Cang Jie pian lice," 60-75. I will refer to these transcriptions as SQZ2_T:\#, with the \# being the order in which they appear in the article. Hu Pingsheng 胡平生 also gives his own transcriptions for these strips. See “Du Shuiquanzi Han jian qiyanben Cang Jie pian" 讀水泉子漢簡七言本蒼頴篇, Fudan Daxue chutu wenxian yu guwenzi yanjiu zhongxin, September 11, 2012 (http:/ / www. gwz.fudan.edu.cn/SrcShow.asp?Src_ID=1064), accessed September 30, 2016.

154. Although Zhang successfully passed his defense, the dissertation is embargoed and will not be publicly available for a few more years. See n. 6 for a full citation. 
Cang Jie pian fragments could not have been used to forge the Peking University Cang Jie pian.

Text found on fourteen strips from the Shuiquanzi manuscript (hereafter SQZ) matches text written on twelve strips from the Peking University manuscript (hereafter PKU). These matches are found only between these two editions, and not in other Cang Jie pian witnesses discovered earlier. Characters underlined represent the "novel" overlap. Take for example the match between PKU $57+58$ (top row) and SQZ2 $\mathrm{T}: 52+\mathrm{SQZ} 2 \mathrm{~T}: 53$ [SQZ2_P:22] (bottom row): ${ }^{155}$

PKU: 皮池溝洫淵泉隄防江漢澮汾河胨涊漳伊雉涇渭維楫舩方 百四 SQZ: 宗隄防泥式式江漢覦汾多淮渭流湯湯維楫船方[莋]

Disregarding the three-character commentaries included in the Shuiquanzi edition, as well as the additional (tentative) "莋" at the end of SQZ2_T:53 where PKU 58 concludes the chapter with a character count, there are then four sentences with overlap between these two series of strips. Only a few slight variations need to be noted. Strip SQZ2_P:22 is broken and lacks the first character "伊" extant in PKU 57, which does not impact our evaluation. While the character "舩" on PKU 58 is given as “船” by Hu Pingsheng for the Shuiquanzi strip, the writing is unclear on the strip here, so I cannot tell if there is significant graphic variance; they are in any case allographs (yiwen 異文). ${ }^{156}$ Finally, besides including the first character of “淵," PKU 57 has “泉” where SQZ2_ T:52 has been transcribed by Zhang Cunliang as “宗.” Unfortunately, no

155. Transcriptions for the Peking University Cang Jie pian are taken from: Beijing Daxue cang Xi Han zhushu [yi], 67-141. For strips \#57 and 58, see 124 and 126, nn. 9 and 10. In general, the Shuiquanzi transcriptions follow $\mathrm{Hu}$, "Du Shuiquanzi Han jian qiyanben Cang Jie pian," except for strips where photographs are not yet available, in which case I rely on Zhang's transcriptions. In this case, see "Shuiquanzi Han jian qiyanben Cang Jie pian lice," 68 . Note that while Zhu Fenghan uses direct transcriptions in the Peking University Cang Jie pian publication, Hu's transcriptions are more interpretative. For the reader's convenience, I will provide the more familiar interpretative character forms when there is no significant variance at the site of the novel match (and also for all peripheral text). For example, while Zhu's transcription of "湑" seems to differ from Hu's transcription of “經” in the line “伊雒涇渭," an examination of both manuscripts reveals that the variance is only at the level of our modern transcription, and not with how the character was written by the ancient scribe. Both the Peking University and Shuiquanzi characters have a direct transcription of "淕," an alternative for "經." For more on the necessity of disambiguating transcription practices, see Crispin Williams, "A Methodological Procedure for the Analysis of the Wenxian Covenant Texts," Asiatische Studien/Études Asiatiques 59.1 (2005), 61-114.

156. See the listing for “船” in Zong Fubang 宗福邦, Chen Shinao 陳世鐃, and Xiao Haibo 蕭海波, Guxun Huizuan 故訓匯纂 (Beijing: Shangwuyin, 2003), 1901. In his annotations, Zhu also cites the Guangyun entry identifying “舩” and “船," see Beijing Daxue cang Xi Han zhushu [yi], 126, n. 11. 
photographs are currently available of this particular Shuiquanzi strip that would allow us to evaluate Zhang's transcription. Assuming his transcription is correct, the visual similarity between these two characters is striking. The data for both of these two Shuiquanzi strips was first published only in 2010, more than a year after the Peking University Cang Jie pian was secured.

The following is a list of all the matching textual content between the Peking University and Shuiquanzi Cang Jie pian manuscripts. As before, the characters underlined are "novel" matches that have not been seen before in any previous discoveries. Note that parallel text not underlined is extant on other witnesses:

PKU 9 vs. SQZ2_T:46 (SQZ2_P:12)

PKU: 兼百越貢織飭端脩洹變大制裁 男女蕃 殖 六畜逐字

SQZ: $\quad$ (陶?) 主變大制裁好衣服男女藩(屏?)

PKU 10 vs. SQZ2_T:33 $3^{157}$

PKU: 顫㥴觭贏 骱奏左右 熬悍驕裙誅罰貲耐丹勝誤亂

SQZ: 键觭贏思美 $\square$ 差左右行

PKU 47 vs. SQZ2_T:20 (SQZ2_P:27) ${ }^{158}$

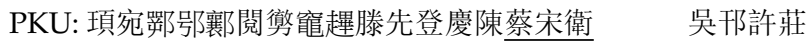

SQZ: 蔡宋衛故有王

PKU 51 vs. SQZ1_T:1 (SQZ1_P:1) ${ }^{159}$

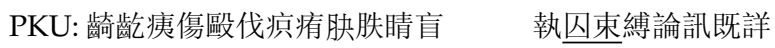

SQZ: 肤肤营盲樂府師執回東

157. In the Fuyang Cang Jie pian edition (see Fuyang Han jian zhenglizu, "Fuyang Han jian Cang Jie pian" and n. 6 above for full citations, labels are marked with "FY"), the strips FY Co89 + FY CoO3 may overlap with this section; however the characters are too illegible to be considered as a match, particularly for the "䚚” position. With FY Co89, following “觭” there seems to be a "亡" component to the next character. While this match between the Peking University and Shuiquanzi versions is thus not the strongest evidence, it was included for the sake of completeness. As there is no photograph for the Shuiquanzi strip, again the transcription is based on the rendition provided by Zhang Cunliang.

158. I did not include the overlap that occurs at “吳邗許莊” with SQZ2_T:21 (SQZ2_P:42), as there is also a strip in the British Library collection of shavings (labels marked with "YT") which matches this content, namely YT 3445. The British Library shavings are found in: Wang Tao 汪濤, Hu Pingsheng 胡平生, and Wu Fangsi 吳芳思， Yingguo guojia tushuguan cang Sitanyin suo huo weikan Han wen jiandu 英國國家圖書館藏 斯坦因所獲未刊漢文簡牘 (Shanghai: Shanghai cishu, 2007).

159. FY C105 + FY Co41 overlap with this section in part. 


$$
\text { PKU } 54 \text { vs. SQZ2_T:49 (SQZ2_P:33) }{ }^{160}
$$

PKU: 宇關廷廟郎殿層屋內窗牑戶房桴楣欀㮰柱枅橋梁

SQZ: 堆正怒關廷廟郎列譠馬

$$
\text { PKU 57+58 vs. SQZ2_ T:52 + SQZ2_T:53 (SQZ2_P:22) }
$$

PKU: 皮池溝洫淵泉隄防 江漢澮汾河泲涊漳伊雒涇渭 維楫舩方 百四 SQZ: 宗隄防泥式式江漢澮汾多涇渭湯湯維楫船方 [ 莋]

PKU 61 vs. SQZ2_T:26 (SQZ2_P:28) ${ }^{161}$

PKU: 崋巒岑崩阮嵬阤阬阿尉馺瑣漆图氏㒸贅拾鋏鎔

SQZ: 崩山柀隮阮嵬阤阬水不行阿尉馺

$$
\text { PKU } 62 \text { vs. SQZ1_T:4 (SQZ1_P:4) }{ }^{162}
$$

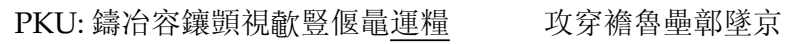

SQZ: 偃㫣運糧載穀行

$$
\text { PKU } 63 \text { vs. SQZ2_T:1 (SQZ2_P:16) }{ }^{163}
$$

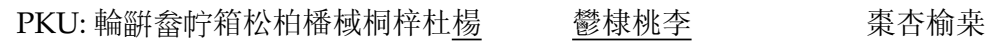

SQZ: 楊棺楟朴鬱棣桃李入所欲百五字

$$
\text { PKU } 64 \text { vs. SQZ2_T:64 + SQZ2_P:34 }{ }^{164}
$$

PKU: 蕉葦菅萳
SQZ: 莞蒲鹳蔣
耑末編爲薄莞蒲閵蔣織

$$
\begin{aligned}
& \text { PKU 65 vs. SQZ2_T:63 (SQZ2_P:45) }{ }^{166} \\
& \text { PKU: 堯舜禹湯 䫓印[趮] [䗗] 䁒䁒 }
\end{aligned}
$$

SQZ: 禹湯稱不絕禍迎 趮 厥怒佛曰

160. FY Co28 overlaps up to the character "關." See also SQZ2_T:48. Hu's transcription also seems to mistakenly switch “郎” with “廟," I have corrected for that here.

161. FY Co26 and potentially FY Cog8 overlap with other parts of this text.

162. FY Co36 + FY Co40 overlap before the character "運."

163. The transcription is repeated at $\mathrm{SQZ}_{2} \mathrm{~T}: 51$. A photograph is also available in the earliest (April 2009) publication: Wu, Wei, and Zhang, "Gansu Yongchang Shuiquanzi Han muqun," 4. This section of overlapping text is particularly interesting, as it shows a chapter division in the Shuiquanzi manuscript that is different from the Peking University edition. Note that the right component for the character "棣" on PKU 63 is simplified, with horizontal strokes on the bottom.

164. As there is no photograph for first Shuiquanzi piece available yet, I am using the transcription Zhang provides.

165. Note that one shaving from the British Library collection might overlap with a couple characters from this pair. YT 2275 has the characters “鹿獐," and before “鹿” there seems also to be the bottom component of "米" in "糜." The shaving is too fragmentary however to confidently call it matching text.

166. PKU 65 is damaged, and some of the overlapping characters are partial. Zhu bases his transcription of “趮” in part on the Shuiquanzi parallel. See Beijing Daxue cang Xi Han zhushu, 133, n. 3 . 
Novel matches between the Peking University and Shuiquanzi Cang Jie pian manuscripts thus consist of a total of fifty-two characters, with the longest string of consecutive characters reaching up to seven, nearly two full lines (excluding the Shuiquanzi commentary). With only about half of the Shuiquanzi Cang Jie pian published to date, it is likely that additional novel matches will be discovered, once the entire manuscript is available for scrutiny.

The Shuiquanzi material offers the best data for us to confirm the authenticity of novel text in the Peking University Cang Jie pian. A similar argument may also be made however using the British Library collection of wood shavings. Aurel Stein first collected these shavings from the remains of Han period fortifications around Dunhuang, likely during his second expedition over a century ago. ${ }^{167}$ Due to an editorial decision by Édouard Chavannes, they were not immediately published in full. ${ }^{168}$ Although scholars were always aware of the shavings' existence, it was not until 2007 that a formal volume was finally published with transcriptions and photographs, entitled Yingguo guojia tushuguan cang Sitanyin suo huo weikan Han wen jiandu 英國國家圖書館藏斯坦因所 獲未刊漢文簡牘 (abbreviated here to Yingguo guojia tushuguan). ${ }^{169}$ Photographs for these pieces have also been available freely online, as part of the International Dunhuang Project database. ${ }^{170}$ Consequently, the data from these shavings was technically available to a potential forger now for many decades - if a forger were granted access to the original artifacts, that is. Images have been easily accessible since as early as

167. Stein's report on his second expedition was eventually published as Aurel Stein, Serindia: Detailed Report of Explorations in Central Asia and Westernmost China (Oxford: Clarendon Press, 1921), in five volumes. Documentation for the shavings is ambiguous, however, and it is unclear precisely when and where Stein collected these materials. Most evidence suggests that they were found during the second expedition. See Yingguo guojia tushuguan, 2; and in Stein, Serindia, vol. 2, 646: "A curious discovery was made in a shallow layer about sixteen yards to the north-west of the tower. Here was found a great mass of wooden 'shavings' covered with Chinese characters, probably over a thousand in all. It might have passed for a great find-if Chiang Ssu-yeh had not at once noticed that the writing was obviously by the same hand and the phrases constantly recurring. He was, no doubt, right in concluding that these were chips from improvised tablets which some officer or clerk, eager to improve his penmanship after the wont of the present-day literatus, had used again and again for writing exercises, planing them down with a knife each time to obtain a fresh surface."

168. Only those strips he deemed decipherable and worthwhile received treatment in his translation: Édouard Çhavannes, Les Documents Chinois Découverts par Aurel Stein dans les Sables du Turkestan Oriental (Oxford: Imprimerie de l'Université, 1913).

169. See $n .158$ above.

170. The International Dunhuang Project homepage may be found at: (http://idp. bl.uk/), last accessed September 30, 2016. I am not sure of exactly when the images for the Cang Jie pian pieces were first made publicly available in this database. 
2007, when it was publicized that the cache contained numerous pieces relevant to the Cang Jie pian. This is all before Peking University acquired their collection of manuscripts.

There is however one strip fragment which may still satisfy the conditions of my methodology, and also help authenticate the Peking University Cang Jie pian. Among the strips published initially in Yingguo guojia tushuguan, there is at least one piece which was not identified as belonging to the Cang Jie pian - either at that time, by Hu Pingsheng et al. in their accompanying essays, or later by other scholars, even up to the point of the Peking University manuscript's publication. ${ }^{171}$ Thus while the data for the strip was publicly available, its identity as belonging to the Cang Jie pian has never been appreciated. I may now show that it does belong to the Cang Jie pian, with content that overlaps with the Peking University edition. The strip I am referring to is YT 3559, which may be compared with PKU 3. Again underlined text represents a "novel" match not seen before in other witnesses:

PKU 3 vs. YT $3559^{172}$

PKU: 疢痛遬欬毒藥醫工抑按啟久嬰 但 捾援何竭負戴

YT:

釰久嬰[担]捾掁抲拫

The variants here are for the most part unremarkable, and generally involve a slight alteration to one character component. Therefore, I will not deal with each individually. In the case of "担", the left component is also located on a tear, obscuring how it was written, but the right component is clear. The relationship between “竭” and “拫” is more difficult to discern. Since the meaning of jie “竭” ("to lift up") and hen “拫” ("to drag") fit the context of this sentence, which lists verbs of carrying or pulling, it is possible that they are lexical variants. The right component for both characters is also visually similar, particularly toward the top. The Stein shaving does include an obvious stroke off to the right here, however, while the character in the Peking University manuscript loops back to the left and underneath the component. Nevertheless, there is enough of an affinity to these two characters to suggest some textual

171. For instance, Liang Jing does not include it among the British Library shavings in her Chutu Cang Jie pian yanjiu. See 19-27.

172. Transcriptions for the British Library shavings are based on those provided in Yingguo guojia tushuguan, with reference to the photographs also included. See esp. 46 and plate 111. What makes this specific example even more convincing is the fact that both PKU 3 and YT 3559 overlap in their initial text with the conclusion of strip FY C037. We thus know that YT 3559, regardless of its relationship to the Peking University manuscript, may be linked to Cang Jie pian content from another cache that was archaeologically excavated. 
association, especially in light of the additional matches found in the same line of text.

Once again, to the best of my knowledge no other scholar has identified YT 3559 as affiliated with the Cang Jie pian, including in the discussions provided as part of the Yingguo guojia tushuguan volume itself. Moreover, YT 3559 is not included in the appended chart, Beida cang Han jian Cang Jie pian yu qita chutu jianben duizhaobiao 北大漢簡蒼頡篇與其他 出土簡本對照表, from the formal publication of the Peking University Cang Jie pian. This suggests that, in their preparations, the editors were still unaware of the existence of this overlapping strip from the British Library shavings. ${ }^{173}$ Therefore, despite the availability of the raw data long before the Peking University Cang Jie pian's publication, I would argue that this piece was never fully appreciated in the academic community. The novel match provided here thus offers supplementary proof for the authenticity of this manuscript.

One final observation on the topic of parallel text: It is curious that the Peking University Cang Jie pian does not include any content related to the so-called opening chapter of the text, namely the lines beginning with “蒼頡作書以教後嗣," from which Wang Guowei has argued the title of the text itself was likely drawn. ${ }^{174}$ This is by far the most prevalent content that we see among the fragments collected in northwest China. The opening chapter has long been the focus of Chinese scholars who engage in textual reconstruction, especially since it is one of only two chapters that have been nearly completely restored before the publication of the Peking University Cang Jie pian. ${ }^{175}$ If the Peking University Cang Jie pian is authentic, then the absence of this chapter may of course

173. “Beida cang Han jian Cang Jie pian yu qita chutu jianben duizhaobiao" 北大藏 漢簡蒼頍篇與其他出土簡本對照表, in Beijing Daxue cang Xi Han zhushu [yi], see esp. 155 .

174. Wang Guowei 王國維, “Cang Jie pian canjian ba” 蒼頴篇殘簡跋 in Guantang Jilin (wai er zhong) 觀堂集林 (外二種), Ershi shiji Zhongguo shixue mingzhu二十世紀中國史學 名著 series (Shijiazhuang: Hebei jiaoyu 2001), vol. 5, 126. Wang turns to a strip from Aurel Stein's collection where “蒼頴作" is scribbled on the verso. See Gansu sheng wenwu kaogu yanjiusuo, Dunhuang Han jian 敦煌漢簡 (Beijing: Zhonghua shuju chuban, 1991), strip \#1975. Sun Xingyan 孫星衍 had earlier guessed that the title derived from an opening line beginning with “倉頴," though at the time his only proof was the parallel convention in the Jijiu pian 急就篇, as that text starts with “急就." See Sun Xingyan, “Cang Jie pian" 倉頴篇 in Congshu jicheng chubian 叢書集成初編 (Beijing: Zhonghua, 1985-1991), vol. 105, foreword, 1-2.

175. For a recent overview of debates surrounding reconstruction of the opening chapter, see Liang, “Cang Jie pian shou zhang de faxian yu yanjiu” 蒼頴篇首章的發現與 研究, in Chutu Cang Jie pian yanjiu, 83-87. She also published this essay in: “Cang Jie pian shou zhang de faxian yu yanjiu" 蒼頡篇首章的發現與研究," Jianbo yanjiu 簡帛研究 (2013): 201-6. 
be purely coincidental, as it is hard for us to estimate how much content was lost from this particular edition. ${ }^{176}$ With a purposeful counterfeit, however, it is harder to rely on this explanation. ${ }^{177}$ If forgers were to compose a Cang Jie pian manuscript based solely on materials extant before the Peking University collection came to light, why would they choose to ignore some of the richest content available? Although the limitations of this argumentum ex silentio are obvious, I feel compelled nonetheless to raise the issue for the reader's further contemplation.

In summary, experts familiar with handling bamboo-strip manuscript artifacts have concluded, based on their connoisseurship, that the Peking University Han strips are authentic. Features such as the remnants of binding strings, how the strips splintered, and the calligraphic style are a few factors these scholars considered when rendering their judgment. Xing Wen offers the only dissenting opinion, questioning the authenticity of the Laozi manuscript, but I have shown his critiques to be unfounded. The scientific analysis conducted by the Peking University School of Archaeology and Museology, while not providing radiocarbon dating data, did prove that the bamboo and other materials used for these strips are consistent with what we would expect from Han period

176. The Han shu Yiwen zhi notes that in the early Han there was a Cang Jie 蒼頴 edited by "village teachers" into fifty-five chapters, each bearing sixty characters (see Han shu 30.1721). The Peking University Cang Jie pian however must have been a different edition, judging from how the chapter titles relate to the recorded character counts, ranging from 104 to 152 characters total. This frustrates any attempts to estimate how much content is actually missing from the Peking University manuscript, if much at all. Interestingly, the Fuyang Shuanggudui Cang Jie pian does not have content from the opening chapter either. It might not be coincidental that two of our longer and potentially older versions of the text, both likely taken from aristocratic tombs in central or eastern China, happen to lack this chapter. This is a topic I explore further in my dissertation.

177. As both Hu Pingsheng and Sarah Allan have emphasized, forgers tend to base their work on previously unearthed examples. See nn. 28 and 134 above. As one example, Enno Giele briefly documents the forgery of strips mimicking a text from Wuwei 武威 Mozuizi 磨嘴子 granting dove-headed staffs to the eldery. See Enno Giele, "Excavated texts: contexts and methodology," in China's Early Empires: A Re-appraisal (Cambridge: Cambridge University Press, 2010) 114. Of course, if the Peking University Cang Jie pian was part of a cache of fake manuscripts, it might have been split up on the market, with pieces related to the Cang Jie pian still for sale or purchased previously and in unknown private collections. It would be extremely coincidental however if all content from a potential opening chapter happened to be separated from the rest of the manuscript on the market, with no traces remaining in the Peking University collection. 
manuscripts. In addition to these considerations, I have further argued that the verso marks, first fully appreciated with the Peking University cache, were a novel feature not recognized in previous caches, but have now been shown to be a material aspect of many genuine bamboo-strip manuscripts. In the case of the Cang Jie pian, the focus of my own research, I have also demonstrated that there is content from the Peking University manuscript that matches text from the Shuiquanzi version, only recently excavated, and the British Library shavings, only recently identified. The timing of these discoveries (or awareness of the existence of these materials) reasonably precludes the possibility that a forger could have incorporated the verso marks as they appear on many of the Peking University Han manuscripts, or the matching text found in the Cang Jie pian in particular.

\section{In Brief Defense of the Study of Looted Manuscripts}

Having addressed questions regarding the authenticity of the Peking University Han bamboo strips, let me now offer a few words on the dilemma of professional ethics raised by working with pilfered materials. Recently, Paul Goldin has argued that scholars should not research looted bamboo-strip manuscripts. In his article "Heng Xian and the Problem of Studying Looted Artifacts," Goldin introduces the Heng Xian manuscript from the Shanghai Museum collection, and shows how the ordering of the strips is still under debate. ${ }^{178} \mathrm{In}$ fact, the manuscript might not even constitute a single text, but may be two discrete texts instead, with numerous strips missing. The emphasis of Goldin's review however is that we do not know the archaeological context from which the Heng Xian manuscript was taken. Important data that could have aided scholars in arranging the strips is now lost forever due to the looting. He asks whether "[our] work indirectly abets this destruction of knowledge," and deems institutions and individuals who have purchased and edited collections like the Peking University Han strips to be complicit in the growing tomb robbery epidemic. ${ }^{179}$ While acknowledging that not all scholars are involved with handling purchased artifacts at the institutional level, Goldin warns that we all inevitably have an impact on this trade. For his own research, he states: "I have come to subscribe to the view that scholars must not contribute to the sale of looted antiquities by providing

178. Goldin, "Heng Xian and the Problem of Studying Looted Artifacts," 153-60. See n. 13 above for full citation.

179. See esp. Goldin, "Heng Xian," 156-57. 
authentication and expertise, and that by referring to such objects in print, we inescapably provide authentication and expertise." 180

Goldin is to be commended for taking a public stand on this controversial issue, and for his concern with protecting China's cultural heritage. We all would like to see tomb robbery eliminated in China. In light of Goldin's call to action, I feel compelled to explain my decision to continue working with the Peking University Cang Jie pian, and to give voice to the other side of this debate. I will concern myself here only with the question of whether or not individual scholars have an obligation to avoid studying looted manuscripts. ${ }^{181}$

In my opinion, when deciding how best to protect China's cultural heritage, we are forced to weigh between, on the one hand, the material and intellectual losses that may be suffered in the future by further incentivizing looting and, on the other hand, the material and intellectual losses we will suffer imminently by neglecting looted artifacts already on the market, as well as the future loss of neglecting those that may surface later. There are good reasons to favor either side of this balance. I would however argue, contra Goldin, that ignoring the Peking University manuscripts and other looted bamboo strips may ultimately prove to be the more detrimental course of action.

In Chinese scholarship, the purchase and study of looted manuscripts is often described as an act of "qiangjiu 搶救," or "rescuing," and treated like an extension of "salvage archaeology 搶救性考古." 182 With salvage archaeology, a site facing destruction (as is often the case with

180. Goldin, "Heng Xian," 158.

181. In his article, Goldin highlights two specific practices which he deems to be detrimental: the purchase of looted manuscripts from the antiquities market; and the study of looted manuscripts by scholars. For the former concern, Goldin argues that "every time a cultural or academic institution such as the Shanghai Museum makes a large (and highly publicized) purchase of looted artifacts, it only encourages the next cycle of looting" (156). To this he adds the issue of repatriation, especially if it involves purchasing artifacts for exorbitant amounts, justified in the name of patriotic duty. Undoubtedly, knowledge that a well-endowed institution is willing to spend money on looted bamboo strips (or find a donor who will) incentivizes tomb robbery to some degree-a market cannot exist without customers, and here we have customers with deep pockets. As I will discuss shortly, the growth of the market for Chinese antiquities, and for bamboo-strip manuscripts in particular, is far more complex than this simple equation however. I do not believe we ought to lay exceptional blame for this unfortunate phenomenon on the willingness of Peking University or like institutions to acquire these caches. While I will excuse myself from delving further into this aspect of the debate for now, my sympathies will become apparent in the conversation that follows, and many of my arguments will hold true at both the individual and institutional levels.

182. Hu, "Lun jianbo bianwei yu liushi jiandu qiangiu," 101; Liu, Zoujin Qinghua jian, 35-46. On this, please consult the Chinese edition, as the English translation purposefully excises "rescue" from the descriptions of their work, sensitive to this debate. 
new construction projects encroaching upon ancient remains, for instance) is excavated in an attempt to study and preserve whatever data may still be collected before it is lost permanently. In China, more and more salvage archaeology has been needed to study the remains of tombs compromised by looters. This is how the Guodian bamboo-strips manuscripts came to be discovered, as Goldin himself points out. ${ }^{183}$ For many scholars, the acquisition and study of looted manuscripts is thus a continued effort to this same end. Whether tomb robbers displaced burial goods within the grave itself, or took them even further afield from their original context, does not detract from our mandate to learn as much as we can from them; it only makes their study that much more challenging.

Ancient bamboo strips are also particularly difficult to preserve. ${ }^{184}$ Caches like those donated to Peking University are completely waterlogged after being submerged in a tomb for over 2,00o years. Hydrolysis compromises the bamboo's cellular structure, and molds may form, further damaging the strips. Crusted grime that has accumulated on the strips must be removed with the utmost caution, as even the softest of touches might break them apart. Moreover, dewatering treatment will warp the strips if not done correctly; and if the strips are kept in distilled water instead, the water must be constantly checked and refreshed. These artifacts must also be kept in an environment that minimizes light exposure and maintains an ideal temperature and humidity range. Considering the cost and care required to successfully preserve ancient bamboo strips, Hu urges individuals against collecting these artifacts. ${ }^{185}$ At times it proves too much for museums, even when treating strips that were scientifically excavated and stored. ${ }^{186}$ One can therefore only imagine the sort of loss that occurs when ancient bamboo strips are left on the antiquities market, without the supervision of experts trained to preserve them. ${ }^{187}$

183. Goldin, "Heng Xian," 157; Hubei sheng Jingmen shi bowuguan, "Jingmen Guodian yi hao Chu mu" 荊門郭店一號楚墓, Wenwu 1997.7, 35; Jingmenshi bowuguan, Guodian Chu mu zhujian, 1.

184. For an in-depth discussion of all the measures Tsinghua University took to ensure the preservation of their cache, see Liu, Zoujin Qinghua jian, 35-46.

185. Hu, "Lun jianbo bianwei yu liushi jiandu qiangjiu," 105-6.

186. As one example, it appears that mold has developed on the Wangjiatai bamboo strips, perhaps explaining why this collection has yet to be published in full. See Edward Shaughnessy, Unearthing the Changes: Recently Discovered Manuscripts of the Yi Jing (I Ching) and Related Texts (New York: Columbia University Press, 2013), 148.

187. Liu Guozhong describes how the strips acquired by Tsinghua University were sealed in plastic wrap and, for a few of the bundles, placed on a pallet of fresh bamboo slats as well. While this method prevented the strips from drying out, the stale water and untreated bamboo accelerated microorganism growth and led to molding. See Liu, Zoujin Qinghua jian, 38. If left on the market longer under these conditions the ancient 
In attempting to protect China's cultural heritage, however, it is not the material artifact alone that requires rescuing. Equally important to consider are the intellectual losses suffered when scholars are not given an opportunity to research these artifacts. This is true both when looters destroy archaeological materials on site, and also if we were to forbid research on authentic artifacts purchased on the antiquities market. Goldin argues that "if one wants to study excavated artifacts, there are plenty of properly excavated materials still awaiting thorough investigation." ${ }^{\prime 188}$ That the study of early China has been blessed with rich new discoveries (via scientific excavation alone), however, does not mean we should ignore the historical import of bamboo-strip manuscripts lacking a full provenance, so long as we are able to positively authenticate them. If all scholars were to neglect purchased collections, as Goldin envisions, then we sacrifice some of the most fascinating sources in our field. In the case of the Cang Jie pian, overlooking the Peking University edition would render further research on the text largely impotent. In this sense, by failing to subject manuscripts to study or to integrate them into the new narratives we tell about China's past, are we not then also harming China's cultural heritage?

Of course, the difference between working with looted manuscripts purchased on the antiquities market, and "salvage archaeology" proper, is that the former involves an economic transaction that benefits the looters and vendors who deal with the artifacts illicitly. The main concern of scholars like Paul Goldin therefore is that we are incentivizing this industry, and in doing so exacerbate the looting problem. This leads to the destruction of other archaeological sites in the future, with the material and intellectual loss that that may entail. In specific, Goldin points out that even by simply referring to purchased collections of bamboo strips in our research, scholars-by the nature of their position of authority and expertise in the field-lend credence to these looted artifacts, publicize their existence and value, and thereby generate demand for illicitly obtained goods.

We cannot ignore Goldin's warning that scholarly attention to purchased collections of bamboo strips inevitably impacts the demand for looted goods. It is difficult however to estimate the extent of the impact we have over this market. We must ask ourselves therefore whether or not it is worth forfeiting authentic sources that we could have otherwise saved and studied. ${ }^{189}$ When deliberating upon this question, it is

strips would have deteriorated to an even greater extent, and might have been lost forever.

188. Goldin, "Heng Xian," 158.

189. This is of course taking Goldin's call to action seriously and universally: we cannot fall back on the assumption that there will always be other scholars who still 
important to bear in mind that tomb robbery is not just a modern phenomenon, but also existed in antiquity. Oftentimes archaeologists will excavate a tomb only to discover that it was pilfered already, perhaps even on multiple occasions in the distant past. ${ }^{190} \mathrm{I}$ raise the enduring nature of tomb robbery here not as an excuse for us to ignore the problem, but rather to emphasize how complex and engrossing the demand for looted goods may be.

The fact that scholars study purchased collections of bamboo-strip manuscripts may well lend them a measure of historical value, thus stimulating a market for particular collectors. ${ }^{191}$ Other factors however are also driving demand. For instance, a Zhou bronze vessel, while important as an historical artifact, might be appreciated aesthetically regardless of its antiquity, or may be valued simply because of the material out of which it is made-the bronze itself. Unless we address these other factors at the same time, whatever impact our scholarly sacrifice could have over the market for looted goods would be muted. It is possible that we might try to gauge this impact by investigating if certain regions known for preserving bamboo-strip manuscripts have experienced a disproportional increase in tomb robbery since the publication

study these looted manuscripts. If the goal is to not work on looted materials, then the goal is to have no scholars work on them.

190. Wang Zijin 王子今 documents the persistent problem of tomb robbery throughout Chinese history in: Zhongguo daomu shi: yi zhong shehui xianxiang de wenhua kaocha 中國盜墓史：一種社會現象的文化考察 (Beijing: Zhongguo guangbo dianshi, 2000). Legal statutes dictating harsh penalties for tomb robbery have been discovered among recently unearthed Qin and Han period caches of bamboo strips, highlighting how prevalent (and distressing) this crime was in antiquity. See for instance the Ernian lüling 二年律令 statute on robbery “Dao lü 盜律” in the Zhangjiashan Han strips: Zhangjiashan ersiqi hao Han mu zhujian zhengli xiaozu, Zhangjiashan Han mu zhujian 張家山 漢墓竹簡 (Beijing: Wenwu, 2001), 143, strip \#65-66; an excellent translation and study of this collection may be found in Anthony J. Barbieri-Low and Robin D. S. Yates, Law, State, and Society in Early Imperial China: A Study with Critical Edition and Translation of the Legal Texts from Zhangiiashan Tomb no. 247 (Leiden: Brill, 2015), vol. 2, 467, see esp. 482 , n. 50. Sima Qian records how mechanized weapons were even built into the First Emperor's tomb to protect the treasures buried alongside him, while all the workers familiar with the tomb were likewise executed after its construction, to ensure that knowledge of the tomb's layout was not disseminated. Trees were then also planted to hide the tomb and make it seem like a hill. See Shi ji, 6.265. This apparently did not stop Xiang Yu 項羽 however from razing the tomb. Multiple citations from the Shi ji and Han shu on this are raised in the discussion in Wang, Zhongguo daomu shi, 54-58.

191. My impression is that these collectors are largely based out of Asia, and China, in particular, now. As a Western sinologist writing primarily in English, I would question what sort of sway my work will have over the broader Chinese public. Then again, as foreigners we might also lend international prestige to these collections, particularly when we attend conferences on them, or do publish in Chinese. 
of research on looted collections beginning in the 1990s. No comprehensive report with current data on looting in China has been published, however, frustrating any attempt to discover such patterns. ${ }^{192}$

What we do know is that tomb robbery has occurred in these regions in the past, and that in those instances bamboo strips have been intentionally destroyed or left behind. That is to say, until recently tomb robbers have targeted other artifacts, placing little or no value on bamboo strips. Recall the infamous case of the third-century C.E. Ji zhong 汲冢 cache, when a robber was caught breaking into the tomb of a Wei king. According to one account, upon entering the tomb he gathered a large bundle of bamboo strips, but then burned them as a torch in order to seek out the more precious treasures, thereby destroying many strips. ${ }^{193}$ Might Dingzhou Han tomb \#40, excavated in 1973, offer a parallel to this anecdote? It too was robbed, and a fire apparently started, searing many of the discarded bamboo strips. ${ }^{194}$ At the very least the Dingzhou robbery reveals that this class of artifact was in some sense disregarded, and thus left damaged or destroyed. ${ }^{195} \mathrm{Hu}$ Pingsheng reminds collectors that

192. One possible approach could be to compile transcripts of court cases trying individuals for tomb robbery. Sarah Allan's discussion on the provenance of the Shanghai Museum strips utilizes trial records to argue that the collection might have been taken from Guojiagang 郭家崗, showing the potential of such data. See Buried Ideas, 53. Beyond a very general statement given by the State Administration of Cultural Heritage 國家文物局 comparing the number of trials in 2009 against those in 2010 ("Gongan bu Guojia wenwu ju bu shu 2011 daji wenwu fanzui zhuanxiang xingdong" 公安部國 家文物局部署2011打擊文物犯罪專項行動, May 13, 2015 (http://www.sach.gov.cn/ art/2011/5/13/art_722_109187.html), accessed September 30, 2016; I am indebted to Robert Murowchick for pointing me to this brief), I have not been able to locate comprehensive statistics, and systematically compiling all relevant cases is beyond the scope of this article. Trials are also inevitably only a partial glimpse into this phenemonon.

193. Traditional accounts name the robber as Bu Zhun 不准. See Jin shu 晉書 (Beijing: Zhonghua, 1974), 51.1432-33. Edward Shaughnessy however argues that "buzhun 不准" is not a name, but rather an adverb, meaning "illicitly." See his overview of the find in Edward L. Shaughnessy, Rewriting Early Chinese Texts (Albany: State University of New York Press, 2006), esp. p. 134.

194. Dingxian Han mu zhujian zhenglizu, "Dingxian 40 hao Han mu chutu zhujian jianjie" 定縣40號漢墓出土竹簡簡介, Wenwu 1981.8, 11; Paul Van Els, “Dingzhou: The Story of an Unfortunate Tomb," Asiatische Studien/Études Asiatiques 63 (2009), 909-41.

195. The discovery of the Chu silk manuscript is another case in point, though much earlier. Noel Barnard interviewed one of the boys supposedly involved in the robbery, who stated that they thought the leather-like material was goat-skin, and only retrieved a few pieces for later examination as they noticed some characters and pictures drawn on it. "At least three individual pieces were observed but as no one was really interested, no one assisted the boys to lift the remaining planks [and retrieve more].... there may well still remain other brush-written Manuscripts between the planks...." See Noel Barnard, The Ch'u Silk Manuscript-Translation and Commentary 
bamboo-unlike bronze-is not an inherently valuable material. ${ }^{196}$ While previous looters might have overlooked bamboo strips for this reason, Goldin bemoans the fact that, after the Shanghai Museum purchase signaled the true value of these artifacts, they "will never make the same mistake again." 197

But is this necessarily a bad thing? That is to say, should our goal be to completely devalue bamboo-strip manuscripts on the antiquities market, as Goldin implies when he argues for us to ignore collections like the Peking University strips in our research? On the one hand, it would be impractical to hide the import of this class of artifact, particularly if we continue to research properly excavated bamboo-strip manuscript collections at the same time. On the other hand, if looters are already planning to rob a tomb to look for other artifacts, such as bronze vessels for instance, it would be preferable in my opinion for them not to disregard the bamboo strips in the process. Even if they do not destroy the strips while trampling on the site, there is a good chance these fragile artifacts would not survive long if left behind. My fear is that fortunate discoveries like that at Guodian are the exception, not the rule. ${ }^{198}$ At least by advertising the historical import of bamboo-strip manuscripts, looters may take some care in preserving the strips along with their other pilfered artifacts, which could give the manuscripts a chance to survive for future generations. Instead of trying to devalue bamboo-strip manuscripts by hiding their historical import, might it not be better to embrace the value of these artifacts, and educate the public about why the loss of their archaeological context is therefore so tragic? If this is the correct approach to adopt, then the study of purchased collections of bamboo-strip manuscripts is all the more significant, as we can highlight the shortcomings of their unfortunate circumstances.

(Canberra: Department of Far Eastern History, Australian National University, 1973), part 2, 1-18, citation from 3. The Guodian cache may serve as another more recent example, as Goldin implies in his article, however Scott Cook suggests (following Peng Hao's account in the preliminary report) that the looters might have had difficulty accessing the strips instead, once water and mud seeped into the head compartment. See Scott Cook, The Bamboo Texts of Guodian: A Study and Complete Translation (Ithaca: Cornell University East Asia Program, 2012) vol. 1, 4, n. 7; "Jingmen Guodian yi hao Chu mu," 35; Sarah Allan and Crispin Williams, ed., The Guodian Laozi: Proceedings of the International Conference, Dartmouth College, May 1998 (Berkeley: Society for the Study of Early China, Institute of East Asian Studies, University of California Berkeley, 2000), 117-18.

196. Hu, "Lun jianbo bianwei yu liushi jiandu qiangjiu," 105.

197. Goldin, "Heng Xian," 157.

198. Once a formerly sealed and self-contained tomb environment is opened, oxygen is introduced allowing microorganisms to grow, threatening this class of artifact. 
In summary, while Goldin's call to abstain from studying looted bamboo-strip manuscripts is praiseworthy in its intentions, I personally believe that it would be a detrimental course of action. We are presented with a choice: either to recover what information we can from looted artifacts, at the risk of inspiring further acts of pilfering archaeological sites; or to sacrifice already looted artifacts we could have saved and studied, risking that our actions ultimately have little impact on the antiquities market, and might lead to the destruction of bamboo strips by looters regardless. In both cases, the risks are uncertain and difficult to weigh objectively. For my own research, I would rather act upon the known quantity (the artifacts already looted) than the unknown (those additional artifacts which will be looted because of the incentive we provide). While I would not deny that our scholarship incentivizes tomb robbery to a certain extent, it is questionable how significant an impact it has, especially in light of the complex mechanisms driving demand for illicit artifacts. Instead of devaluing the historical import of looted bamboo strips, we should embrace their value and aim to educate the public instead about the disastrous consequences of tomb robbery.

北京大學藏西漢竹書：關於非考古出土簡牘的鑒定和研究

傅希明

提要

近二十年來, 中國主要學術機構相繼購藏了多批戰國秦漢簡牘。本文介 紹的是 2009 年初北京大學獲贈入藏的漢簡。雖然北大漢簡提供了可以 大大推推中國早期歷史研究的珍貴新資料, 但是因為這批材料不是考古 出土的, 相關研究受到很大限制, 並導致對竹簡真實性以及研究這類被 盜文物會促進文物盜賣黑市發展的雙重擔憂。本文回顧了最近關於如何 鑒定非考古出土簡牘的討論, 討論了北大漢簡的真實性是如何得到證實 的, 駁斥了最近有學者提出的北大漢簡《老子》爲偽作的主張, 然後以 北大簡《蒼頡篇》爲例, 提出了論證購藏簡牘真實性的方法。最後, 本 文在閭述中國學術界普遍采取的”抢救性考古”立場的基礎上，討論了研 究被盜簡牘的學者的職業責任。

Keywords: Peking University, Laozi, authenticity, Cang Jie pian, bamboo-strip manuscripts

北京大學, 老子, 真偽性,蒼頡篇, 竹簡 